\title{
MICROBE-MEDIATED ADAPTATION IN PLANTS
}

\author{
A Dissertation \\ Presented to the Faculty of the Graduate School \\ of Cornell University \\ In Partial Fulfillment of the Requirements for the Degree of \\ Doctor of Philosophy
}

by

Renee Petipas

August 2018 
(C) 2018 Renee Petipas 


\title{
MICROBE-MEDIATED ADAPTATION IN PLANTS
}

\author{
Renee Petipas, $\mathrm{Ph}$. D. \\ Cornell University 2018
}

Plant-associated microbes affect a wide-variety of plant functional traits, and thus they likely affect patterns of plant local adaptation. However, the role of microbes in plant local adaptation is rarely tested. In a survey of the plant local adaptation literature, I found that the vast majority of studies that report local adaptation (94\%) performed transplants into microbe-containing soils and measured traits that are microbemediated. In these studies, microbe-mediated effects are confounded with plant genotype effects. For my dissertation research, I sought to describe the phenomenon of microbe-mediated adaptation and provide a definitive test using a modified reciprocal transplant experiments that moved seeds and microbes into two habitats. Here I present my dissertation work in three chapters:

In my first chapter, I propose two ways in which microbes facilitate patterns of adaptation for plants, microbe-mediated local adaptation and microbe-mediated adaptive plasticity. Microbe-mediated local adaptation is when plant genotypes have higher fitness at their home site because of a genotype-specific affiliation with locally important microbe(s). Microbe-mediated adaptive plasticity is when a plant genotype has higher fitness in multiple habitats because it demonstrates plasticity in associating with locally important microbes. 
In my second chapter, I describe soil conditions, plant phenotype, and microbial communities in two habitats. I used high-throughput tagged amplicon sequencing of SSU-rRNA genes (for bacteria) and ITS1 (for fungi) to characterize the root microbiome of Saint John's wort, Hypericum perforatum. At each root sampling location, I quantified soil characteristics to evaluate habitat variables that are correlated with root microbial communities. I also collected information on plant growth and fecundity for each focal plant to identify microbes that are correlated with plant phenotype. We found that bacterial and fungal communities were significantly different between habitats. Community differences were correlated with soil nitrogen and $\mathrm{pH}$, and two taxa in the phylum Actinobacteria were significantly correlated with plant height.

In my third chapter, I test for microbe-mediated adaptation using the two habitats, limestone barrens (alvars) and old-fields, described in chapter two. I conducted reciprocal transplant experiments in two years, exploring microbe effects on plant germination, survival, and growth. I found that alvar seeds had higher probability of germination when transplanted into home soils with microbes, but only when transplanted into their home habitat. Similarly, alvar seedlings had a higher probability of survival when transplanted into their home live soils, but here transplant site was unimportant. I also found local microbes inhibited local adaptation for old-field seedlings and facilitated local adaptation for alvar seedlings. My results indicate that microbial mutualists were important for plants growing in marginal alvar habitats, and that microbes changed patterns of local adaptation. 


\section{BIOGRAPHICAL SKETCH}

Renee was born in Gilford, New Hampshire. She attended the University of New Hampshire where she received a bachelor of science in Environmental Conservation Studies. After graduating she worked for Dr. Annie Schmitt at Brown University as a National Science Foundation post-baccalaureate fellow. This was a formative experience that introduced Renee to the world of evolutionary ecology and sent her on an academic track. In 2008, she joined the lab of Dr. Alison Brody at the University of Vermont. Renee worked on the ecology of arbuscular mycorrhizal fungi on the African savannah for her Master's degree. This work instilled an appreciation for the importance of plant-microbe interactions. Next, she moved to the lab of Dr. Monica Geber to investigate population level dynamics of plant-microbe interactions. Next, Renee will move onto a postdoctoral position at Washington State University. Renee was awarded a National Science Foundation-Postdoctoral Research Fellowship in Biology to work in the lab of Dr. Maren Friesen. 
This work is dedicated to my loves, Nabil and Lilah 


\section{ACKNOWLEDGMENTS}

Navigating graduate school takes patience, hard work, creative thinking, strong mentorship, and loads of support. I was fortunate to have many people help me along the way and I am extremely grateful for their guidance, support, and love.

First, I would like to thank the staff of EEB. They helped me accomplish research objectives, navigate my finances, resolve administrative issues, and guide me in my teaching duties. I would also like to thank the amazing, hard-working Instructional Technologists at Cornell, especially Pat Graham and Liz Balko that guided me in managing and developing content for BioEE1780 Evolution and Diversity, without them I would be lost. I also want to thank the staff of the Cornell's Statistical Consulting Unit, especially Lynn Johnson who always patiently helped me during repeated visits work through statistics for several projects.

Next, I would like to thank the graduate student and postdoc community at Cornell. This incredibly talented and passionate group of students pushed me in the nicest way possible to always improve my scientific rigor, while simultaneously creating a caring, supportive environment. I am especially grateful to my running buddies Karin van der Burg, Erin Larson, and Lizzie Lombardi for the good conversations over many miles. I was also lucky to find a group of graduate student and postdoc families to pal up with and this made the journey of parenting in graduate school much more bearable. Thank you, Maya Weltman-Fahs and Alessandro Farsi, Josh and Erin Meyer-Gutbrod, Susan Whitehead and Abe Lee, and Christy and Yunus Kinkhabwala. You guys are the best! Finding you all definitely improved my life. 
I also want to thank my friends and office mates: Maya Lim, Sam Chamberlain, and Sahas Barve for many giggles. Finally, I want to thank Suzi Claflin for her continuous love and support. When Lilah had a fever at six months old, and Nabil was living in Madison, Suzi was the one that went to the store at $10 \mathrm{pm}$ to buy Tylenol. I'll always be thankful to her for that and many more things.

I was also lucky during my time at Cornell to part of a wonderful academic community. I especially want to thank my lab mates: Billie Gould, Aubrie James, Gregor Siegmund, and Kate Eisen. Their high standards coupled with positivity encouraged me to be a better scientist. My lab mates helped me in every possible waythey encouraged me, read my work, helped me in the field, shared food and coffee, and provided much needed comic relief. During my $\mathrm{PhD}$ research I adopted a wonderful helper, Amy Wruck. She moved from field-assistant, lab-mate, to friend, and eventually family member. Amy will always be an important part of our lives.

I also want to thank Monica Geber for being an excellent mentor. Monica is a perfectionist that gently but insistently encourages perfectionism in her students. I benefitted enormously from her mentorship. I strive to be a scientist of her caliber one day. I would also like to thank my committee members Dan Buckley, Jenny KaoKniffen, and Anurag Agrawal. I was extremely grateful to be incorporated into the Agrawal lab shortly after arriving at Cornell and I have immensely enjoyed and benefited from my interactions with Anurag and his lab. Anurag's advice has been invaluable and he is one of my biggest science influences. I hope he will always be a mentor in my life. 
I want to thank my crazy and wonderful parents. My parents rescued me many times during my $\mathrm{PhD}$, including the time I had a huge experiment to put out and somehow managed to forget Lilah's daycare was closed for the week. More importantly, they had the courage to let me try and fail as a child, which led to feelings of independence and self-sufficiency. As a parent, I realize how totally difficult this can be and I appreciate very much how they raised me. I want to thank my husband, Nabil Elrouby, my favorite (adult) person in the world. His advice and support have been indispensable throughout my $\mathrm{PhD}$. His ability to easily see the heart of a problem and advise correctly has resulted in me taking many wise decisions. And his unwavering love and support has made feel confident moving forward through many difficulties. Finally, my baby girl, Lilah Joy Elrouby, whose precocious antics have been a source of joy and laughter for five years. I hope she knows someday how lucky we feel to have her in our lives and how deeply we love her 


\section{TABLE OF CONTENTS}

BIOGRAPHICAL SKETCH v v

DEDICATION vi vi

ACKNOWLEDGEMENTS vii

TABLE OF CONTENTS $x$

LIST OF FIGURES $\quad x i$

LIST OF TABLES xiii

CHAPTER ONE Microbe-mediated adaptation in plants $\quad 1$

CHAPTER TWO The bacterial and fungal microbiome of

Hypericum perforatum in two distinct habitats

CHAPTER THREE

A test of microbe-mediated adaptation in plants: Microbe-mediated adaptation to 


\section{LIST OF FIGURES}

CHAPTER ONE

Figure 1.1 A-C

Adaptation reaction norms with and without microbes

Figure 1.2 A\&B

Conditions that promote the evolution of adaptive 12 plasticity or local adaptation

Figure 1.3

Reciprocal transplant design to understand how microbes

contribute to plant adaptation

Figure 1.4 A-C

Potential outcomes of reciprocal transplant design to test

for microbe-mediated adaptation (main effects)

Figure 1.4 D-F

Potential outcomes of reciprocal transplant design to test

for microbe-mediated adaptation (two-way interactions)

Figure $1.4 \mathrm{G}$

Potential outcomes of reciprocal transplant design to test 20

for microbe-mediated adaptation (three-way interactions)

\section{CHAPTER TWO}

Figure 2.1 A\&B

Constrained analysis of principle coordinates (CAP) for bacteria and fungi mapping plant phenotype and soil depth

Figure 2.2 A\&B

Constrained analysis of principle coordinates (CAP) for 55 bacteria and fungi mapping soil edaphic conditions

Figure 2.3 A-D Bacterial and fungal OTU richness and Chaol diversity in 56 alvars and old-fields

Figure 2.4 A-E

Fungal OTUs that were differentially abundant in alvars and old-fields

Figure 2.5 A\&B Regression analysis exploring the relationship between 64 the abundance of OTUs 5 and 57 with plant height

CHAPTER THREE 
Figure 3.1

Figure 3.2

Figure 3.3 A-D

Figure 3.4 A\&B

Figure 3.5 A-D

Figure 3.6 A\&B

Figure 3.7 A-D

Figure 3.8 A\&B

Figure 3.9 A-D

Figure $3.10 \mathrm{~A}-\mathrm{H}$
Reciprocal transplant design used to test for microbemediated adaptation in limestone barrens

Map of transplant sites

Probability of germination was affected by transplant habitat, seed source, soil source, and presence of microbes Germination reaction norms for treatments with and without microbes

Probability of seedling survival was significantly increased for alvar seedlings when they were transplanted with alvar soils with microbes Survival reaction norms for treatments with and without microbes

Plants transplanted into the old-field sites had more total biomass when transplanted with live soil inoculum Total biomass reaction norms for treatments with and without microbes

Alvar plants and plants transplanted into alvar soils produced more arbuscules Regression analysis to understand how proportion of arbuscules in the root affected total plant biomass 


\section{LIST OF TABLES}

\section{CHAPTER ONE}

Table 1.1

Analysis of variance table exploring how habitat, plant genotype, and microbial source affect patterns of local adaptation

\section{CHAPTER TWO}

Table 2.1

Aspects of soil conditions and plant phenotype that differed between alvars and old-field habitats

Permutational analysis of variance (PERMANOVA)

Table 2.2 examining how bacterial community composition is related to soil nutrient conditions

Table 2.3 Permutational analysis of variance (PERMANOVA) examining how bacterial community composition is related to soil depth and plant phenotype

Table 2.4 Permutational analysis of variance (PERMANOVA) examining how fungal community composition is related to soil nutrient conditions

Table 2.5

Permutational analysis of variance (PERMANOVA) examining how fungal community composition is related to soil depth and plant phenotype

Table 2.6 Procrustes analysis exploring concordance between microbial communities and soil nutrients and plant 66 phenotype

\section{CHAPTER THREE}

Table 3.1

Percent germination of plants in reciprocal transplant design to test microbe-mediated adaptation 
Table 3.2

Table 3.3

Table 3.4
Percent survival of plants in reciprocal transplant design to test microbe-mediated adaptation Plant total biomass at the conclusion of the reciprocal transplant experiment

Average proportion of mycorrhizal colonization 


\section{CHAPTER 1}

\section{MICROBE-MEDIATED ADAPTATION IN PLANTS}

In preparation for Trends in Ecology and Evolution as Renee H. Petipas, Jennifer A. Lau, and Monica A. Geber. Microbe-mediated adaptation in plants.

\section{Abstract}

There is growing interest in the role that microbes play in host adaptation. Here we discuss two ways in which microbes can facilitate patterns of adaptation for plants, microbe-mediated local adaptation and microbe-mediated adaptive plasticity. Microbe-mediated local adaptation is when plant genotypes have higher fitness at their home site because of a genotype-specific affiliation with locally important microbe(s). Microbe-mediated adaptive plasticity is when a plant genotype has higher fitness in a variety of habitats because it demonstrates plasticity in associating with locally important microbes. Currently, it is an open question when, where, and how often microbes affect patterns of adaptation, although recent works suggest microbes could play an important role in adaptation by local adaptation and adaptive plasticity. Here we discuss how to test for and differentiate between microbe-mediated local adaptation and microbe-mediated adaptive plasticity. We also discuss implications and future research directions in the field of microbe-mediated adaptation. This work not only has important implications for our understanding of plant evolutionary ecology, but also has implications for conservation, restoration, and agriculture. 


\section{Introduction}

Evolutionary ecologists consider plants to be autonomous organisms that respond to environmental pressures through evolution by natural selection and plasticity. In reality, symbioses with microbes are an indivisible part of plant ecology and evolution. Without exception, plants affiliate with a diversity of eukaryotic and prokaryotic microorganisms that inhabit the roots and rhizosphere (Partida-Martinez and Heil 2011). These microbes affect plant life history (Lau and Lennon 2011, 2012, Wagner et al. 2014, Panke-Buisse et al. 2017), functional traits (Friesen et al. 2011), adaptive phenotypes (Rodriguez et al. 2008), plasticity (Goh et al. 2013), the strength

and direction of selection (Wagner et al. 2014, Lau and Lennon 2011), and heritability of adaptive phenotypes (Gehring et al. 2017). Here we consider how microbes affect two fundamental aspects of plant evolutionary ecology: local adaptation and adaptive plasticity.

\section{Microbes affect plant adaptation}

Local adaptation and adaptive plasticity are non-exclusive evolutionary responses to heterogeneous selection pressures. Local adaptation is the result of genetic differentiation in response to local conditions and is manifest when local genotypes have higher fitness in their home habitat compared with foreign genotypes (Kawecki and Ebert 2004). Adaptive plasticity is the result of phenotypic plasticity in response to local conditions and is manifest when local phenotypes have higher fitness in their home habitat compared with foreign phenotypes (Dudley and Schmitt 1996). 
Microorganisms have the potential to influence both local adaptation and adaptive plasticity. Microbes can alter plant functional traits (Friesen et al. 2011) in ways that increase plant fitness in response to biotic and abiotic factors, such as drought (Lau and Lennon 2012, Marasco et al. 2012), herbivory (Lee et al. 2012), low nutrients (Johnson et al. 2010), heavy metals (Meharg and Cairney 2000) and pathogens (Berendsen et al. 2012). Despite recent interest in the role of microbes in plant adaptation (Johnson et al. 2010, Smith et al. 2011, Lau and Lennon 2012, Lankau 2013, Johnson et al. 2013, Wagner et al. 2014, Pickles et al. 2015, Revillini et al. 2016, Rúa et al. 2016, Van Nuland et al. 2016) the framework for such investigations is lacking. We propose that microbe-mediated adaptive responses are the result of microbe-mediated local adaptation (MMLA) when plant genotypes have higher fitness at their home site because of a genotype-specific affiliation with locally important microbe(s) (Figure 1.1B), or microbe-mediated adaptive plasticity when a plant genotype has higher fitness in a variety of habitats because it demonstrates plasticity in associating with locally important microbes (Figure 1.1C).

In this review, we elaborate on these definitions and provide examples. We also explore how to test for and differentiate between microbe-mediated local adaptation and microbe-mediated adaptive plasticity. Finally, we discuss implications and future research directions in the field of microbe-mediated adaptation. The framework presented here is not exclusive to plants. We focus primarily on plants because of the long and rich history of local adaptation and adaptive plasticity studies in this group and the ease of experimental manipulation, but this framework is easily usable in non- 


\section{Without Microbes}

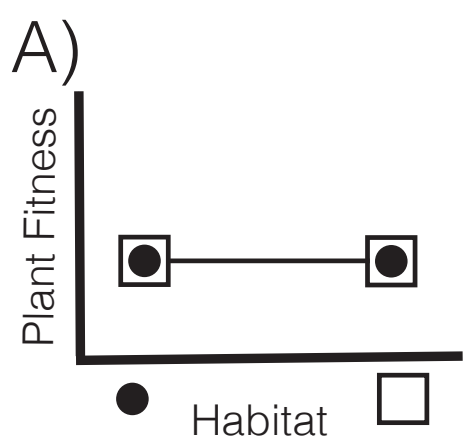

With Microbes
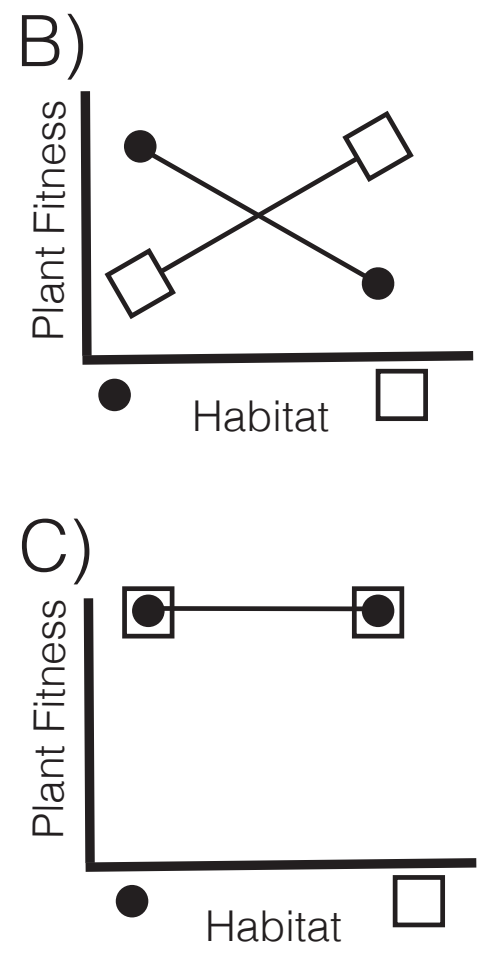

Figure 1.1 A-C: Without microbes (A) genotypes have similar fitness values in both habitats. When microbes are added you could find two patterns: B) Plant genotype interacts with microbial genotypes or communities in ways that enhance adaptation to local conditions (microbe-mediated local adaptation) or C) Plants are able to affiliate with locally important microbes in both habitats and subsequently have higher fitness across habitats compared to the plants without microbes (microbe-mediated adaptive plasticity). 
plant systems. Indeed, interest in microbe-mediated adaptation has been growing across taxa (e.g. Biere and Tack 2013, Alberdi et al. 2016).

\section{Microbe-mediated local adaptation}

Microbe-mediated local adaptation happens when natural selection operates on plant traits that attract, retain, and regulate locally important microbe(s). The outcome is microbe-mediated changes to plant functional traits that lead to higher fitness of local plant genotypes compared with foreign plant genotypes that do not associate as well with local microbe(s). Microbe-mediated local adaptation can occur when plant genotype and microbial genotype interact to determine plant fitness in response to environmental conditions, or when plant genotype affects microbial community composition in ways that determine plant fitness in response to environmental conditions.

Plant-microbe resource mutualisms provide some of the best evidence for microbemediated local adaptation. Soil nutrient limitation is heterogeneous across the landscape. In response, some resource mutualisms have evolved to access the most limiting nutrient. In one example, researchers used a fully factorial greenhouse experiment manipulating seed source, soil source, microbial source, and the presence/absence of microbes, to ask how seed source and microbial source interacted to affect nutrient acquisition from different soil types that were limiting in either nitrogen or phosphorus. They found that genotypes of Andropogon gerardii were coevolved with local arbuscular mycorrhizal communities to access the most limiting nutrient at each site, as measured by percent nitrogen or phosphorus accumulated in 
plant tissues. In other words, accessing limiting nutrients was predicated not only on plant genotype but also on being paired with sympatric (home) microbes. However, this enhanced nutrient uptake only translated to patterns of local adaptation in two of the sites (Johnson et al. 2010). Coevolved microbes also mediate plant responses to other environmental factors, such as herbivory, pathogens, drought, and heavy metals, but further work needs to be done to understand how this affects patterns of local adaptation.

Although many studies have focused on coevolved interactions between plants and microbes, even diverse microbial communities can lead to microbe-mediated adaptation. Like other macro-organisms, plants host a wide variety of microbes in their rhizosphere, and these communities are a heritable component of the plant phenotype (Schweitzer et al. 2008, Peiffer et al. 2013, Simonsen and Stinchcombe 2014). In addition, these heritable microbial communities affect plant phenotypes in ways that lead to adaptive responses to the local environments. For example, ectomycorrhizal fungal (EcM) communities of drought-adapted pinyon pine were heritable and inoculum from under drought-adapted trees reduced mortality and enhanced plant growth of drought tolerant plant genotypes by $25 \%$ under drought conditions (Gehring et al. 2017). Authors used the powerful approach of combining observational and experimental studies to identify an Ascomycete fungus in the genus, Geopora, that was correlated with drought tolerant trees. In this case, it seems that adaptive effects were the result of shifts in community composition (species 
presence/absence) when trees are exposed to drought rather than the evolution of coadapted fungal strains.

A discerning reader might question if microbe-mediated local adaptation is different from "regular" (plant genotype-mediated) local adaptation. Indeed, microbes are part of a local environment and plants can adapt to them. We argue that it is worth exploring because of the ubiquitous yet cryptic nature of plant microbial interactions. The earliest plant colonization of land was facilitated by microbes (Strullu-Derrien et al. 2014, Remy et al. 1994), and currently every plant on earth engages in some type of interaction with microbes (Partida-Martinez and Heil 2011). Over evolutionary time, plants have evolved in ways that shape microbial structure and function, and microbes have evolved in myriad ways to influence plant traits and therefore interactions with the environment. Additionally, these changes are still occurring today on microevolutionary timescales. Therefore, it is an interesting and open question in what ways and how frequently plant interactions with the environment are facilitated by microbes. Interactions with microbes are not only ubiquitous but are also cryptic in nature. Reciprocal transplant experiments have a long and rich history (see Cheplick 2015 for a nice overview). Throughout this time, microbes have been a confounding factor in experimental designs. This could lead to the erroneous conclusion that plant genotypic effects are responsible for adaptive outcomes, when in reality microbes have profound effects on many plant functional traits. Disentangling microbial from plant genotypic contributions to adaptation is important from a basic research perspective and also informs applied issues, such as predicting plant responses to human-mediated changes (see Implications section).

Microbe-mediated adaptive plasticity 
Microbe-mediated adaptation can happen via genetic differentiation in plant populations but it isn't necessary. Plants exhibit a high degree of phenotypic plasticity and in many cases plastic responses are adaptive (Agrawal et al. 1999, Dudley and Schmitt 1996). Phenotypic plasticity occurs when a single genotype exhibits different phenotypes depending on abiotic and/or biotic conditions, and adaptive plasticity is when phenotypes are plastic in variable environments in ways that maximize fitness (Agrawal 2001). Microbe-mediated adaptive plasticity is when plant genotypes have higher fitness across a range of habitats because they demonstrate plasticity in traits that attract, retain, and regulate locally important microbes, and associating with locally important microbes subsequently affects plant functional traits in ways that enhance fitness.

There is an extensive body of literature exploring how to test for adaptive plasticity and when it is expected to evolve (Dewitt and Scheiner 2004). The most rigorous demonstration of adaptive plasticity involves identifying different phenotypic traits and performing reciprocal transplants to link traits to fitness in different habitats. In a canonical example, authors tested the hypothesis that elongated stems of Impatiens capensis were adaptive in high density, low light environments. To test this idea, they manipulated the ratio of red to far red light to produce Impatiens phenotypes with elongated and non-elongated stems. Then these two morphs were transplanted into high and low-density environments. Authors found that plants with elongated stems had higher fitness in high density environments, and plants with non-elongated stems had higher fitness in low density environments (Dudley and Schmitt 1996). 
There is growing interest in how microbes affect plant adaptive plasticity (Goh et al. 2013), and evidence is accumulating that microbes affect plasticity of many important traits. For example, microbe-mediated adaptive plasticity could affect plant response to herbivory. In one case, authors collected mycorrhizal inoculum from large, herbivore exclosure treatments that either excluded all ungulate herbivores, allowed only native herbivores, or allowed native herbivores plus cattle. These ungulate exclosure treatments were immediately adjacent with no barriers to gene flow for the wind pollinated grass used in the experiment, thus authors assumed admixture of the plant population. Plants inoculated with AM fungi from areas with native herbivores tolerated herbivory more than plants inoculated with AM fungi from areas that also contained cattle and areas that had no ungulate herbivores for 18 years. And although mycorrhizal communities became less mutualistic in areas without herbivores, bacterial communities became more mutualistic. Plants inoculated with bacterial wash from areas with no herbivores had more biomass than any other microbial treatment (González et al. 2018), indicating perhaps that bacterial-enhanced plant competition could be adaptive in densely vegetated areas without herbivores.

Flowering time is another trait that is a good candidate for exploring microbemediated adaptive plasticity (Lau and Lennon 2011, 2012, Wagner et al. 2014, PankeBuisse et al. 2016). In one experiment, authors found that microbes from four naturally occurring soil microbiomes affected plasticity in flowering time of Boechera stricta. Authors didn't test whether different microbe-mediated flowering times were 
adaptive in the field and therefore didn't establish adaptive plasticity. Later work showed that microbe-mediated changes in flowering time could be selected for in multi-generation experiments. In this work, authors used Arabidopsis thaliana genotype, Col-0, as a standardized plant genotype, to guarantee that shifts in flowering time were the product of microbiome selection and not interactions with underlying plant genotype. They then inoculated plants with naturally collected soil microbiomes and in each generation selected new microbial inoculum from the four earliest flowering plants, to be used in the next generation. Flowering time decreased by up to $10 \%$ in treatments that received early flowering microbes (Panke-Buisse et al. 2016).

An interesting research goal will be to develop a framework that allows us to hypothesize when microbe-mediated local adaptation will dominate versus microbemediated adaptive plasticity. We can look to existing literature to inform these hypotheses. The adaptive plasticity hypothesis states that given sufficient heritable genetic variation in plasticity, phenotypes should be variable in ways that maximize fitness in response to selection pressures in different environments (Thompson 1991). Additionally, adaptive phenotypic plasticity is expected to evolve when: 1) environmental cues are reliable, 2) different phenotypes are optimal in different environments, and 3) no phenotype is optimal for all environments (Moran 1992, Ghalambor et al. 2007; Figure1.2 B). Microbe-mediated adaptive plasticity will evolve when all of the above conditions are met and additionally 4) microbes reliably covary with environments. If environments are not variable, cues are not reliable, variable phenotypes are no longer adaptive, and/or microbial presence is not reliable, then the 
cost of plasticity will be too high (Grenier et al. 2016). In this case, if the postulates of natural selection are fulfilled, natural selection will act to remove plastic genotypes and converge on a fixed optimal phenotype (Figure1.2 A).

\section{Testing for microbe-mediated adaptation}

Experimental designs employed widely for plant evolutionary ecology can be used to test for microbe-mediated adaptation and to distinguish between microbe-mediated local adaptation and microbe-mediated adaptive plasticity. Here we advocate using reciprocal transplant experiments to understand how microbes affect patterns of plant adaptation and to distinguish between microbe-mediated local adaptation and microbemediated adaptive plasticity. Reciprocal transplants can be employed exactly as in the traditional design with the added element of manipulating microbe(s) (Figure 1.3).

Reciprocal transplants are done by locating two or more populations that inhabit different environments or occur along an environmental gradient. Populations are often chosen because one or more environmental variable is demonstrably different between populations. In the classical experiment, putative genotypes of plants are transplanted into a different environment and replanted into their natal environment. A reciprocal transplant to test for microbe-mediated adaptation, through either adaptive plasticity or local adaptation, would involve transplanting plant genotypes into different habitats and providing those plants with local or foreign microbes. 
A)

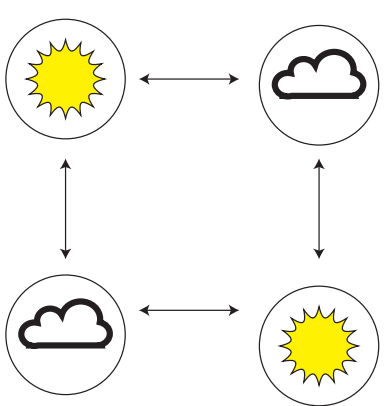

B)

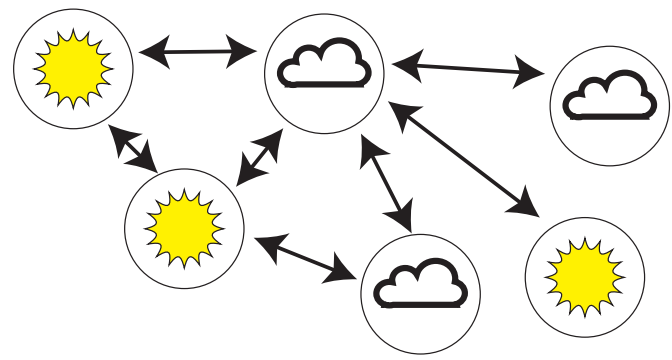

Figure 1.2 A\&B: The scale of environmental heterogeneity, gene flow, and whether offspring are likely to encounter the same habitat as parents can influence whether adaptation will happen via genetic differentiation or adaptive plasticity. A) When environmental heterogeneity is coarse-grained, gene flow is minimal, and offspring are unlikely to encounter an environment different than their parents' environment then adaptation via genetic differentiation (local adaptation) is expected. In contrast, B) when there is fine-grained environmental heterogeneity, more gene flow, and offspring are likely to encounter an environment different than their parents' environment then adaptive plasticity may evolve. Arrows indicate gene flow and the thickness of the arrow indicates the relative amount of gene flow between habitats. 
The exact details of the experimental set-up will depend on habitat characteristics, focal plant species, and microbial taxa of interest but regardless some version of the following could be deployed. 1) Create microbial treatments by isolating some fraction of the plant microbiome. Some options here include: isolates of individual taxa, microbial washes, or whole soil inoculum (for a discussion of efficacy see Howard et al. 2017). 2) Determine controls for microbial treatments. When working with soils, researchers isolate soil microbial effects without confounding them with soil abiotic effects by using a sterilized soil medium with a small amount of live or sterilized inoculum added back. The choice of soil sterilization methods can be taxon specific (e.g. fungicide) or general (autoclaving or gamma irradiation). Each method has advantages and disadvantages and thus should be researched carefully (Trevors 1996). 3) Devise a transplantation scheme. Transplantation can occur directly in the soil using a mesh barrier to keep in microbial inoculum and exclude microbial taxa from the surrounding soil environment. Mesh with $0.45 \mu \mathrm{m}$ opening has been used to exclude other fungi and some bacterial taxa (McGuire 2007). Plants can be transplanted into pots with microbial treatments and placed in aboveground arrays in the two habitats. When transplanting into the field, especially if plants are surrounded by the soil environment, contamination by non-target microbes will always be an issue. For this reason, the duration of the experiment will need to be planned carefully, and sterile treatments will need to be monitored for contamination.

A statistical model to understand interactive contributions of plant and microbes to plant local adaptation would include some measure of plant fitness (e.g. germination, 


\section{Habitat}

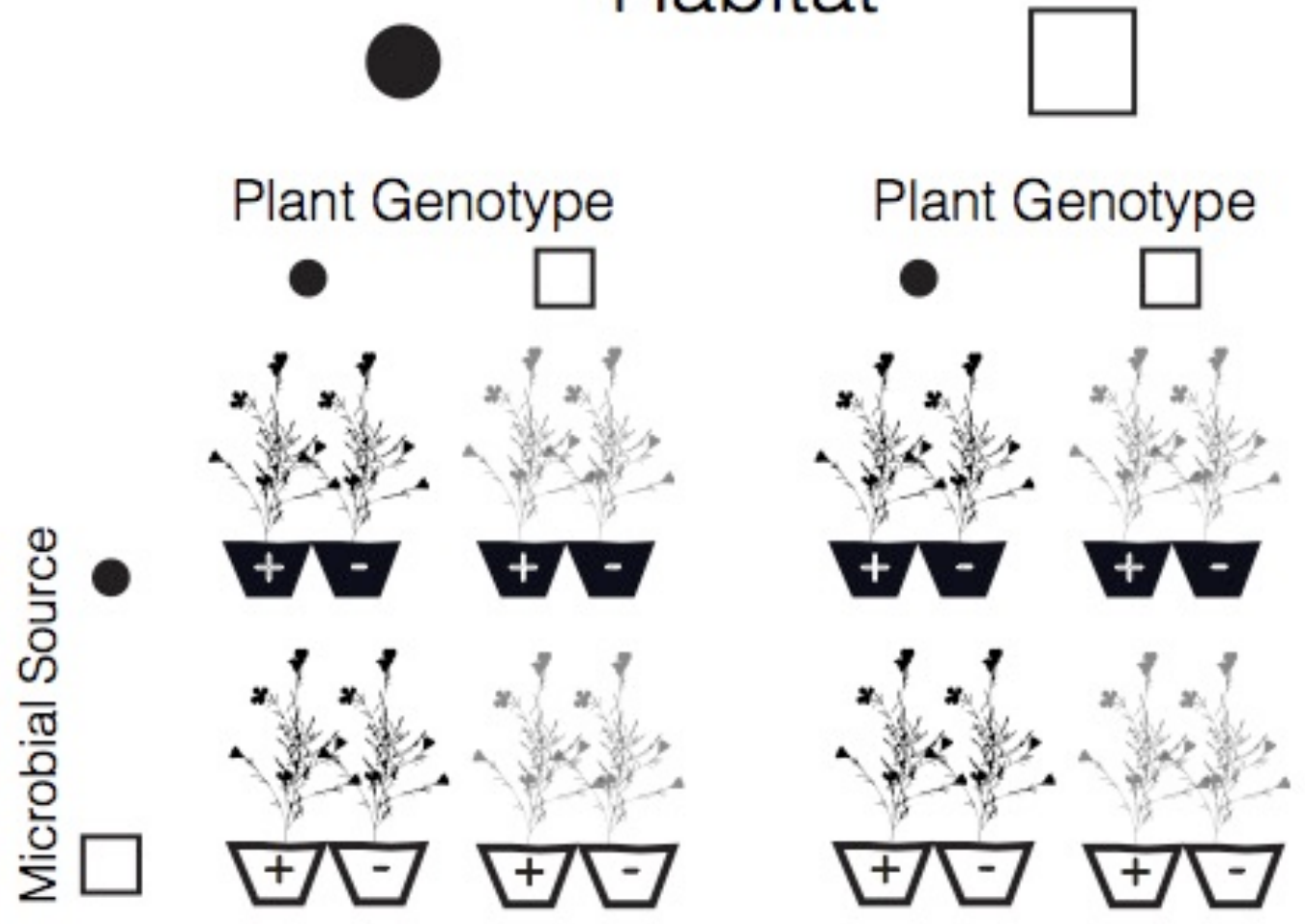

Figure 1.3: Fully factorial reciprocal transplant design to understand how microbes contribute to plant adaptation. In this design we move plant genotypes (circle $=$ darkshaded plants, square $=$ light-shaded plants) between two habitats (represented by circle and square shapes), with either microbes from circle habitat or square habitat. A sterilized inoculum treatment (“_"“ indicates plants with autoclaved inoculum added vs "+" where live soil filtrate is added) is included to control for the addition of microbial filtrate. 
survival, reproductive fitness) as a response variable and habitat type, plant genotype, microbial source, and sterilization as fixed effects (Figure 1.3). Unfortunately, this design results in the unsavory outcome of a four-way interaction. With large enough sample sizes and patience, one can overcome the complexity of a four-way interaction, but to fully understand complex interactions subsequent hypothesis testing should be done using planned comparisons. For clarity, the figures presented here assume that patterns of adaptation are attributable to microbes (Figure 1.1B and C), and thus we only present the live inoculum treatments.

Models can be constructed to determine how habitat type, plant genotype, and microbial source affect fitness outcomes (Table 1.1). Significant main effects of habitat would indicate one habitat is more favorable overall to plant growth (Figure 1.4A). Significant main effects of plant genotype would mean fixed genetic differences that don't differ when exposed to different habitats or microbial communities (Figure 1.4B). Significant main effects of microbial source would indicate that both plant populations benefit from the microbes isolated from one habitat (Figure 1.4C). A two-way interaction between habitat and plant genotype would indicate plant local adaptation or maladaptation without a contribution of microbes (Figure 1.4D). A two-way interaction between habitat and microbial source would indicate microbe-mediated adaptive plasticity; that microbes are most beneficial in their home habitat but plant genotypes can utilize any microbes (Figure 1.4E). Twoway interactions between plant genotype and microbial source $\left(\mathrm{G}_{\mathrm{p}} \mathrm{x} \mathrm{G}_{\mathrm{m}}\right)$ would indicate plant genotypes do best with their own microbes, regardless of habitat (Figure 
Table 1.1: Analysis of variance table exploring how habitat, plant genotype, and microbial source affect patterns of local adaptation. Interpretations are meant to represent possible outcomes but careful interpretation of data will be necessary to understand significant terms. $+\mathrm{G}_{\mathrm{m}}$ is used loosely and can mean genetic change by microbes or shifts in community composition that drive microbe-mediated local adaptation.

\begin{tabular}{|c|c|c|}
\hline Fixed Effects & Interpretation & Interaction type \\
\hline Plant Genotype & Plant genotype vigor differs & \\
\hline Microbial Source & microbes from another & \\
\hline Habitat*:Plant Genotype & Plant genotype mediated local adaptation & $\mathrm{G}_{\mathrm{p}} \mathrm{xE}$ \\
\hline Habitat *Microbial Source & Microbe-mediated adaptive plasticity & $\mathrm{G}_{\mathrm{m}} \mathrm{XE}$ \\
\hline
\end{tabular}


1.4F). A three-way interaction between plant genotype, microbial source, and habitat $\left(\mathrm{G}_{\mathrm{p}} \mathrm{x} \mathrm{G}_{\mathrm{m}} \mathrm{xE}\right)$ would indicate microbe-mediated local adaptation, if home genotypes have higher fitness with their home microbes in their home habitat (Figure 1.4G). These outcomes are possibilities and not an exhaustive list of what could occur, so careful interpretation of data will be necessary to draw appropriate conclusions.

In some cases, microbe mediated adaptive responses are the result of coevolved interactions that occur between genotypes of plants $\left(G_{p}\right)$ and genotypes of microbes $\left(\mathrm{G}_{\mathrm{m}}\right)$ but are insensitive to the surrounding environment $(E)$. In other words, $\mathrm{G}_{\mathrm{p}} \mathrm{x} \mathrm{G}_{\mathrm{m}}$ interactions determine plant fitness without being affected by local conditions. For example, sympatric combinations of genotypes of tufted vetch (Vicia cracca) and strains of Rhizobium leguminosarum biovar. viciae collected from habitats with low, medium, and high soil nitrogen levels were found to have higher fitness than allopatric combinations regardless of the soil nitrogen environment they were exposed to in transplant experiments (Cauwenberghe et al. 2016), indicating coevolution between legume and rhizobia that was insensitive to nitrogen conditions.

The reciprocal transplant design described above has the added of advantage of testing for $\mathrm{G}_{\mathrm{p}} \mathrm{x} \mathrm{G}_{\mathrm{m}}$ or $\mathrm{G}_{\mathrm{p}} \mathrm{x} \mathrm{G}_{\mathrm{m}} \mathrm{xE}$ interactions. Simultaneous transplantation of the plant genotypes and microbial genotypes into contrasting habitats would give insight into sensitivity of plant-microbe interactions to environmental factors. If $\mathrm{G}_{\mathrm{p}} \mathrm{xG}$ m $\mathrm{xE}$ interactions dominated, positive effects of microbial symbionts wouldn't be evident 

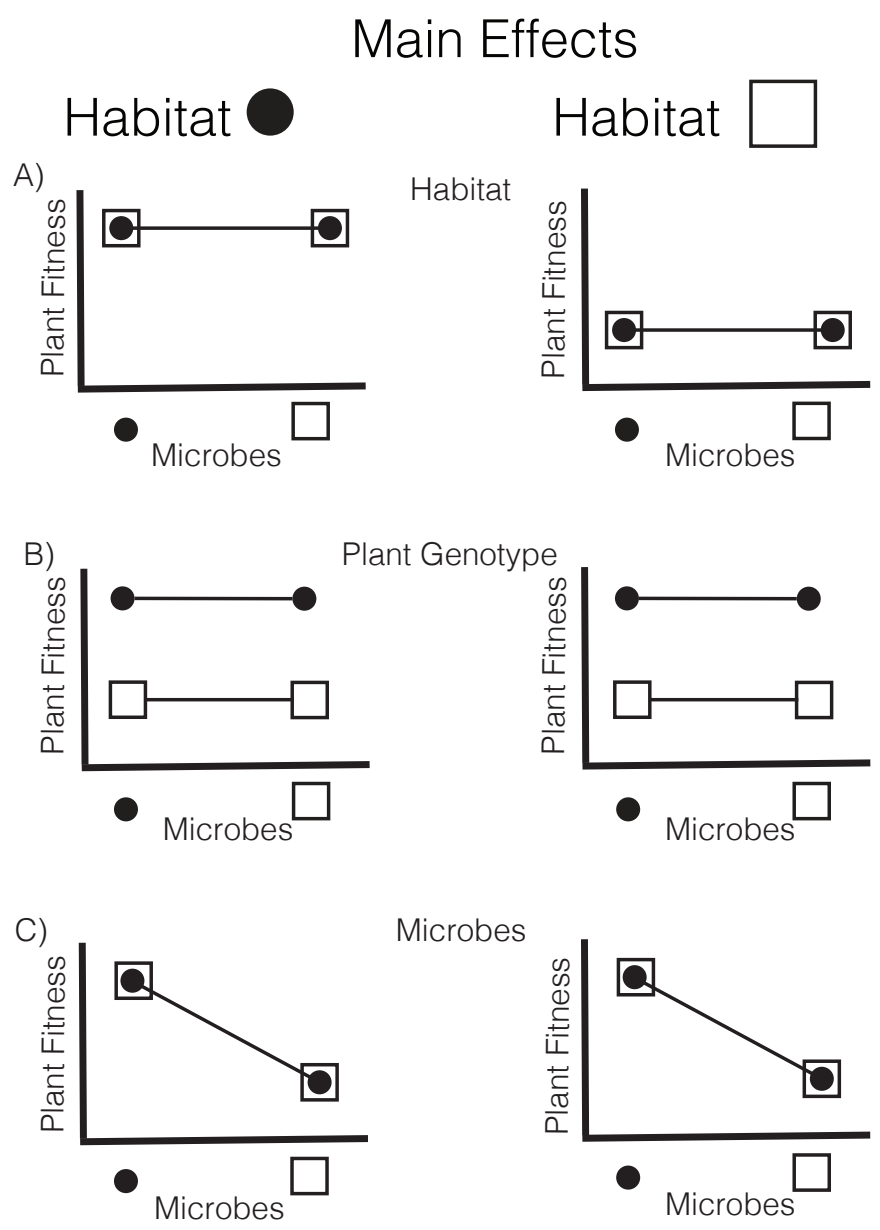

Figure 1.4 A-C: Outcomes of fully factorial design to test for microbe-mediated adaptation (either via local adaptation or adaptive plasticity). A-C demonstrate outcomes for significant main effects of habitat, plant source, or microbial source alone. The circle represents plants collected from the circle habitat and square indicates plants collected from the square habitat. 

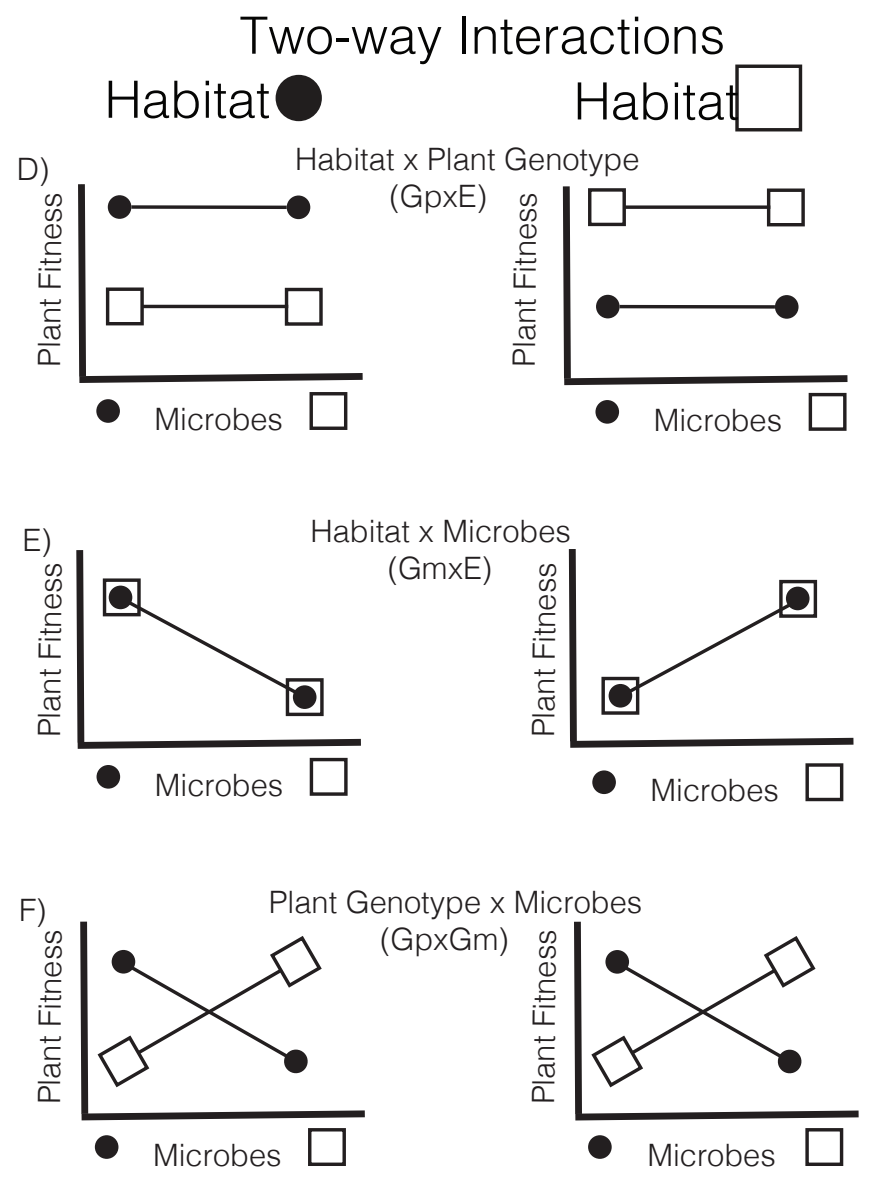

Figure 1.4 D-F: Potential outcomes for significant two-way interactions between all possible combinations of habitat, plant source, or microbial source. A two-way interaction between habitat and microbial source indicates microbe-mediated adaptive plasticity. The circle represents plants collected from the circle habitat and square indicates plants collected from the square habitat. 


\section{Three-way Interaction}
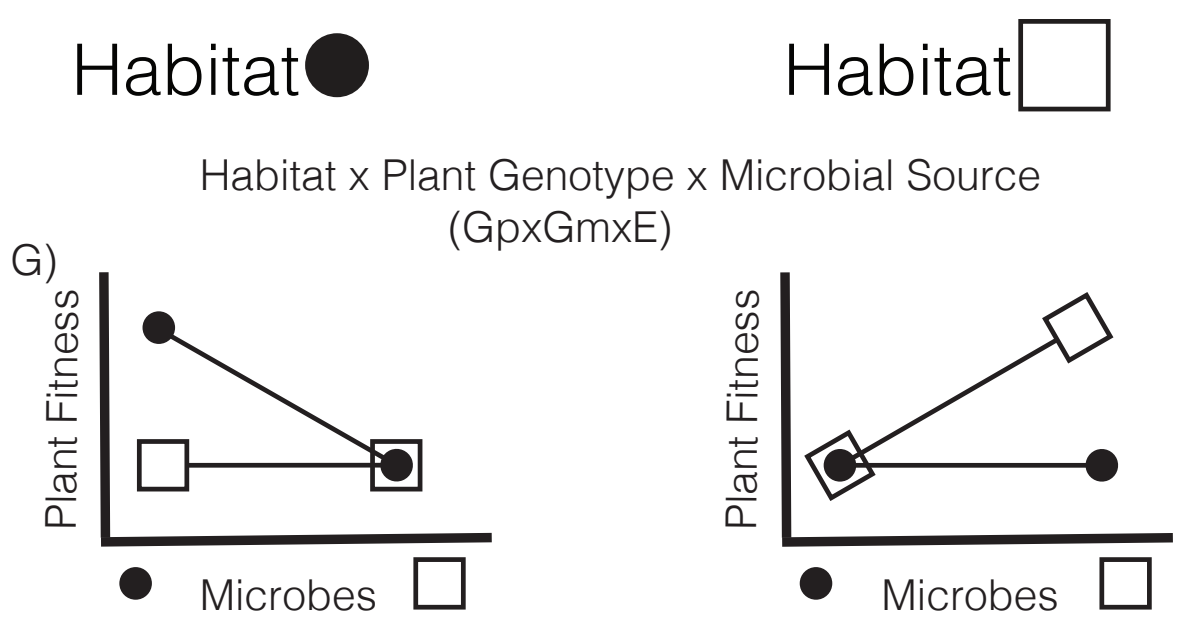

Figure 1.4 G: A three-way interaction between habitat x plant source $\mathrm{x}$ microbial source indicates microbe-mediated local adaptation. These reaction norms are meant to represent potential outcomes and are not an exhaustive list of all possible findings. The circle represents plants collected from the circle habitat and square indicates plants collected from the square habitat. 
when both microbes and plant genotypes were moved into novel habitats (Figure $1.4 \mathrm{G}$ ); in contrast, if $\mathrm{G}_{\mathrm{p}} \mathrm{x} \mathrm{G}_{\mathrm{m}}$ interactions dominated, plants would still benefit from microbial symbionts when both were moved into novel habitats (Figure 1.4F).

Reciprocal transplant experiments don't tell us about the plant traits that are under selection or adaptive, and therefore omit an important piece of information (Cheplick 2015). Care should be taken to measure not only plant fitness, but also plant functional traits that are influenced by the presence of microbes. This has two advantages, selection gradients can be estimated by comparing the relationship between fitness and a particular trait value to identify the type (directional, stabilizing, disruptive) and strength of selection acting on a population. This is important because selection could be an ongoing process that isn't manifest in fitness values yet (e.g. Wagner et al. 2014). Additionally, to rigorously demonstrate adaptive plasticity one needs to understand the relationship between trait values and fitness in variable habitats (Dewitt and Scheiner 2014). In the case of microbe-mediated adaptive plasticity, microbes affect trait values in ways that enhance plant fitness across habitats, resulting in fitness homeostasis (Figure 1.1 C).

The same caveats and considerations that apply to typical reciprocal transplant experiments also apply to microbe-mediated adaptation transplant experiments. Researchers should design experiments with care to decide the relevant spatial scale of adaptation in their system, which aspects of fitness to measure (survival, germination, and reproduction), and how long the experiment should be monitored to detect 
patterns of adaptation (Cheplick 2015). When designing a transplant experiment to address microbe-mediated adaptation, additional care should be taken to determine which microbial players are relevant, what manipulations would best isolate these taxa, and sterilization methods that would be most effective. Finally, since microbemediated adaptation experiments are simultaneously manipulating multiple factors, proper planning of sample sizes is important to have the power to detect significant interactive effects.

\section{Implications and Future Research Directions}

Microbe-mediated adaptation and the spatial scale of adaptation

Intra-population specialization can occur in plant microbe interactions, allowing for adaptation to fine-scale differences in biotic and abiotic conditions, an important factor considering strong selective gradients can be found over small spatial scales (Turkington and Harper 1979, Kalisz 1986, Galloway 1995). Intrapopulation adaptation could occur via microbe-mediated local adaptation if the plant population is highly-selfing with little admixture. Or it could occur via microbe-mediated adaptive plasticity if plants exhibit a high degree of plasticity for microbial attraction, retention, and regulation traits within a population.

Work done with a native Kenyan grass, Themeda triandra, indicates that microbes can affect drought phenotypes over small spatial scales. Authors focused on savanna areas that have abundant and regularly spaced termite mounds. The presence of termites drastically affects edaphic conditions, changing nutrient and water availability over 
small spatial scales $(>50 \mathrm{~m})$ and posing an adaptive challenge for wind pollinated Themeda triandra, which is unlikely to genetically differentiate over these spatial scales. When T. triandra seeds from a common source were exposed to different arbuscular mycorrhizal communities collected on and off termite mounds they had different drought phenotypes. Plants inoculated with off-mound fungi closed stomata quickly when exposed to drought and halted biomass accumulation, whereas plants inoculated with on-mound fungi kept stomata open longer under drought conditions and continued to acquire biomass (Petipas et al. 2017).

\section{Microbe-mediated adaptation and climate change (temporal scale of adaptation)}

Plants can be helped or hindered by association with microbes under changing conditions. Some plants will have a hard time shifting their ranges if microbial mutualists aren't moving at the same rate (Lankau and Keymer 2016). On the other hand, plasticity in plant-microbe associations may prove to be adaptive in the face of changing climate. A plant that is able to affiliate with a variety of microbes and/or is more effective at excluding microbial pathogens (Engelkes et al. 2008) will have an advantage as plant ranges change and local microbial communities shift. In addition, microbial change may be more evolutionary labile than plant genetic change. Microbes are less constrained to changing conditions because of wide-ranging metabolic strategies, high mutation rates, and short generation time.

The significance of microbe-mediated adaptive plasticity was evident in a multigeneration selection experiment that manipulated soil moisture for replicated plant 
populations and their associated microbial communities over the course of multiple generations. There was minimal genetic response by plants but drought-adapted microbes buffered plants against contemporary exposure to drought (Lau and Lennon 2012). Plants experienced a 58\% reduction in fitness during drought when grown in association with wet-adapted microbes, but only a $20 \%$ reduction in fitness when grown in association with drought-adapted microbes. This rapid response mediated by microbes is promising for plant responses to climate change. In general, experimental findings have supported the idea that microbes will enhance plant response to environmental change (Kivlin et al. 2013).

\section{Microbe-mediated adaptation and agriculture and restoration}

The genomics era has (re)awakened people to the idea of using microbes in restoration (Wubs et al. 2016) and to make crops more productive, less susceptible to disease, and more drought tolerant (Bakker et al. 2012, Reid and Greene 2012). Rhizoctonia solani is an important fungal pathogen that infects a variety of economically important crops, such as sugar beet and rice. Rhizoctonia infection can be suppressed by inoculation with certain disease suppressive soil communities. Metagenomic work identified members of Proteobacteria, Firmicutes, and Actinobacteria that were associated with Rhizoctonia disease suppressive soils. From this work, authors were able to isolate one strain of Pseudomonas that decreased disease incidence and they determined the mode of action was probably via secondary metabolites (Mendes et al. 2011).

Microbe-mediated adaptation and speciation 
Perhaps the most extreme potential outcome of microbe-mediated adaptation is speciation of plant hosts. Given that microbes can influence plant reproductive traits including plant phenology (Lau and Lennon 2012, Wagner et al. 2014, Panke-Buisse et al. 2016), reproductive isolation and eventually speciation could potentially be affected by microbes. Recent work found differences in plant-mycorrhizal fungi interactions led to coexistence of Howea palms, and the authors speculated mycorrhizal fungi led to this adaptive divergence perhaps via flowering time (Osborne et al. 2017). Microbes are correlated with host speciation at deeper evolutionary time scales. For example, plants in the coffee family (Rubiaceae) form symbiotic associations with leaf fungal endophytes. These endophytes produce secondary metabolites that protect hosts from pathogens and herbivores, and thus authors proposed they affected host evolution. They found plant lineages hosting leaf endophytes had higher rates of speciation compared with those without endophytes (Verstraete et al. 2017).

\section{Challenges}

To really understand the effects of microbes to the extent we can harness them as technologies, we need to be able to identify and isolate important members of the community. The age of informatics has allowed us a glimpse into the diversity and complexity of the microbiome, but much work remains to disentangle single species from multi-species effects and how relevant microbial genotypic diversity is for

adaptive benefits. For example, we know relatively little about intra-specific diversity 
in many microbial taxa, including important groups such as arbuscular mycorrhizal fungi (Johnson et al. 2012).

A further challenge is understanding context dependency in plant-microbe interactions. Plants do not universally benefit from interactions with microbes (even those generally referred to as mutualists), but rather these interactions are highly context dependent (Johnson 1993, Bronstein 1994) and depend on local selection pressures. One of the top research priorities into microbe-mediated adaptation should be efforts to delineate this context dependency.

The stress gradient hypothesis posits that as stress increases mutually beneficial interactions dominate and antagonistic interactions are reduced (Bertness and Callaway 1994). This idea was originally put forth to understand plant-plant interactions, but is also a promising framework to understand the context dependency of beneficial plant-microbe interactions (O’Brien et al. 2016, David et al. 2018). Microbes facilitate plant survival and fitness under nutrient stress and water limitation but engaging in mutualistic interactions is costly, and therefore plants might forgo trading with mutualists when resources are abundant locally. This is evident in resource mutualisms. For example, legumes show autoregulation of rhizobia when soil nitrogen is abundant. There are other axes of variation that could drive contextdependency in plant-microbe relationships, including plant characteristics such as annual/perennial, native /invasive, inbreeding/outcrossing, as well as microbial 
characteristics such as vertical/horizontal transmission, obligate/facultative, microbial species interactions, and priority effects.

\section{Conclusions}

Microbe-mediated adaptation either through adaptive plasticity or local adaptation is an important area of inquiry that will expand our basic knowledge of plant evolutionary ecology, and also give us insight into the important problems of our day. Microbe-mediated adaptation may have important implications for agriculture, climate change, and restoration. Developing these microbially-based technologies to deal with these issues is predicated upon a careful delineation of microbe-mediated adaptation, which we hope we have provided here. 


\section{REFERENCES}

Agrawal, A. A. 2001. Phenotypic plasticity in the interactions and evolution of species. Science 294:321-326.

Agrawal, A. A., S. Y. Strauss, and M. J. Stout. 1999. Costs of induced responses and tolerance to herbivory in male and female fitness components of wild radish. Evolution 53:1093-1104.

Alberdi, A., O. Aizpurua, K. Bohmann, M. L. Zepeda-Mendoza, and M. T. P. Gilbert. 2016. Do vertebrate gut metagenomes confer rapid ecological adaptation? Trends in Ecology \& Evolution 31:689-699.

Bakker, M. G., D. K. Manter, A. M. Sheflin, T. L. Weir, and J. M. Vivanco. 2012. Harnessing the rhizosphere microbiome through plant breeding and agricultural management. Plant and Soil 360:1-13.

Berendsen, R. L., C. M. J. Pieterse, and P. A. H. M. Bakker. 2012. The rhizosphere microbiome and plant health. Trends in Plant Science 17:478-486.

Bertness, M. D., and R. Callaway. 1994. Positive interactions in communities. Trends in Ecology \& Evolution 9:191-193. 
Biere, A., and A. J. M. Tack. 2013. Evolutionary adaptation in three-way interactions between plants, microbes and arthropods. Functional Ecology 27:646-660.

Bronstein, J. L. 1994. Conditional outcomes in mutualistic interactions. Trends in Ecology and Evolution 9: 214-217.

Cauwenberghe, J. V., W. Visch, J. Michiels, and O. Honnay. 2016. Selection mosaics differentiate Rhizobium-host plant interactions across different nitrogen environments. Oikos 125:1755-1761.

Cheplick, G. P. 2015. Approaches to plant evolutionary ecology. Oxford University Press, New York, New York, USA.

David, A. S., K. B. Thapa-Magar, and M. E. Afkhami. 2018. Microbial mitigationexacerbation continuum: a novel framework for microbiome effects on hosts in the face of stress. Ecology 99:517-523.

DeWitt, T. J., and S. M. Scheiner. 2004. Phenotypic variation from single genotypes: a primer. Pages 1-9 in T. J. DeWitt and S. M. Scheiner, editors. Phenotypic plasticity: functional and conceptual approaches. Oxford University Press, New York, New York, USA.

Dudley, S. A., and J. Schmitt. 1996. Testing the adaptive plasticity hypothesis: 
density-dependent selection on manipulated stem length in Impatiens capensis. American Naturalist 147:445-465.

Engelkes, T., E. Morriën, K. J. F. Verhoeven, T. M. Bezemer, A. Biere, J. A. Harvey, L. M. McIntyre, W. L. M. Tamis, and W. H. Van der Putten. 2008. Successful range-expanding plants experience less above-ground and below-ground enemy impact. Nature 456:946-948.

Friesen, M. L., S. S. Porter, S. C. Stark, E. J. von Wettberg, J. L. Sachs, and E. Martinez-Romero. 2011. Microbially mediated plant functional traits. Annual Review of Ecology, Evolution, and Systematics 42:23-46.

Galloway, L. F. 1995. Response to natural environmental heterogeneity: maternal effects and selection on life-history characters and plasticities in Mimulus guttatus. Evolution 49:1095-1107.

Gehring, C. A., C. M. Sthultz, L. Flores-Rentería, A. V. Whipple, and T. G. Whitham. 2017. Tree genetics defines fungal partner communities that may confer drought tolerance. Proceedings of the National Academy of Sciences 114:11169-11174.

Ghalambor, C. K., J. K. McKay, S. P. Carroll, and D. N. Reznick. 2007. Adaptive versus non-adaptive phenotypic plasticity and the potential for contemporary adaptation in new environments. Functional Ecology 21:394-407. 
Goh, C.H., D. F. Veliz Vallejos, A. B. Nicotra, and U. Mathesius. 2013. The impact of beneficial plant-associated microbes on plant phenotypic plasticity. Journal of Chemical Ecology 39:826-839.

González, J. B., R. H. Petipas, O. Franken, E. T. Kiers, K. E. Veblen, and A. K. Brody. 2018. Herbivore removal reduces influence of arbuscular mycorrhizal fungi on plant growth and tolerance in an East African savanna. Oecologia $187: 123-133$.

Grenier, S., P. Barre, and I. Litrico. 2016. Phenotypic plasticity and selection: nonexclusive mechanisms of adaptation. Scientifica 2016:1-9.

Howard, M. M., T. H. Bell, and J. Kao-Kniffin. 2017. Soil microbiome transfer method affects microbiome composition, including dominant microorganisms, in a novel environment. FEMS Microbiology Letters 364:11512.

Johnson, D., F. Martin, J. W. G. Cairney, and I. C. Anderson. 2012. The importance of individuals: intraspecific diversity of mycorrhizal plants and fungi in ecosystems. New Phytologist 194:614-628.

Johnson, N. C. 1993. Can fertilization of soil select less mutualistic mycorrhizae? Ecological Applications 3:749-757. 
Johnson, N. C., C. Angelard, I. R. Sanders, and E. T. Kiers. 2013. Predicting community and ecosystem outcomes of mycorrhizal responses to global change. Ecology Letters 16:140-153.

Johnson, N. C., G. W. T. Wilson, M. A. Bowker, J. A. Wilson, and R. M. Miller. 2010. Resource limitation is a driver of local adaptation in mycorrhizal symbioses. Proceedings of the National Academy of Sciences 107:2093-2098.

Kalisz, S. 1986. Variable selection on the timing of germination in Collinsia verna (Scrophulariaceae). Evolution 40:479-491.

Kawecki, T. J., and D. Ebert. 2004. Conceptual issues in local adaptation. Ecology Letters 7:1225-1241.

Kivlin, S. N., S. M. Emery, and J. A. Rudgers. 2013. Fungal symbionts alter plant responses to global change. American Journal of Botany 100:1445-1457.

Lankau, R. A. 2013. Species invasion alters local adaptation to soil communities in a native plant. Ecology 94:32-40.

Lankau, R. A., and D. P. Keymer. 2016. Ectomycorrhizal fungal richness declines towards the host species' range edge. Molecular Ecology 25:3224-3241. 
Lau, J. A., and J. T. Lennon. 2011. Evolutionary ecology of plant-microbe interactions: soil microbial structure alters selection on plant traits. New Phytologist 192:215-224.

Lau, J. A., and J. T. Lennon. 2012. Rapid responses of soil microorganisms improve plant fitness in novel environments. Proceedings of the National Academy of Sciences 109: 14058-14062.

Lee, B., S. Lee, and C. M. Ryu. 2012. Foliar aphid feeding recruits rhizosphere bacteria and primes plant immunity against pathogenic and non-pathogenic bacteria in pepper. Annals of Botany 110:281-290.

Marasco, R., E. Rolli, B. Ettoumi, G. Vigani, F. Mapelli, S. Borin, A. F. Abou-Hadid, U. A. El-Behairy, C. Sorlini, A. Cherif, G. Zocchi, and D. Daffonchio. 2012. A Drought resistance-promoting microbiome is selected by root system under desert farming. PLoS ONE 7:e48479.

McGuire, K. L. 2007. Common ectomycorrhizal networks may maintain monodominance in a tropical rain forest. Ecology 88:567-574.

Meharg, A. A., and J. Cairney. 2000. Ectomycorrhizas—extending the capabilities of rhizosphere remediation? Soil Biology and Biochemistry 32: 1475-1484. 
Mendes, R., M. Kruijt, I. de Bruijn, E. Dekkers, M. van der Voort, J. H. M. Schneider, Y. M. Piceno, T. Z. DeSantis, G. L. Andersen, P. A. H. M. Bakker, and J. M. Raaijmakers. 2011. Deciphering the rhizosphere microbiome for diseasesuppressive bacteria. Science 332:1097-1100.

Moran, N. A. 1992. The evolutionary maintenance of alternative phenotypes. American Naturalist 139:971-989.

O'Brien, A. M., R. J. H. Sawers, J. Ross-Ibarra, and S. Y. Strauss. 2016. Extending the Stress-Gradient hypothesis: greater adaptation between teosinte and soil biota at higher stress sites. bioRxiv: [doi: 10.1101/031195]

Osborne, O. G., R. De-Kayne, M. I. Bidartondo, I. Hutton, W. J. Baker, C. G. N. Turnbull, and V. Savolainen. 2017. Arbuscular mycorrhizal fungi promote coexistence and niche divergence of sympatric palm species on a remote oceanic island. New Phytologist 217:1254-1266.

Panke-Buisse, K., S. Lee, and J. Kao-Kniffin. 2017. Cultivated sub-populations of soil microbiomes retain early flowering plant trait. Microbial Ecology 73: 394-403.

Partida-Martinez, L. P., and M. Heil. 2011. The microbe-free plant: fact or artifact? Frontiers in Plant Science 2:1-16. 
Peiffer, J. A., A. Spor, O. Koren, Z. Jin, S. G. Tringe, J. L. Dangl, E. S. Buckler, and R. E. Ley. 2013. Diversity and heritability of the maize rhizosphere microbiome under field conditions. Proceedings of the National Academy of Sciences 110: $6548-6553$.

Petipas, R. H., J. B. González, T. M. Palmer, and A. K. Brody. 2017. Habitat-specific AMF symbioses enhance drought tolerance of a native Kenyan grass. Acta Oecologica 78:71-78.

Pickles, B. J., B. D. Twieg, G. A. O'Neill, W. W. Mohn, and S. W. Simard. 2015. Local adaptation in migrated interior Douglas-fir seedlings is mediated by ectomycorrhizas and other soil factors. New Phytologist 207:858-871.

Reid, A., and S. E. Greene. 2012. How microbes can help feed the world: a report from the American Academy of Microbiology. American Society for Microbiology, Washington, DC, USA.

Remy, W., T. N. Taylor, H. Hass, and H. Kerp. 1994. Four hundred-million-year-old vesicular arbuscular mycorrhizae. Proceedings of the National Academy of Sciences 91:11841-11843. 
Revillini, D., C. A. Gehring, and N. C. Johnson. 2016. The role of locally adapted mycorrhizas and rhizobacteria in plant-soil feedback systems. Functional Ecology 30:1086-1098.

Rodriguez, R. J., J. Henson, E. Van Volkenburgh, M. Hoy, L. Wright, F. Beckwith, Y.O. Kim, and R. S. Redman. 2008. Stress tolerance in plants via habitat-adapted symbiosis. The ISME Journal 2:404-416.

Rúa, M. A., A. Antoninka, P. M. Antunes, V. B. Chaudhary, C. Gehring, L. J. Lamit, B. J. Piculell, J. D. Bever, C. Zabinski, J. F. Meadow, M. J. Lajeunesse, B. G. Milligan, J. Karst, and J. D. Hoeksema. 2016. Home-field advantage? evidence of local adaptation among plants, soil, and arbuscular mycorrhizal fungi through meta-analysis. BMC Evolutionary Biology:1-15.

Schweitzer, J. A., J. K. Bailey, D. G. Fischer, C. J. LeRoy, E. V. Lonsdorf, T. G. Whitham, and S. C. Hart. 2008. Plant-soil microorganism interactions: heritable relationship between plant genotype and associated soil microorganisms. Ecology $89: 773-781$.

Simonsen, A. K., and J. R. Stinchcombe. 2014. Standing genetic variation in host preference for mutualist microbial symbionts. Proceedings of the Royal Society B: Biological Sciences 281:20142036. 
Smith, D. S., J. A. Schweitzer, P. Turk, J. K. Bailey, S. C. Hart, S. M. Shuster, and T. G. Whitham. 2011. Soil-mediated local adaptation alters seedling survival and performance. Plant and Soil 352:243-251.

Strullu-Derrien, C., P. Kenrick, S. Pressel, J. G. Duckett, J.P. Rioult, and D.G. Strullu. 2014. Fungal associations in Horneophyton ligneri from the Rhynie Chert (c. 407 million year old) closely resemble those in extant lower land plants: novel insights into ancestral plant-fungus symbioses. New Phytologist 203:964-979.

Thompson, J. D. 1991. Phenotypic plasticity as a component of evolutionary change. Trends in Ecology and Evolution 6:246-249.

Trevors, J. T. 1996. Sterilization and inhibition of microbial activity in soil. Journal of Microbiological Methods 26:53-59.

Turkington, R., and J. L. Harper. 1979. The growth, distribution and neighbour relationships of Trifolium repens in a permanent pasture: IV. Fine-scale biotic differentiation. The Journal of Ecology 67:245-254.

Van Nuland, M. E., R. C. Wooliver, A. A. Pfennigwerth, Q. D. Read, I. M. Ware, L. Mueller, J. A. Fordyce, J. A. Schweitzer, and J. K. Bailey. 2016. Plant-soil feedbacks: connecting ecosystem ecology and evolution. Functional Ecology 30:1032-1042. 
Verstraete, B., S. Janssens, and N. Rønsted. 2017. Non-nodulated bacterial leaf symbiosis promotes the evolutionary success of its host plants in the coffee family (Rubiaceae). Molecular Phylogenetics and Evolution 113:161-168.

Wagner, M. R., D. S. Lundberg, D. Coleman-Derr, S. G. Tringe, J. L. Dangl, and T. Mitchell-Olds. 2014. Natural soil microbes alter flowering phenology and the intensity of selection on flowering time in a wild Arabidopsis relative. Ecology Letters 17:717-726.

Wubs, E. R. J., W. H. Van der Putten, M. Bosch, and T. M. Bezemer. 2016. Soil inoculation steers restoration of terrestrial ecosystems. Nature Plants 2:1-5. 


\section{CHAPTER 2}

\section{THE BACTERIAL AND FUNGAL MICROBIOME OF HYPERICUM PERFORATUM IN TWO DISTINCT HABITATS}

In preparation for Phytobiomes as Renee H. Petipas, Steven A. Higgins, Chantal Koechli, Spencer J. Debenport, Monica A. Geber, and Daniel H. Buckley. The bacterial and fungal microbiome of Hypericum perforatum in two distinct habitats.

\section{Abstract}

Root-associated microbes contribute to plant nutrition, health, and stress-tolerance. Saint John's wort, Hypericum perforatum subsp. perforatum, is a medicinally and ecologically important perennial plant species that has a broad global distribution. Despite the importance of this species, little is known about the factors that structure its microbial communities and the identity of microbes that enhance plant growth and fitness. Here we collected $H$. perforatum root samples in two distinct habitats: alvars, a type of limestone barren, and old-fields. These habitats occur immediately adjacent to each other in Jefferson County, New York. We used high-throughput amplicon sequencing of the SSU-rRNA gene (bacteria) and the internal transcribed spacer region 1 (ITS1, fungi) to characterize the root microbiome of $H$. perforatum. At each root sampling location, we quantified soil characteristics to evaluate habitat variables that correlate with root microbial communities. We also collected information on plant height and fecundity to identify microbes that are correlated with plant size and fitness. We found that bacterial and fungal communities were significantly different 
between habitats. These differences were correlated with soil nitrogen, $\mathrm{pH}$, and plant height. Bacterial community composition was correlated with soil depth but not fungal community composition. Bacterial richness was similar between habitats but fungal richness was higher in old-fields. Microbial taxa positively associated with plant height included two OTUs belonging to the bacterial phylum Actinobacteria. This work contributes to a growing body of knowledge of the environmental determinants of microbial consortia and microbial taxa that are correlated with plant health.

\section{Introduction}

There is growing awareness that the plant root-associated bacteria and fungi that live on and within plant roots affect adaptive phenotypes (Berendsen et al. 2012, Bakker et al. 2012, Vandenkoornhuyse et al. 2015, Haney et al. 2015, Wintermans et al. 2016). Microbes affect a range of plant functional traits (Friesen et al. 2011) that mediate a plant's response to the environment and ultimately influence plant productivity and fitness (Rodriguez et al. 2008, Rodriguez and Redman 2008, Goh et al. 2013). This new appreciation of the plant microbiome has instigated efforts to develop microbial products that can be used in agriculture. However, advances in this field have been hampered by a poor understanding of how biotic and abiotic factors affect microbial community composition and hence adaptive benefits for plants. Here we explore how the root microbiome of St. John's Wort (Hypericum perforatum) differs between two distinct habitats in northern New York. We specifically consider how soil nutrients, 
$\mathrm{pH}$, and soil depth affect microbial communities and how plant phenotypes are correlated with microbial communities and specific microbial taxa.

Soil macronutrients and $\mathrm{pH}$ are important determinants of the soil and plant root microbiome. Enhanced nitrogen causes decreases in fungal biomass and shifts in fungal community composition (Treseder 2004, Lauber et al. 2008). Bacteria show more variable responses; they either remain unaffected (Högberg et al. 2006, Marschner et al. 2001, Fierer et al. 2011) or have reductions in biomass and/or shifts in community composition (Fierer et al. 2011, Ramirez et al. 2012). Phosphorus availability also affects fungal abundance (Cassman et al. 2016) and community composition (Lauber et al. 2008), mainly via shifts in the relative abundance of taxa from Sordariomycetes and Agaricales. Enhanced phosphorus also causes changes to bacterial community composition but does not necessarily affect bacterial abundance (Cassman et al. 2016). In a comprehensive examination of fungal and bacterial diversity at 25 nutrient addition sites, Leff et al. (2015) found that nutrient addition affected fungal diversity weakly but community composition strongly, with mycorrhizal fungi declining disproportionately to other fungal taxa. Similarly, bacterial diversity was only marginally impacted but community composition shifted in response to nutrient additions. Potassium and plant micronutrients (e.g. calcium, magnesium, iron, etc.) affect microbial communities but the effects are less well studied. 
Soil $\mathrm{pH}$ can also impact microbial communities. Bacterial richness and diversity decrease in more acidic soils (de Vries et al. 2012, Fierer and Jackson 2006, Högberg et al. 2006, Lauber et al. 2008), whereas fungi are potentially less sensitive to $\mathrm{pH}$ (Frostegård et al. 1993, Rousk et al. 2010). Soil depth is another important determinant of soil microbial communities. Even with relatively minor changes in depth $(10-20 \mathrm{~cm})$ bacterial communities shift dramatically and look more different than microbial communities sampled from soil surfaces in different biomes (Eilers et al. 2012). Likewise, the abundance (Ekelund et al. 2001), distribution, and species richness (Jumpponen et al. 2010) of fungi are strongly affected by soil depths, even within horizons. For both bacteria and fungi, diversity and abundance tend to decrease with increasing soil depths (Jumpponen et al. 2010, Ko et al. 2017).

While local soil conditions (nutrients, depth, etc.) shape "bulk" soil microbial communities, further selection of microbes happens in the rhizosphere. The rhizosphere is the layer of soil directly adjacent to plant roots where plants secrete a vast array of compounds that act as chemical attractants or repellents of microorganisms. Differences in bacterial and fungal community composition and diversity near, on, or within the roots occur at the level of plant species and even genotype (Lundberg et al. 2012, Schweitzer et al. 2008, Peiffer et al. 2013, Lamit et al. 2016). Genotype-specific differences in root colonization are likely mediated by plant traits that affect microbial communities (de Vries et al. 2012, Wehner et al. 2013), including root architecture and exudation profiles. In turn, microbes that are retained in the rhizosphere and within roots are important determinants of plant fitness and stress 
tolerance (Berendsen et al. 2012). A range of important plant functional and demographic traits are affected by interactions with microbes, including germination, survival, biomass, flowering time, height, and reproductive fitness (Friesen et al. 2011).

At this point, substantial work has been done to understand the root microbiome of many model/crop plants, including corn (Bouffaud et al. 2014), rice (Edwards et al. 2015), wheat (Mahoney et al. 2017), barley (Bulgarelli et al. 2015), poplar (Beckers et al. 2017), sugar cane (de Souza et al. 2016), and Arabidopsis (Bulgarelli et al. 2012, Lundberg et al. 2012). From this work we can extract some generalities about the plant root microbiome, including the importance of the soil environment, and the small but consistently reproducible effects of plant genotype on root microbiome composition.

Moving forward, the field will benefit from explorations of the root microbiome in non-model, non-crop species under a range of environmental conditions. This area of inquiry is important for two reasons. First, expanding our efforts to new plant taxa in diverse environments will provide new understanding about the context-dependency of the plant microbiome structure and function, a necessary goal given the growing interest in microbe-based technologies for agriculture and restoration. Second, exploring a range of plant species in different habitats can aid in the identification of microbial taxa that enhance plant stress tolerance, productivity, and reproductive fitness. Bioprospecting in a wide diversity of plant species and habitats could lead to the discovery of plant-associated microbes that could aid in agriculture and 
restoration. Here we sequence the bacterial and fungal root microbiome of Hypericum perforatum in two distinct habitats. At each root sampling location, we quantified soil characteristics to evaluate habitat variables that correlate with root microbial communities. We also collected information on plant growth and fecundity for each focal plant to identify microbes that are correlated with plant growth and fitness.

\section{Methods}

Study system Hypericum perforatum, known commonly as Saint John's Wort, is a medicinally important plant species that is used throughout the world to treat mild to moderate depression (Linde et al. 1996). Hypericum occurs natively in Africa, Asia, and parts of Europe and was introduced to North America in the late 1700s (Muhlenberg 1793). It is a perennial herb that occurs in a wide range of open, well-drained habitats. Saint John's Wort has a diversity of reproductive strategies including clonal growth and outcrossing. However, pseudogamous apomicty seems to be the most common strategy with $>90 \%$ of seeds produced apomictically (Maron et al. 2007).

We explored the community composition of bacteria and fungi present in roots of Hypericum growing in two habitats, a type of limestone barrens called alvars, and oldfields around Lake Ontario in Jefferson County, NY. Alvars are a globally rare habitat that occur throughout Northern Europe and around the Great Lakes in North America. They are characterized by limestone/dolostone bedrock that is covered by a thin and discontinuous layer of soil (Reschke et al. 1999). Alvars have low plant productivity and high plant species richness, which is unsurprising given the extreme temporal and 
spatial environmental heterogeneity that occurs on alvars. Three distinct alvar types occur in New York State: shrublands, grasslands, and pavement grasslands (Edinger 2014). For our characterization of the Hypericum microbiome we chose to focus on alvar pavements and alvar grasslands. We chose alvar pavements, hereafter referred to as "dry alvar" because they provide an extreme adaptive challenge to plants and are the most different from old-fields. We chose alvar grasslands, hereafter referred to as "wet alvar", because they represent a mid-point between alvars and old-fields. They have similar plant cover to old-fields, more overlapping plant species, and intermediate soil depths. Microbial communities between dry and wet alvars were indistinguishable (i.e. no differences in species richness or community composition) and were combined into a single category labelled "alvar" for simplicity.

\section{Site selection}

We selected three geographic locations (hereafter called "sites") where we could identify one wet alvar, one dry alvar, and one old-field habitat for root sampling. Alvar habitats were chosen based on the opening size ( $>2$ acres) and the presence of Hypericum perforatum, we then paired alvar habitats with a nearby old-fields. At each of our sampling habitats ( $\mathrm{N}=6$ alvar and $\mathrm{N}=3$ old-field) we demarcated an area to be used for root sampling. At two of the three sampling sites (Chaumont and 3-mile) we sampled within an $\sim$ two-acre sampling area $\left(8000 \mathrm{~m}^{2}\right)$. The openings at the third location were smaller (Lim), so we were only able to designate a sampling area of $\sim$ one-acre $\left(3500 \mathrm{~m}^{2}\right)$.

\section{Rhizosphere sampling and plant phenotyping}

In August of 2014, at each site, we collected rhizosphere samples from ten $H$. perforatum plants per habitat. Both habitat types were sampled at one site per day, and 
whether the old-field or alvar was collected first in the day was varied. We identified focal plants by laying out transects heading in the four cardinal directions that spanned the natural openings ( $\sim 50 \mathrm{~m}$ transects). Hypericum perforatum is capable of rhizomatous growth, so we selected plants spaced by a minimum of two meters to avoid sampling the same individual. At each focal plant we measured the soil depth, recorded plant height, number of buds, and number of flowers. We also collected a rhizosphere sample consisting of a standardized root volume that contained surrounding soil and roots. To collect a standardized amount of soil and roots we used a $1.5 \mathrm{~cm}$ chisel to a depth of $10 \mathrm{~cm}$, resulting in $\sim 700 \mathrm{ml}$ of soil, per collection point. The soil and roots were placed in a Whirlpak bag and then on ice while in the field, and then later in the day placed in the freezer at $-20{ }^{\circ} \mathrm{C}$ until DNA extraction and sequencing. From these rhizosphere samples, we removed 150-200 $\mathrm{ml}$ of soil for soil nutrient analyses. These were placed in paper bags, dried at $40{ }^{\circ} \mathrm{C}$ for four days, and then sieved. We measured total nitrogen by dry combustion at $1350{ }^{\circ} \mathrm{C}$. Soil $\mathrm{pH}$ was measured in distilled water. Organic matter was quantified by loss on ignition (LOI) at $375^{\circ} \mathrm{C}$. All nutrients were extracted in ammonium acetate buffer $(\mathrm{pH} 4.9$, modified Morgan). Phosphorus was determined colorimetrically by Ion Analyzer. All others were measured by inductively coupled plasma-optical emission spectrometry (ICPOES). The values are presented in parts per million $(\mathrm{mg} / \mathrm{kg})$ extractable levels in modified Morgan extract. Total nitrogen is presented as percent total nitrogen. Soil analyses were performed at the Analytical Lab and Maine Soil Testing Service at the University of Maine.

\section{DNA extraction and sequencing}

To describe the fungal and bacterial communities we removed the roots from the soil samples. We were careful to only sample roots that were visibly attached to the focal 
Hypericum plant. Root samples were washed thoroughly in deionized water to remove visible soil matter. Roots were then finely ground $(>3 \mathrm{~mm})$ using liquid nitrogen and a mortar and pestle. We then weighed out $\sim 0.05 \mathrm{~g}$ of root material for DNA extraction. Extractions were done with the MoBio PowerPlant DNA extraction kit (Qiagen, Germantown, MD). We modified the extraction protocol to include a bead beating step to ensure that root tissue was disrupted sufficiently and then extractions proceeded according to manufacturer's directions. DNA yields were quantified using Quant-iT PicoGreen dsDNA Assay Kit (Life Technologies, Grand Island, NY). Bacterial SSU-rRNA were amplified with primers 515F and 927R (V4-V5; Kozich et al. 2013)) and fungal internal transcribed spacer 1 (ITS1) gene regions were amplified with primers nBITS2 and 58A2R. Amplicons were prepared in triplicate reactions containing $5 \mathrm{ng}$ of DNA template, $12.5 \mu \mathrm{l}$ of Q5 Hot Start High-Fidelity 2X Mastermix (New England BioLabs, Ipswich, MA, USA), $1.25 \mu 1$ bovine serum albumin, $0.6 \mu 1$ of Picogreen reagent, and $2.5 \mu 1$ of combined forward and reverse barcoded primers in a total volume of $25 \mu 1$. Thermocycler conditions for bacterial PCR amplification were $95{ }^{\circ} \mathrm{C}$ for 2 minutes, followed by 30 cycles of $95{ }^{\circ} \mathrm{C}$ for 20 seconds, $55^{\circ} \mathrm{C}$ for 15 seconds, $72{ }^{\circ} \mathrm{C}$ for 10 seconds, with a final extension of $72{ }^{\circ} \mathrm{C}$ for 5 minutes. The thermocycler conditions for fungal ITS1 amplification were $95^{\circ} \mathrm{C}$ for $30 \mathrm{sec}$, followed by 30 cycles of $95^{\circ} \mathrm{C}$ for 5 seconds, $50{ }^{\circ} \mathrm{C}$ for 20 seconds, $72{ }^{\circ} \mathrm{C}$ for 10 seconds, with a final extension of $72{ }^{\circ} \mathrm{C}$ for 2 minutes. We then pooled triplicate reactions and standardized using the SequalPrep Normalization Plate Kit (Life Technologies, Grand Island, NY, USA). Finally, standardized reactions were pooled and then purified using the Wizard SV Gel and PCR Clean-up System (Promega, Madison, WI, USA). We submitted pooled libraries for 2 x $250 \mathrm{bp}$ (bacteria) and 2 x 300 bp (fungi) paired-end sequencing using the Illumina MiSeq 
platform at the Cornell Biotechnology Resource Center Genomics Facility (Ithaca, NY, USA).

\section{Bioinformatic pipeline}

A total of 5,624,189 and 13,450,730 reads for bacterial 16S and fungal ITS1 amplicons, respectively, were processed using a custom bioinformatic pipeline. We merged forward and reverse reads using PEAR (v.0.9.2, minimum overlap 50 bp, assembly probability 0.001, and PHRED score cutoff of 30, Zhang et al. 2014), removed sequencing primers and adapters using cutadapt v1.14, and demultiplexed reads into individual samples with deML (Martin 2011, Renaud et al. 2014). We defined operational taxonomic units (OTUs) using a 3\% dissimilarity cutoff with VSEARCH v2.5.2, an OTU clustering algorithm that simultaneously removes singletons and chimeric sequences. Taxonomic affiliations of 16S and ITS1 sequences were performed with the SINTAX algorithm within USEARCH v9.2.64 (sintax cutoff 0.8) using the GreenGenes v13.8 or UNITE v7.2 sequence databases, respectively (DeSantis et al. 2006, Edgar 2010, Kõljalg et al. 2013, Edgar 2016) Prior to analyzing data we removed OTUs from our analysis that were not found in $\geq 20 \%$ and $\geq 5 \%$ of samples for bacteria and fungi, respectively. Due to the coamplification of $H$. perforatum ITS1 regions by the fungal ITS1 primers, this threshold was lowered to preserve fungal OTUs for analysis. In the end, we identified 729 bacterial OTUs in 68 samples and 166 fungal OTUs in 57 samples. Sequences and associated metadata will be deposited into NCBI sequence database.

\section{Data analysis}

Statistical analyses were performed in R (Version 3.3.1, R Development Core Team, 2016). We used permutational multivariate analysis of variance (PERMANOVA) to 
understand how soil geochemistry differed between habitats. We then ran univariate analysis of variance (ANOVA) to understand how each individual soil parameter, plant phenotype, and soil depth varied between habitats. Univariate tests were conducted using the lme4 package (Bates et al. 2015) and p-values were estimated using lmerTest (Kuznetsova et al. 2017). To correct for multiple comparisons we adjusted our critical cut-off ( $p$-value) by Bonferroni corrections.

To understand how community composition varied between the two habitats we calculated Bray-Curtis dissimilarity distances for bacteria and Jaccard dissimilarity distances for fungi to run a Principle coordinate analysis (PCoA) analysis in the vegan package (Oksanen 2016). We performed a PERMANOVA using the 'adonis' function to understand how community composition varied between habitats. Using the same package, we ran a constrained analysis of principle coordinates (CAP) to understand how environmental variables correlated with microbial communities in the two habitats. To test which environmental variables affected microbial community composition we again used PERMANOVA and the 'adonis' function on soil geochemical measures and aspects of plant phenotype (height and bud number). We used univariate analyses to understand how richness and corrected richness values (Chao1) varied between habitats. To identify species that were more commonly found in one habitat we calculated the indicator value index (IndVal; De Cáceres and Legendre 2009) and used the indicspecies package (De Cáceres and Jansen 2016) to perform permutation tests that test the significance of OTU associations with habitat. We only report significant habitat-specific taxa at a stringent cut-off of $P=0.001$. To 
determine the putative identity of fungal OTUs, we queried our fungal ITS1 sequence data using the blastn algorithm (Altschul et al. 1997) against species hypotheses (SH) within the UNITE fungal database (Kõljalg et al. 2013). In each case, we calculated which $\mathrm{SH}$ occurred most frequently in the top ten sequences that produced significant alignments with our fungal ITS1 sequence data.

To determine how bacterial and fungal communities were correlated with each other and also with plant phenotype and soil geochemistry we used Procrustes analysis. Procrustean techniques offer a way to understand associations between multivariate data matrices. In our case we sought to align fungal and bacterial ordinations with each other, and also each taxonomic group independently with soil chemistry and plant phenotype. Although Mantel tests are more commonly used to understand concordance between multivariate objects, Procrustean approaches have higher statistical power and a more refined ability to detect correspondence at the level of individual observations (Peres-Neto and Jackson 2001). We used the repeatedmedians algorithm to fit ordinations and tested for significance using a Procrustean randomization test with 9,999 permutations (PROTEST; Jackson 1995 ).

To identify taxa that correlate with aspects of plant phenotype, we used a method similar to that described in Wagner et al. 2014. We looked at which PCoA axes were correlated with plant phenotype. We then regressed significant axes against bacterial OTU abundances to determine OTUs that were contributing significantly to variation in those axes. OTUs that remained significant after p-value adjustments were used for 
further analysis where we looked for correlation between individual OTUs and plant phenotype. We found a strong correlation between the height of a focal plant and the number of buds produced $\left(\mathrm{F}=45.2, \mathrm{R}^{2}=0.40, P<0.0001\right)$, so to simplify our analysis we used plant height as a representation of plant size and fecundity. Unfortunately, we were unable to do the same analysis with our fungal data because of low sequencing depth.

\section{Results}

Soil geochemistry and plant phenotype

Overall soil nutrient conditions were different between old-fields and alvars $\left(\right.$ MANOVA; $\left.\mathrm{F}_{(15,29)}=11.18, P<0.0001\right)$. After Bonferroni correction, alvars had significantly higher $\mathrm{pH}\left(\mathrm{F}_{(1,26)}=17.02, P=0.0003\right)$ and shallower soils $\left(\mathrm{F}_{(1,52.6)}=169.31\right.$, $P<0.0001)$; whereas old-field had significantly more soil magnesium $\left(\mathrm{F}_{(1,26)}=17.19\right.$, $P=0.0003)$. After Bonferroni correction, we found plants growing in the old-fields were significantly taller than alvar plants $\left(\mathrm{F}_{(1,56)}=79.68, P<0.0001\right)$. A summary of soil geochemistry and phenotype results can be found in Table 2.1.

\section{Microbial community analysis}

We found significant differences in community composition of bacteria $(F=6.06$, $\left.\mathrm{R}^{2}=0.084, P=0.0001\right)$ and fungi $\left(\mathrm{F}=2.858, \mathrm{R}^{2}=0.050, P=0.0001\right)$. Overall, differences in community composition of bacteria were influenced by plant phenotype and soil depth $\left(\mathrm{F}_{(4,30)}=2.19, P=0.0001\right.$; Figure $\left.2.1 \mathrm{~A}\right)$ and also soil geochemistry $\left(\mathrm{F}_{(16,18)}=1.74\right.$, $P=0.0001$; Figure 2.2A). Fungal community composition was similarly influenced by plant phenotype and soil depth $\left(\mathrm{F}_{(4,28)}=1.17, P=0.0034\right.$; Figure $\left.2.1 \mathrm{~B}\right)$ and also soil 
Table 2.1: Aspects of soil nutrient conditions, soil depth, and plant phenotype differed between alvars and old-field habitats. Values are means and standard errors and the habitat with higher values is indicated in the p-value column. Highlighted rows indicate soil variables and aspects of plant phenotype that continued to be significant after Bonferroni corrections for multiple comparisons. Significance codes: 0 ‘***', 0.001 '**', 0.01 '*’, 0.05 '?'

\begin{tabular}{|c|c|c|c|c|c|c|c|}
\hline \multirow[b]{2}{*}{ Soil Variable } & \multicolumn{3}{|c|}{ Alvar } & \multicolumn{3}{|c|}{ Field } & \multirow[t]{2}{*}{ P-value } \\
\hline & Mean & SE & $\mathbf{N}$ & Mean & SE & $\mathbf{N}$ & \\
\hline Total nitrogen & 0.7 & 0.09 & 15 & 0.4 & 0.03 & 15 & Alvar ** \\
\hline pH & 6.7 & 0.09 & 15 & 6.2 & 0.08 & 15 & Alvar *** \\
\hline Organic matter & 14.7 & 1.51 & 15 & 10.0 & 0.55 & 15 & Alvar ** \\
\hline Phosphorus & 1.7 & 0.20 & 15 & 1.6 & 0.08 & 15 & $\mathrm{NS}$ \\
\hline Potassium & 116.5 & 11.33 & 15 & 152.6 & 18.13 & 15 & NS \\
\hline Magnesium & 92.7 & 17.94 & 15 & 265.7 & 37.66 & 15 & Field $* * *$ \\
\hline Calcium & 5915.6 & 588.9 & 15 & 4157.2 & 376.5 & 15 & Alvar* \\
\hline Aluminum & 32.8 & 4.92 & 15 & 24.7 & 3.95 & 15 & NS \\
\hline Boron & 0.6 & 0.08 & 15 & 0.4 & 0.04 & 15 & NS \\
\hline Copper & 0.1 & 0.003 & 15 & 0.1 & 0.01 & 15 & Field** \\
\hline Iron & 3.2 & 0.19 & 15 & 3.0 & 0.44 & 15 & NS \\
\hline Manganese & 13.6 & 2.11 & 15 & 9.8 & 1.13 & 15 & NS \\
\hline Sodium & 17.1 & 1.74 & 15 & 16.2 & 0.92 & 15 & NS \\
\hline Sulfur & 13.9 & 1.38 & 15 & 12.9 & 0.61 & 15 & NS \\
\hline Zinc & 0.5 & 0.07 & 15 & 0.7 & 0.07 & 15 & NS \\
\hline Soil depth & 11.0 & 0.92 & 30 & 40.0 & 2.19 & 26 & Field $* * *$ \\
\hline Plant height & 37.1 & 1.90 & 30 & 62.4 & 2.45 & 30 & Field*** \\
\hline Bud number & 36.9 & 7.07 & 30 & 67.9 & 10.42 & 30 & Field* \\
\hline
\end{tabular}


geochemistry $\left(\mathrm{F}_{(16,16)}=1.11, P=0.0022\right.$; Figure 2.2B). Percent total nitrogen, soil $\mathrm{pH}$, potassium, and plant height were important drivers of both bacterial and fungal community composition (Table 2.2, Table 2.3, Table 2.4, and Table 2.5). Soil depth affected bacterial community composition $\left(\mathrm{F}=3.77, \mathrm{R}^{2}=0.097, P=0.0002\right.$; Table 2.3) but not fungal community composition $\left(\mathrm{F}=1.17, \mathrm{R}^{2}=0.036, P=0.069\right.$; Table 2.5).

\section{Alpha diversity}

We did not find significant differences in bacterial OTU richness $\left(\mathrm{F}_{(1,64.45)}=3.03\right.$, $P=0.09$; Figure 2.3A) or bacterial Chao1 alpha diversity estimates between habitats $\left(\mathrm{F}_{(1,66.02)}=1.13, P=0.29\right.$; Figure $\left.2.3 \mathrm{C}\right)$. However, we did find fungal OTU richness $\left(\mathrm{F}_{(1,55)}=4.87, P=0.03\right.$; Figure 2.3B $)$ and fungal Chao1 alpha diversity $\left(\mathrm{F}_{(1,53.83)}=7.27\right.$, $P=0.009$; Figure 2.3D) were higher in the old-field habitats.

\section{Indicator species}

Fifty-eight bacterial taxa were differentially abundant between the two habitats. Of these 39 were found on the alvars and 19 were found in the old-fields (Table S2.1). Five fungal taxa were differentially abundant between the two habitats and of these all five were more abundant in the old-fields. Fungal OTU 20 aligned to a potential plant pathogen (Cadophora malorum; Figure 2.4A), and OTU 239 matched to an uncultured Basidiomycete (Figure 2.4B), often found in soil and root samples. OTU 442 aligned to a species within the genus Fusarium, potentially Fusarium oxysporum, another plant pathogen (Figure 2.4C). Similarly, OTU 444 aligned to a species within the genus Fusarium, potentially Fusarium solani (Figure 2.4D). Finally, OTU 66 aligned to fungi called Paraphaeosphaeria sporulosa (Figure 2.4E), an ascomycete fungus that is often isolated from plant roots, but of an unknown functional designation (pathogen, saprophyte, etc.). 

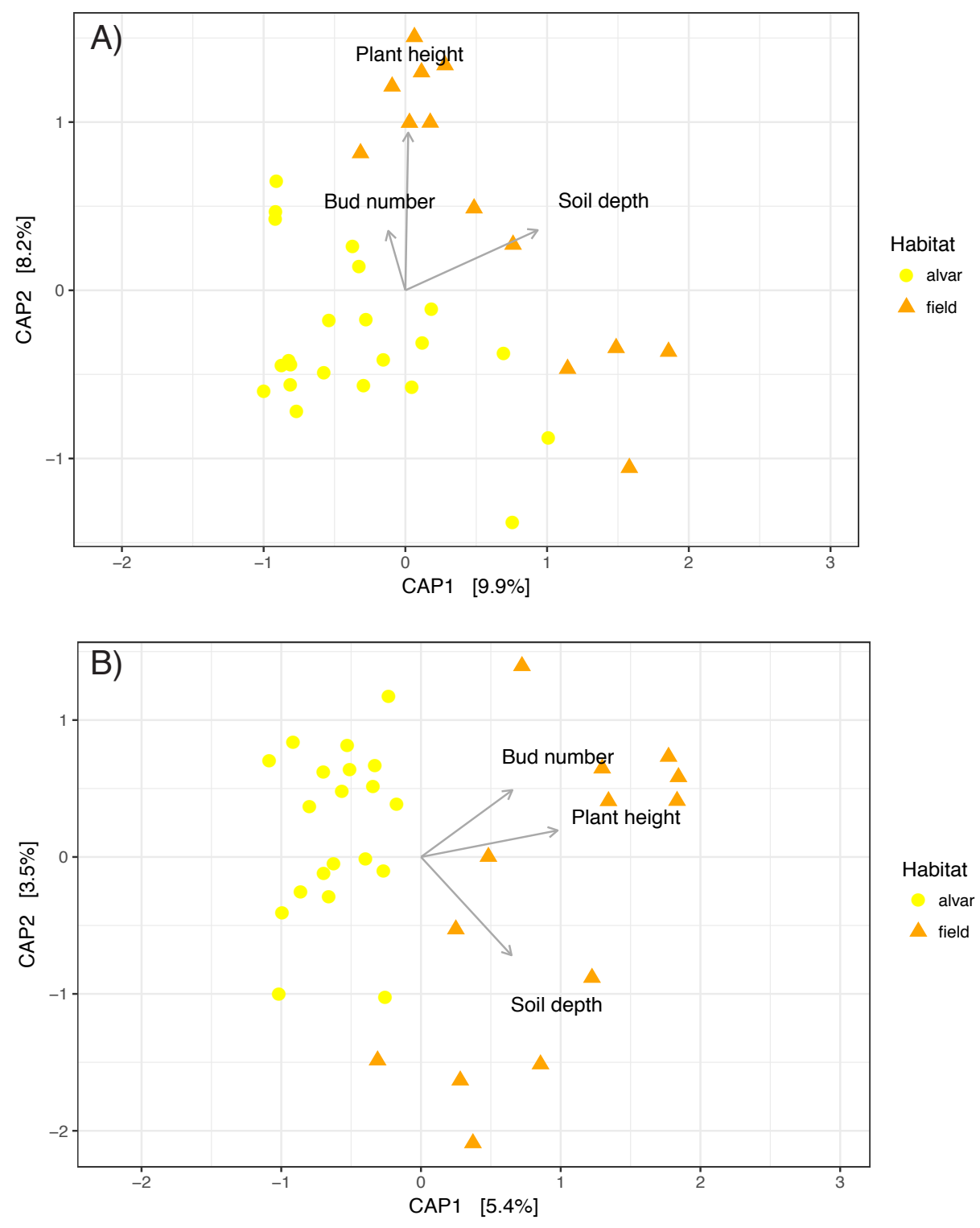

Figure 2.1 A and B: Constrained Analysis of Principle Coordinates (CAP) for bacteria (A) and fungi (B) mapping aspects of plant phenotype and soil depth. Analysis of variance indicated that bacterial and fungal community composition were affected by plant phenotype and soil depth. 

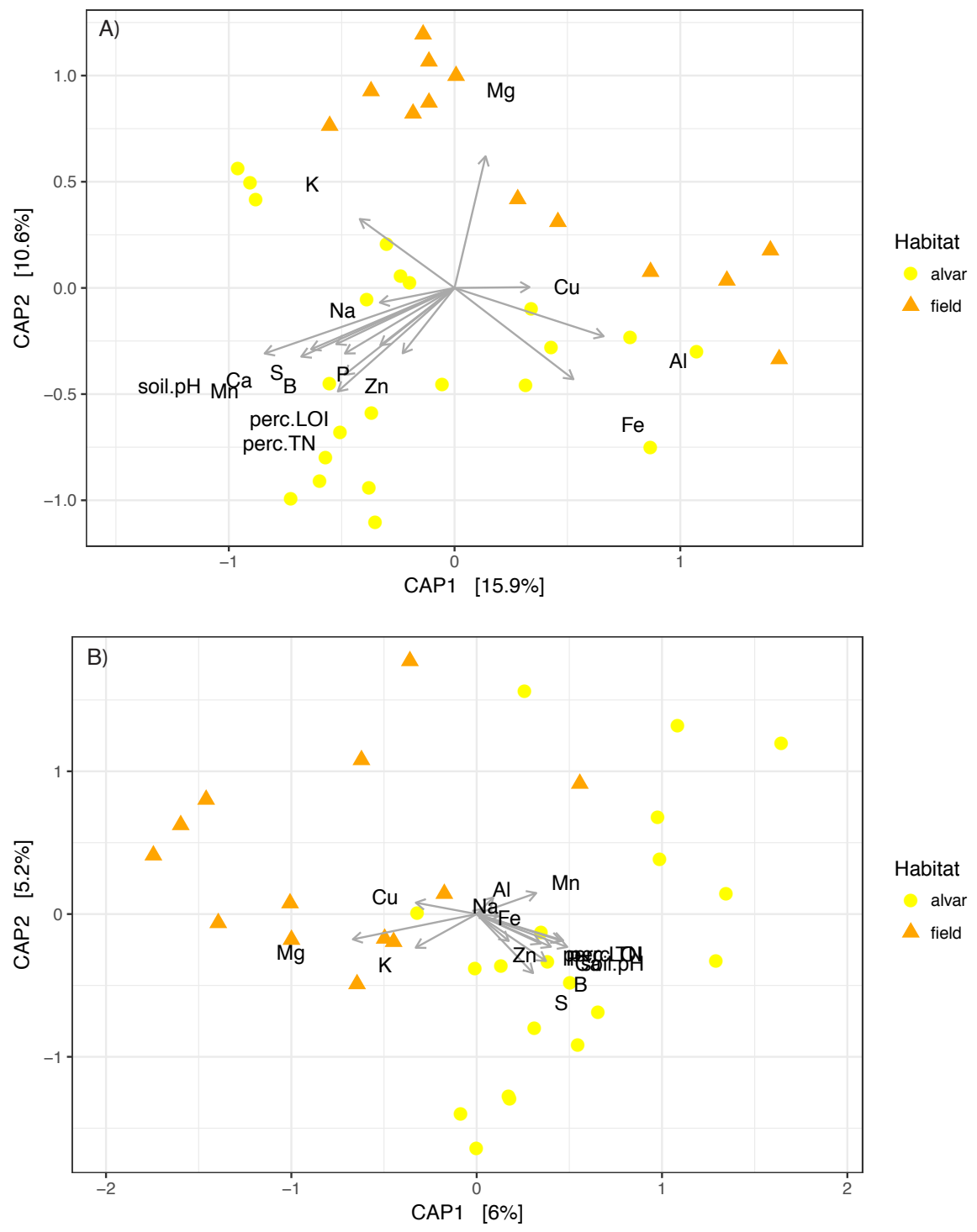

Figure 2.2 A and B: Constrained Analysis of Principle Coordinates (CAP) for bacteria (A) and fungi (B) mapping soil edaphic conditions. Analysis of variance indicated that bacterial and fungal community composition were affected by soil nutrients. 

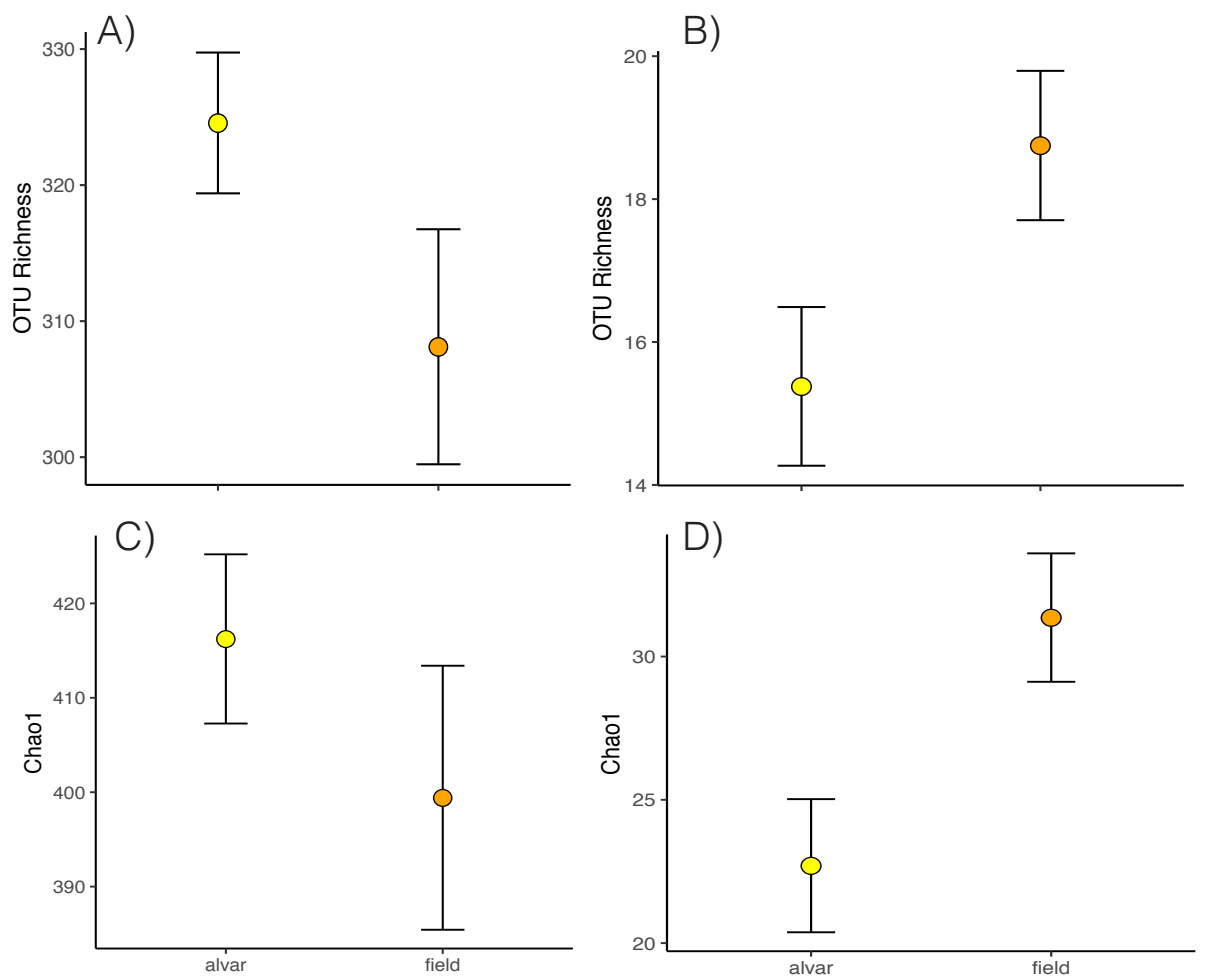

Figure 2.3 A-D: Bacterial richness (A) and Chao1 diversity (C) were not significantly different between alvar and old-field habitats. In contrast, fungal richness (B) and Chao1 (D) were significantly different between the two habitat types. Values are means and bars are standard errors. 

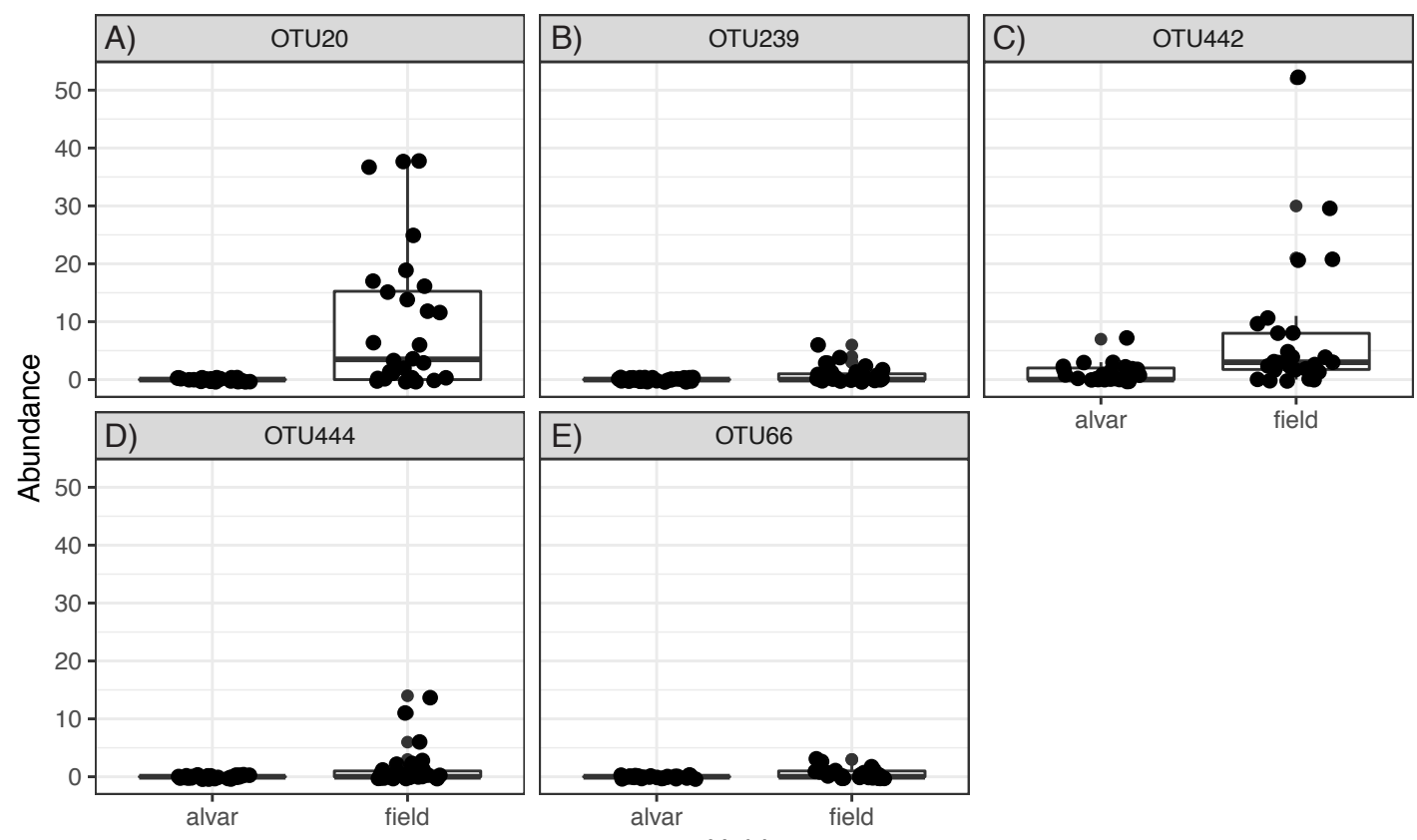

Figure 2.4 A-E: Five fungal OTUs were identified as being more abundant in the oldfield habitat compared with alvar. The midline represents the median of the data and the upper and lower limits of the box represent the third and first quartile. Abundance is measured in sequence counts. 
Procrustes analysis

We did not find any correlation between bacterial and fungal communities $\left(\mathrm{m}^{2}=0.960\right.$, $P=0.54)$. Similarly, we did not find any relationship between bacterial communities and plant phenotype $\left(\mathrm{m}^{2}=0.98, P=0.66\right)$. We did find concordance between fungal communities and plant phenotype $\left(\mathrm{m}^{2}=0.87, P=0.0005\right)$. We found correlations between bacterial communities and soil nutrients $\left(\mathrm{m}^{2}=0.54, P=0.0001\right)$ and also between fungal communities and soil nutrients $\left(\mathrm{m}^{2}=0.82, P=0.004\right)$. A summary of results can be found in Table 2.6.

\section{Identifying microbial taxa correlated with plant height}

Using a different analysis that focused specifically on individual OTUs and specific aspects of plant phenotype, rather than the entire bacterial community and a composite ordination of plant phenotype (as done in the aforementioned Procrustes analysis), we found members of the bacterial community were associated with plant height $\left(\mathrm{F}_{(3,64)}=\right.$ $8.35, P<0.0001)$, and this was mostly driven by significant correlations with PCoA axis $2(P<0.0001)$ and $\mathrm{PCoA}$ axis $3(\mathrm{P}=0.0125)$. To understand which bacterial taxa were correlated with plant height across habitats we chose bacteria with the highest loadings on PCoA 2 and individually tested those for correlations with plant height. We found two OTUs $5\left(\mathrm{~F}_{(1,66)}=18.16, \mathrm{R}^{2}=0.204, P<0.0001\right)$ and $57\left(\mathrm{~F}_{(1,66)}=19.59\right.$, $\mathrm{R}^{2}=0.217, P<0.0001$ ) that were positively correlated with plant height (Figure $2.5 \mathrm{~A}$ and 2.5B). Both OTUs are poorly defined members of the phylum Actinobacteria. 
Table 2.2: Permutational analysis of variance (PERMANOVA) indicates that bacterial community composition is related to soil nitrogen, $\mathrm{pH}$, organic matter, potassium, magnesium, aluminum, manganese, and sulfur. We performed a PERMANOVA using the Bray-Curtis index of dissimilarity for bacterial OTU abundance data. Significance codes: 0 ‘***', 0.001 '**', 0.01 '*', 0.05 '?

\begin{tabular}{|c|c|c|c|c|c|c|c|}
\hline Soil Variable & Df & SumsOfSqs & MeanSqs & F.Model & $\mathbf{R 2}$ & $\operatorname{Pr}(>\mathrm{F})$ & \\
\hline Total nitrogen & 1 & 0.472 & 0.472 & 4.272 & 0.091 & 0.0002 & $* * *$ \\
\hline pH & 1 & 0.466 & 0.466 & 4.210 & 0.090 & 0.0001 & $* * *$ \\
\hline Organic matter & 1 & 0.189 & 0.189 & 1.705 & 0.036 & 0.025 & $*$ \\
\hline Phosphorus & 1 & 0.150 & 0.150 & 1.360 & 0.029 & 0.114 & \\
\hline Potassium & 1 & 0.299 & 0.299 & 2.707 & 0.058 & 0.001 & $* * *$ \\
\hline Magnesium & 1 & 0.185 & 0.185 & 1.669 & 0.036 & 0.034 & $*$ \\
\hline Calcium & 1 & 0.147 & 0.147 & 1.329 & 0.028 & 0.119 & \\
\hline Aluminum & 1 & 0.181 & 0.181 & 1.634 & 0.035 & 0.038 & $*$ \\
\hline Boron & 1 & 0.141 & 0.141 & 1.272 & 0.027 & 0.151 & \\
\hline Copper & 1 & 0.100 & 0.100 & 0.905 & 0.019 & 0.573 & \\
\hline Iron & 1 & 0.139 & 0.139 & 1.253 & 0.027 & 0.166 & \\
\hline Manganese & 1 & 0.198 & 0.198 & 1.788 & 0.038 & 0.023 & $*$ \\
\hline Sodium & 1 & 0.113 & 0.113 & 1.018 & 0.022 & 0.394 & \\
\hline Sulfur & 1 & 0.193 & 0.192 & 1.740 & 0.037 & 0.025 & $*$ \\
\hline Zinc & 1 & 0.121 & 0.121 & 1.091 & 0.023 & 0.296 & \\
\hline Residuals & 19 & 2.101 & 0.111 & & 0.405 & & \\
\hline Total & 34 & 5.192 & & & 1 & & \\
\hline
\end{tabular}


Table 2.3: Using permutational analysis of variance (PERMANOVA) we found bacterial community composition is related to plant height and soil depth but not bud number. We performed a PERMANOVA using the Bray-Curtis index of dissimilarity for bacterial OTU abundance data. Significance codes: 0 ‘***, 0.001 '**, 0.01 '*', 0.05 '?

Df SumsOfSqs MeanSqs $\quad$ F.Model $\quad$ R2 $\quad \operatorname{Pr}(>$ F $)$

\begin{tabular}{|lrrrrrrr|}
\hline Height & $\mathbf{1}$ & $\mathbf{0 . 3 8 4}$ & $\mathbf{0 . 3 8 4}$ & $\mathbf{2 . 8 6 1}$ & $\mathbf{0 . 0 7 4}$ & $\mathbf{0 . 0 0 0 4}$ & $* * *$ \\
Soil depth & $\mathbf{1}$ & $\mathbf{0 . 5 0 6}$ & $\mathbf{0 . 5 0 6}$ & $\mathbf{3 . 7 7 3}$ & $\mathbf{0 . 0 9 7}$ & $\mathbf{0 . 0 0 0 2}$ & $* * *$ \\
Bud number & 1 & 0.143 & 0.143 & 1.069 & 0.028 & 0.331 & \\
Residuals & $\mathbf{3 1}$ & $\mathbf{4 . 1 5 9}$ & $\mathbf{0 . 1 3 4}$ & & $\mathbf{0 . 8 0 1}$ & & \\
Total & $\mathbf{3 4}$ & $\mathbf{5 . 1 9 2}$ & & & $\mathbf{1}$ & & \\
\hline
\end{tabular}


Table 2.4: Permutational analysis of variance (PERMANOVA) indicates that fungal community composition is related to soil nitrogen, $\mathrm{pH}$, potassium, aluminum, and sulfur. We performed a PERMANOVA using the Jaccard index of dissimilarity for fungal OTU presence/absence data. Significance codes: 0 ‘***, 0.001 '**, 0.01 '*’, 0.05 '?

\begin{tabular}{|lrrrrrrr|}
\hline Soil Variable & Df & SumsOfSqs & MeanSqs & F.Model & R2 & Pr(>F) & \\
\hline Total nitrogen & $\mathbf{1}$ & $\mathbf{0 . 6 1 3}$ & $\mathbf{0 . 6 1 3}$ & $\mathbf{1 . 4 0 4}$ & $\mathbf{0 . 0 4 1}$ & $\mathbf{0 . 0 0 3}$ & $* *$ \\
pH & $\mathbf{1}$ & $\mathbf{0 . 6 0 4}$ & $\mathbf{0 . 6 0 4}$ & $\mathbf{1 . 3 8 4}$ & $\mathbf{0 . 0 4 1}$ & $\mathbf{0 . 0 0 3}$ & $* *$ \\
Organic matter & 1 & 0.393 & 0.393 & 0.899 & 0.027 & 0.857 & \\
Phosphorus & 1 & 0.430 & 0.430 & 0.984 & 0.029 & 0.517 & \\
Potassium & $\mathbf{1}$ & $\mathbf{0 . 6 1 7}$ & $\mathbf{0 . 6 1 7}$ & $\mathbf{1 . 4 1 2}$ & $\mathbf{0 . 0 4 2}$ & $\mathbf{0 . 0 0 2}$ & $* *$ \\
Magnesium & 1 & 0.428 & 0.428 & 0.979 & 0.029 & 0.555 & \\
Calcium & 1 & 0.382 & 0.382 & 0.875 & 0.026 & 0.886 & \\
Aluminum & $\mathbf{1}$ & $\mathbf{0 . 5 3 4}$ & $\mathbf{0 . 5 3 4}$ & $\mathbf{1 . 2 2 4}$ & $\mathbf{0 . 0 3 6}$ & $\mathbf{0 . 0 3 2}$ & $*$ \\
Boron & 1 & 0.507 & 0.507 & 1.161 & 0.034 & 0.074 & \\
Copper & 1 & 0.440 & 0.440 & 1.007 & 0.030 & 0.444 & \\
Iron & 1 & 0.450 & 0.450 & 1.031 & 0.030 & 0.361 & \\
Manganese & 1 & 0.516 & 0.516 & 1.182 & 0.035 & 0.062 &. \\
Sodium & 1 & 0.424 & 0.424 & 0.971 & 0.029 & 0.572 & \\
Sulfur & $\mathbf{1}$ & $\mathbf{0 . 5 6 5}$ & $\mathbf{0 . 5 6 5}$ & $\mathbf{1 . 2 9 4}$ & $\mathbf{0 . 0 3 8}$ & $\mathbf{0 . 0 1 3}$ & $*$ \\
Zinc & 1 & 0.480 & 0.480 & 1.098 & 0.032 & 0.179 & \\
Residuals & $\mathbf{1 7}$ & $\mathbf{7 . 4 2 2}$ & $\mathbf{0 . 4 3 7}$ & & $\mathbf{0 . 5 0 1}$ & & \\
Total & $\mathbf{3 2}$ & $\mathbf{1 4 . 8 0 4}$ & & & & $\mathbf{1}$ & \\
\hline
\end{tabular}


Table 2.5: Using permutational analysis of variance (PERMANOVA) we found fungal community composition is related to plant height but not bud number or soil depth. We performed a PERMANOVA using the Jaccard index of dissimilarity for fungal OTU presence/absence data. Significance codes: 0 ' ${ }^{* * * *}, 0.001$ ' $* * *,, 0.01$ '*', 0.05 '?

Df SumsOfSqs MeanSqs $\quad$ F.Model $\quad$ R2 $\quad \operatorname{Pr}(>$ F $)$

\begin{tabular}{|lrrrrrrr|}
\hline \hline Height & $\mathbf{1}$ & $\mathbf{0 . 7 9 2}$ & $\mathbf{0 . 7 9 2}$ & $\mathbf{1 . 7 6 2}$ & $\mathbf{0 . 0 5 4}$ & $\mathbf{0 . 0 0 0 1}$ & $* * *$ \\
Soil depth & 1 & 0.527 & 0.527 & 1.173 & 0.036 & 0.069 &. \\
Bud number & 1 & 0.447 & 0.447 & 0.994 & 0.030 & 0.508 & \\
Residuals & $\mathbf{2 9}$ & $\mathbf{1 3 . 0 4}$ & $\mathbf{0 . 4 5 0}$ & & $\mathbf{0 . 8 8 1}$ & & \\
Total & $\mathbf{3 2}$ & $\mathbf{1 4 . 8 0}$ & & & $\mathbf{1}$ & & \\
\hline
\end{tabular}




\section{Discussion}

Studies of plant microbiomes are still in their infancy. There is much to be learned about how soil environment shapes microbial communities and how plant phenotype correlates with microbial communities and individual taxa. Here we offer evidence that soil edaphic conditions have important effects on structuring microbial communities of a medicinally important plant species, Hypericum perforatum. We found that soil nitrogen, $\mathrm{pH}$, potassium, and plant size were correlated with bacterial and fungal community composition. We demonstrated a correlation between fungal community composition and ordinated plant phenotype data. We were also able to identify two bacterial taxa that were significantly correlated with plant height.

We found that significantly different bacterial and fungal communities occur on alvars compared with old-field habitats. These differences were correlated with total nitrogen, $\mathrm{pH}$, potassium, plant height, and a variety of micronutrients for both bacteria and fungi. However, only bacterial community composition was correlated with soil depth. Nitrogen effects on microbes have been well documented and both fungi and bacteria experience changes in community composition in response to enhanced nitrogen (Frey et al. 2004, Ramirez et al. 2010, 2012, Nemergut et al. 2008, Fierer et al. 2011, Cassman et al. 2016). Interestingly, several studies report that bacteria demonstrate shifts in community composition but not simultaneous changes in species alpha diversity (Ramirez et al. 2010, Fierer et al. 2011), which is consistent with our findings. In contrast, changes in fungal richness usually accompany shifts in fungal community composition. 

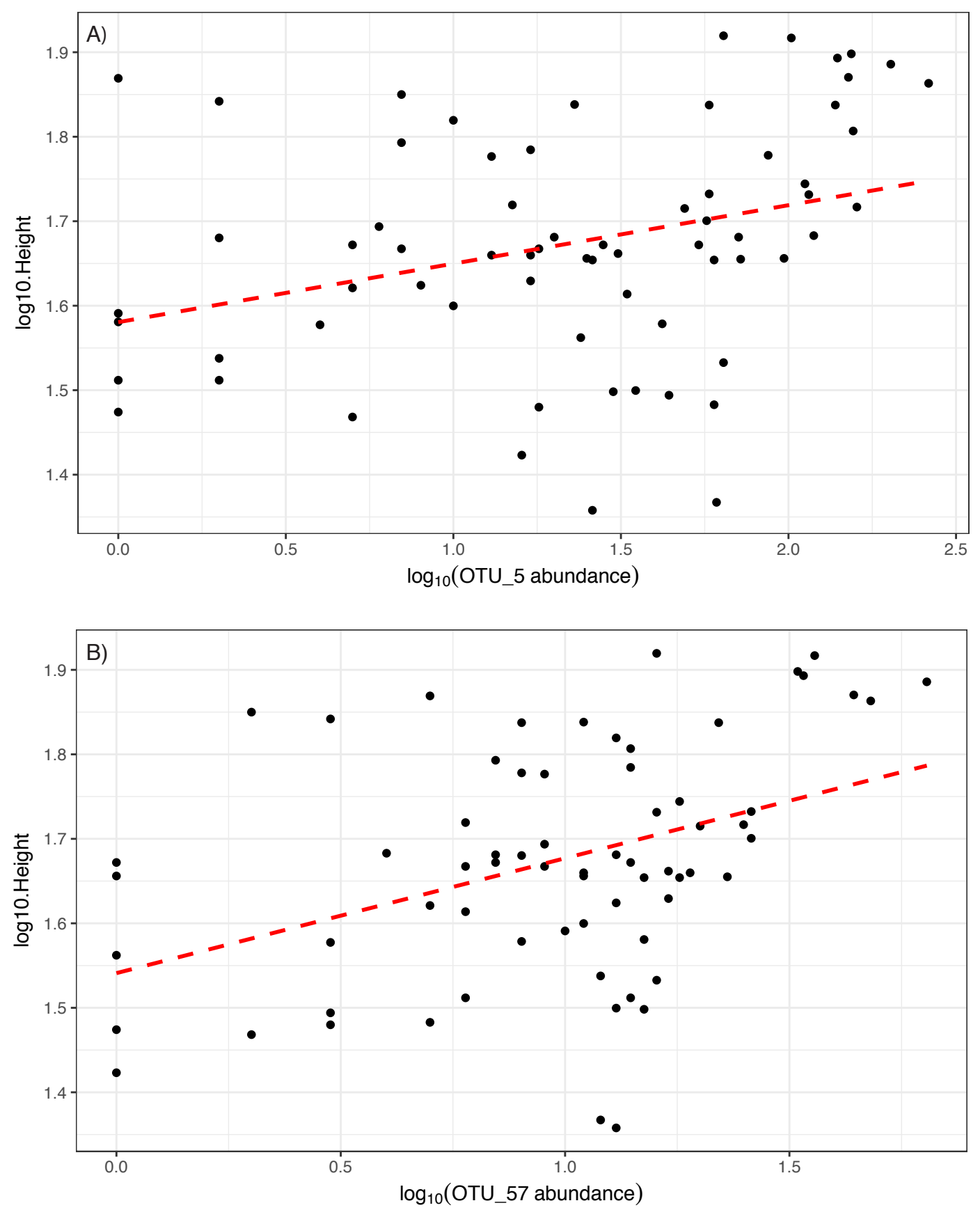

Fig. 2.5 A and B: Two bacterial OTUs (5 and 57) were significantly correlated with plant height $\left(\mathrm{R}^{2}=0.20, P<0.0001\right.$ and $\mathrm{R}^{2}=0.22, P<0.0001$, respectively). Both OTUs are members of the bacterial phylum, Actinobacteria. 
We also found that $\mathrm{pH}$ was correlated with community composition of both bacteria and fungi. The effects of soil $\mathrm{pH}$ on bacterial community composition are well documented. Extensive sampling of soil communities across a long-term liming experiment ( $\mathrm{pH} 4.0-8.0)$ revealed a near doubling of bacterial richness with increasing pH (Rousk et al. 2010). It has been hypothesized that the main determinant of bacterial community composition is soil $\mathrm{pH}$ levels rather than factors that we typically ascribe to driving patterns of biogeography, such as temperature, plant community composition, or nutrient availability (Fierer and Jackson 2006, Lauber et al. 2008, Fierer et al. 2009). However, it is important to note the range of $\mathrm{pH}$ tested in many of these studies is far greater $(\mathrm{pH} 4-8)$ than the range experienced by our plants $(\mathrm{pH} 5.6-$ 7.2). Similar to other reports in the literature, our results suggest that fungal community composition is also affected by $\mathrm{pH}$. In recent work, Glassman et al. (2017) asked if ectomycorrhizal fungal communities were primarily affected by niche (soil nutrients, tree host) or neutral (dispersal distance) processes. They found that one of the strongest predictors of fungal community composition was soil $\mathrm{pH}$ rather than host tree species or dispersal distance (Glassman et al. 2017). Many of the other nutrients found to commonly affect bacterial and fungal community composition (potassium, aluminum, and sulfur) have not been empirically tested but are also correlated with community composition in observational studies (Koorem et al. 2014, Tian et al. 2017). A general caveat of our work is that many soil characteristics are confounded with each other and with habitat, and therefore it is hard to disentangle integrated habitat effects with the effects of a single soil characteristic. 
Table 2.6: Using Procrustes analysis we found concordance between fungal communities and plant phenotype. We also found correlations between bacterial communities and soil nutrients and fungal communities and soil nutrients. The pair of data matrices is compared by using an algorithm that reduces the sum-of-the squared residuals between the two objects $\left(\mathrm{m}^{2}\right.$ statistic).

\begin{tabular}{|c|c|c|c|c|}
\hline $\mathbf{X}$ & $\mathbf{Y}$ & $\mathbf{m}^{2}$ & Correlation & $p$-value \\
\hline Bacterial comm. & Fungal comm. & 0.960 & 0.201 & 0.5428 \\
\hline Bacterial comm. & Plant phenotype & 0.982 & 0.136 & 0.6552 \\
\hline Fungal comm. & Plant phenotype & 0.869 & 0.361 & 0.0005 \\
\hline Bacterial comm. & Soil nutrients & 0.544 & 0.675 & 0.0001 \\
\hline Fungal comm. & Soil nutrients & 0.824 & 0.420 & 0.0042 \\
\hline
\end{tabular}


Extensive work has been done over the last decade to describe the microbiomes of model and crop plant species, including: corn (Bouffaud et al. 2014), rice (Edwards et al. 2015), wheat (Mahoney et al. 2017), barley (Bulgarelli et al. 2015), poplar (Beckers et al. 2017), sugar cane (de Souza et al. 2016) and Arabidopsis (Bulgarelli et al. 2012, Lundberg et al. 2012). Increasingly people are sequencing the microbiome of nonmodel/non-crop plant species, such as: agave (Coleman-Derr et al. 2015), cacti (Fonseca-García et al. 2016), and Boechera stricta (Lundberg et al. 2016). The abundant taxa in our data set are consistent with abundant taxa found in other examinations of angiosperm root microbiomes. The model plant, Arabidopsis thaliana, and its wild relatives have an abundance of bacterial taxa in the groups Actinobacteria, Proteobacteria, Chloroflexi, and Bacteriodetes (Schlaeppi et al. 2014). Follow-up work examining 30 angiosperm species found overlap with these earlier results but expanded this to include taxa from Verrucomicrobia, Planctomycetes, and Armatimondates (Fitzpatrick et al. 2018).

While we found many taxa in common in our alvar and old-field Hypericum populations we also found habitat-specific differences. For example, we found five fungal taxa that were more abundant in old-fields compared with alvars. Interestingly, the putative species assignment for three of the five species was to pathogenic fungal taxa (OTU 22, OTU444, and OTU 442), indicating that these former agricultural fields might be enriched in pathogens. Pathogen enrichment from former agricultural use can last many decades; when a chronosequence of former agricultural fields was surveyed in the Netherlands pathogen enrichment only declined in the fields that had been 
abandoned for over thirty years (Hannula et al. 2017). Although we do not have exact dates since abandonment for our fields it was likely within the last thirty years; for example one old-field habitat (Lim) was in agricultural use as recently as $\sim$ five years ago.

A major objective of this work was to correlate microbial communities (or OTUs) with aspects of plant phenotype. We found that fungal community composition was correlated with plant height, bud number, and flower number between habitats. Further work is necessary to determine which community members significantly contribute to which aspects of plant phenotype. Unfortunately, at this point we lack the power to test within habitats to determine if this effect is driven primarily by the existence of fungal pathogens in the old-fields. Because we had low sampling depth for our fungal sequences we decided to opt for the conservative approach of using presence-absence data for our analysis and therefore were unable explore PCoA axes in ways that allowed us to correlate particular OTUs to phenotypic effects. We were, however, able to explore correlations between bacterial OTUs and plant phenotype.

We found two bacterial OTUs within the phylum Actinobacteria that occur in both habitats and were positively correlated with plant height. Interest has been growing in the plant-growth promoting effects of Actinobacteria. Actinobacteria are a group of Gram-positive filamentous bacteria and are one of the largest designations within the domain (Stackebrandt and Schumann 2006). There is high potential within this group for plant growth promotion. For example, Actinobacteria can fix nitrogen, solubilize 
phosphate, enhance iron acquisition, and produce myriad phytohormones (Sathya et al. 2017). The complexity of the bacterial and fungal community demands we develop hypotheses about taxa that could potentially positively or negatively affect plant growth. Here we have described two bacterial OTUs that correlated strongly with an important plant phenotype, height. Further work should focus on culturing and rigorously testing plant growth promoting effects of these taxa. Another caveat of this work is the correlative nature and although we are speculating that these OTUs could enhance plant growth it is also possible that these OTUs affiliate with larger plants, and only further empirical research will definitively test the growth-promoting capacity of these species.

Major advances have occurred in the field of plant microbiome research over the last decade but we are still in the very early stages of understanding the factors that affect the composition of the plant microbiome. A promising avenue of research is exploring observational data sets to identify taxa that correlate with important aspects of plant phenotype so testing putative growth-promoting taxa can occur in a targeted manner. Here we have provided important information about how soil edaphic conditions affect bacterial and fungal communities and we have identified two OTUs that could be tested in future work for plant growth-promoting effects. 


\section{REFERENCES}

Altschul, S. F., T. L. Madden, A. S. N., Schaffer, A. A., J. Zhang, Z. Zhang, W. Miller, and D. J. Lipman. 1997. Gapped BLAST and PSI-BLAST: a new generation of protein database search programs. Nucleic Acids Research 25: 33893402.

Bakker, M. G., D. K. Manter, A. M. Sheflin, T. L. Weir, and J. M. Vivanco. 2012. Harnessing the rhizosphere microbiome through plant breeding and agricultural management. Plant and Soil 360:1-13.

Bates, D., M. Mächler, B. Bolker, and S. Walker. 2015. Fitting linear mixed-effects models using lme4. Journal of Statistical Software 67:1-48.

Beckers, B., M. O. De Beeck, N. Weyens, W. Boerjan, and J. Vangronsveld. 2017. Structural variability and niche differentiation in the rhizosphere and endosphere bacterial microbiome of field-grown poplar trees. Microbiome 5:1-17.

Berendsen, R. L., C. M. J. Pieterse, and P. A. H. M. Bakker. 2012. The rhizosphere microbiome and plant health. Trends in Plant Science 17:478-486. 
Bouffaud, M.-L., M.-A. Poirier, D. Muller, and Y. Moënne-Loccoz. 2014. Root microbiome relates to plant host evolution in maize and other Poaceae. Environmental Microbiology 16:2804-2814.

Bulgarelli, D., M. Rott, K. Schlaeppi, E. Ver Loren van Themaat, N. Ahmadinejad, F. Assenza, P. Rauf, B. Huettel, R. Reinhardt, E. Schmelzer, J. Peplies, F. O. Gloeckner, R. Amann, T. Eickhorst, and P. Schulze-Lefert. 2012. Revealing structure and assembly cues for Arabidopsis root-inhabiting bacterial microbiota. Nature 488:91-95.

Bulgarelli, D., R. Garrido-Oter, P. C. Münch, A. Weiman, J. Dröge, Y. Pan, A. C. McHardy, and P. Schulze-Lefert. 2015. Structure and function of the bacterial root microbiota in wild and domesticated barley. Cell 17:392-403.

Cassman, N. A., M. F. A. Leite, Y. Pan, M. de Hollander, J. A. van Veen, and E. E. Kuramae. 2016. Plant and soil fungal but not soil bacterial communities are linked in long-term fertilized grassland. Scientific Reports: [doi: 10.1038/srep23680].

Coleman-Derr, D., D. Desgarennes, C. Fonseca-Garcia, S. Gross, S. Clingenpeel, T. Woyke, G. North, A. Visel, L. P. Partida-Martínez, and S. G. Tringe. 2015. Plant compartment and biogeography affect microbiome composition in cultivated and native Agave species. New Phytologist 209:798-811. 
De Cáceres, M., and F. Jansen. 2016. indicspecies: studying the statistical relationship between species and groups of sites. R package version 1.7.6. https://cran.rproject.org/web/packages/indicspecies/index.html.

De Cáceres, M., and P. Legendre. 2009. Associations between species and groups of sites: indices and statistical inference. Ecology 90:3566-3574.

de Souza, R. S. C., V. K. Okura, J. S. L. Armanhi, B. Jorrín, N. Lozano, M. J. da Silva, M. González-Guerrero, L. M. de Araújo, N. C. Verza, H. C. Bagheri, J. Imperial, and P. Arruda. 2016. Unlocking the bacterial and fungal communities assemblages of sugarcane microbiome. Scientific Reports: [doi: 10.1038srep28774].

de Vries, F. T., P. Manning, J. R. B. Tallowin, S. R. Mortimer, E. S. Pilgrim, K. A. Harrison, P. J. Hobbs, H. Quirk, B. Shipley, J. H. C. Cornelissen, J. Kattge, and R. D. Bardgett. 2012. Abiotic drivers and plant traits explain landscape-scale patterns in soil microbial communities. Ecology Letters 15:1230-1239.

DeSantis, T. Z., P. Hugenholtz, N. Larsen, M. Rojas, E. L. Brodie, K. Keller, T. Huber, D. Dalevi, P. Hu, and G. L. Andersen. 2006. Greengenes, a chimerachecked 16S rRNA gene database and workbench compatible with ARB. Applied and Environmental Microbiology 72:5069-5072. 
Edgar, R. 2016. SINTAX: a simple non-Bayesian taxonomy classifier for 16S and ITS sequences. BioRxiv: [doi: 10.1101/074161].

Edgar, R. C. 2010. Search and clustering orders of magnitude faster than BLAST. Bioinformatics 26:2460-2461.

Edinger, G. J., D. J. Evans, S. Gebauer, T. G. Howard, D. M. Hunt, and A. M. Olivero, editors. 2014. Ecological communities of New York state: a revised and expanded edition of Carol Reschke's ecological communities of New York state. Second edition. New York Natural Heritage Program, New York State Department of Environmental Conservation, Albany, New York, USA.

Edwards, J., C. Johnson, C. Santos-Medellín, E. Lurie, N. K. Podishetty, S. Bhatnagar, J. A. Eisen, and V. Sundaresan. 2015. Structure, variation, and assembly of the root-associated microbiomes of rice. Proceedings of the National Academy of Sciences of the United States of America 112:E911-E920.

Eilers, K. G., S. Debenport, S. Anderson, and N. Fierer. 2012. Digging deeper to find unique microbial communities: The strong effect of depth on the structure of bacterial and archaeal communities in soil. Soil Biology and Biochemistry 50:5865 . 
Ekelund, F., R. Rønn, S. C. S. B. A. Biochemistry, 2001. Distribution with depth of protozoa, bacteria and fungi in soil profiles from three Danish forest sites. Soil Biology and Biochemistry 33:475-481.

Fierer, N., and R. B. Jackson. 2006. The diversity and biogeography of soil bacterial communities. Proceedings of the National Academy of Sciences of the United States of America 103:626-631.

Fierer, N., C. L. Lauber, K. S. Ramirez, J. Zaneveld, M. A. Bradford, and R. Knight. 2011. Comparative metagenomic, phylogenetic and physiological analyses of soil microbial communities across nitrogen gradients 6:1007-1017.

Fierer, N., M. S. Strickland, D. Liptzin, M. A. Bradford, and C. C. Cleveland. 2009. Global patterns in belowground communities. Ecology Letters 12:1238-1249.

Fitzpatrick, C. R., J. Copeland, P. W. Wang, D. S. Guttman, P. M. Kotanen, and M. T. J. Johnson. 2018. Assembly and ecological function of the root microbiome across angiosperm plant species. Proceedings of the National Academy of Sciences of the United States of America 115: [doi: 10.1073/pnas.1717617115].

Fonseca-García, C., D. Coleman-Derr, E. Garrido, A. Visel, S. G. Tringe, and L. P. Partida-Martínez. 2016. The cacti microbiome: interplay between habitat-Filtering and host-specificity. Frontiers in Microbiology 7:891-16. 
Frey, S. D., M. Knorr, J. L. Parrent, and R. T. Simpson. 2004. Chronic nitrogen enrichment affects the structure and function of the soil microbial community in temperate hardwood and pine forests. Forest Ecology and Management 196:159_ 171.

Friesen, M. L., S. S. Porter, S. C. Stark, E. J. von Wettberg, J. L. Sachs, and E. Martinez-Romero. 2011. Microbially mediated plant functional traits. Annual Review of Ecology, Evolution, and Systematics 42:23-46.

Frostegård, Å., E. Bååth, and A. Tunlio. 1993. Shifts in the structure of soil microbial communities in limed forests as revealed by phospholipid fatty acid analysis. Soil Biology and Biochemistry 25:723-730.

Glassman, S. I., I. J. Wang, and T. D. Bruns. 2017. Environmental filtering by $\mathrm{pH}$ and soil nutrients drives community assembly in fungi at fine spatial scales. Molecular Ecology 26:6960-6973.

Goh, C.-H., D. F. Veliz Vallejos, A. B. Nicotra, and U. Mathesius. 2013. The impact of beneficial plant-associated microbes on plant phenotypic plasticity. Journal of Chemical Ecology 39:826-839. 
Haney, C. H., B. S. Samuel, J. Bush, and F. M. Ausubel. 2015. Associations with rhizosphere bacteria can confer an adaptive advantage to plants. Nature Plants1:19.

Hannula, S. E., E. Morriën, M. de Hollander, W. H. Van der Putten, J. A. van Veen, and W. De Boer. 2017. Shifts in rhizosphere fungal community during secondary succession following abandonment from agriculture. The ISME Journal 11:2294 2304.

Högberg, M. N., P. Högberg, and D. D. Myrold. 2006. Is microbial community composition in boreal forest soils determined by $\mathrm{pH}, \mathrm{C}-$ to- $\mathrm{N}$ ratio, the trees, or all three? Oecologia 150:590-601.

Jackson, D. A. 1995. PROTEST: A PROcrustean Randomization TEST of community concordance. Ecoscience 2:297-303.

Jumpponen, A., K. L. Jones, and J. Blair. 2010. Vertical distribution of fungal communities in tallgrass prairie soil. Mycologia 102:1027-1041.

Ko, D., G. Yoo, S.-T. Yun, S.-C. Jun, and H. Chung. 2017. Bacterial and fungal community composition across the soil depth profiles in a fallow field. Journal of Ecology and Environment 41:[doi: 10.1186/s41610-017-0053-0]. 
Koorem, K., A. Gazol, M. Öpik, M. Moora, Ü. Saks, A. Uibopuu, V. Sõber, and M. Zobel. 2014. Soil nutrient content influences the abundance of soil microbes but not plant biomass at the small-scale. PLoS ONE 9:e91998-9.

Kozich, J. J., S. L. Westcott, N. T. Baxter, S. K. Highlander, and P. D. Schloss. 2013. Development of a dual-index sequencing strategy and curation pipeline for analyzing amplicon sequence data on the Miseq Illumina sequencing platform. Applied and Environmental Microbiology 79:5112-5120.

Kõljalg, U., R. H. Nilsson, K. Abarenkov, L. Tedersoo, A. F. S. Taylor, M. Bahram, S. T. Bates, T. D. Bruns, J. Bengtsson-Palme, T. M. Callaghan, B. Douglas, T. Drenkhan, U. Eberhardt, M. Dueñas, T. Grebenc, G. W. Griffith, M. Hartmann, P. M. Kirk, P. Kohout, E. Larsson, B. D. Lindahl, R. Lücking, M. P. Martín, P. B. Matheny, N. H. Nguyen, T. Niskanen, J. Oja, K. G. Peay, U. Peintner, M. Peterson, K. Põldmaa, L. Saag, I. Saar, A. Schüßler, J. A. Scott, C. Senés, M. E. Smith, A. Suija, D. L. Taylor, M. T. Telleria, M. Weiß, and K.-H. Larsson. 2013. Towards a unified paradigm for sequence-based identification of fungi. Molecular Ecology 22:5271-5277.

Kuznetsova, A., P. B. Brockhoff, and R. H. B. Christensen. 2017. lmerTest package: tests in linear mixed effects models. Journal of Statistical Software 82: 1-26. 
Lamit, L. J., L. M. Holeski, L. Flores-Rentería, T. G. Whitham, and C. A. Gehring. 2016. Tree genotype influences ectomycorrhizal fungal community structure: Ecological and evolutionary implications. Fungal Ecology 24:124-134.

Lauber, C. L., M. S. Strickland, M. A. Bradford, and N. Fierer. 2008. The influence of soil properties on the structure of bacterial and fungal communities across landuse types. Soil Biology and Biochemistry 40:2407-2415.

Leff, J. W., S. E. Jones, S. M. Prober, A. Barberán, E. T. Borer, J. L. Firn, W. S. Harpole, S. E. Hobbie, K. S. Hofmockel, J. M. H. Knops, R. L. McCulley, K. La Pierre, A. C. Risch, E. W. Seabloom, M. Schütz, C. Steenbock, C. J. Stevens, and N. Fierer. 2015. Consistent responses of soil microbial communities to elevated nutrient inputs in grasslands across the globe. Proceedings of the National Academy of Sciences 112:10967-10972.

Linde, K., G. Ramirez, C. D. Mulrow, A. Pauls, W. Weidenhammer, and D. Melchart. 1996. St John's wort for depression - an overview and meta-analysis of randomised clinical trials. British Medical Journal 313:253-258.

Lundberg, D. S., S. L. Lebeis, S. H. Paredes, S. Yourstone, J. Gehring, S. Malfatti, J. Tremblay, A. Engelbrektson, V. Kunin, T. G. del Rio, R. C. Edgar, T. Eickhorst, R. E. Ley, P. Hugenholtz, S. G. Tringe, and J. L. Dangl. 2012. Defining the core Arabidopsis thaliana root microbiome. Nature 488:86-90. 
Lundberg, D. S., T. G. del Rio, S. G. Tringe, J. L. Dangl, T. Mitchell-Olds, and M. R. Wagner. 2016. Host genotype and age shape the leaf and root microbiomes of a wild perennial plant. Nature Communications 7:1-15.

Mahoney, A. K., C. Yin, and S. H. Hulbert. 2017. Community structure, species variation, and potential functions of rhizosphere-associated bacteria of different winter wheat (Triticum aestivum) cultivars. Frontiers in Plant Science 8:2276-14.

Maron, J. L., S. C. Elmendorf, and M. Vilà. 2007. Contrasting plant physiological adaptation to climate in the native and introduced range of Hypericum perforatum. Evolution 61:1912-1924.

Marschner, P., C. H. Yang, R. Lieberei, and D. E. Crowley. 2001. Soil and plant specific effects on bacterial community composition in the rhizosphere. Soil Biology and Biochemistry 33:1437-1445.

Martin, M. 2011. Cutadapt removes adapter sequences from high-throughput sequencing reads. EMBnet.journal 17:10-12.

Muhlenberg, H. 1793. Index florae Lancastriensis. Transactions of the American Philosophical Society 3:157-184. 
Nemergut, D. R., A. R. Townsend, S. R. Sattin, K. R. Freeman, N. Fierer, J. C. Neff, W. D. Bowman, C. W. Schadt, M. N. Weintraub, and S. K. Schmidt. 2008. The effects of chronic nitrogen fertilization on alpine tundra soil microbial communities: implications for carbon and nitrogen cycling. Environmental Microbiology 10:3093-3105.

Oksanen, J., G. Blanchet, R. Kindt, P. Legendre, P. Minchin, R. O’Hara, G. Simpson, P. Solymos, H. Stevens, and H. Wagner. 2016. Vegan: community ecology package. R package version 2.3-3. https://cran.rproject.org/web/packages/vegan/index.html.

Peiffer, J. A., A. Spor, O. Koren, Z. Jin, S. G. Tringe, J. L. Dangl, E. S. Buckler, and R. E. Ley. 2013. Diversity and heritability of the maize rhizosphere microbiome under field conditions. Proceedings of the National Academy of Sciences 110: $5648-6553$.

Peres-Neto, P. R., and D. A. Jackson. 2001. How well do multivariate data sets match? The advantages of a Procrustean superimposition approach over the Mantel test. Oecologia 129:169-178.

R Development Core Team. 2017. R: a language and environment for statistical computing. R Foundation for Statistical Computing, Vienna, Austria. https://www.r-project.org. 
Ramirez, K. S., C. L. Lauber, R. Knight, M. A. Bradford, and N. Fierer. 2010. Consistent effects of nitrogen fertilization on soil bacterial communities in contrasting systems. Ecology 91:3463-3470.

Ramirez, K. S., J. M. Craine, and N. Fierer. 2012. Consistent effects of nitrogen amendments on soil microbial communities and processes across biomes. Global Change Biology 18:1918-1927.

Renaud, G., U. Stenzel, T. Maricic, V. W. Bioinformatics, 2014. deML: robust demultiplexing of Illumina sequences using a likelihood-based approach. Nucleic Acids Research 31: 770-772.

Reschke, C., R. Reid, J. Jones, T. Feeney, and H. Potter. 1999. Conserving great lakes alvars: final technical report of the International Alvar Conservation Initiative. The Nature Conservancy, Chicago, Illinois, USA.

Rodriguez, R. J., J. Henson, E. Van Volkenburgh, M. Hoy, L. Wright, F. Beckwith, Y.-O. Kim, and R. S. Redman. 2008. Stress tolerance in plants via habitat-adapted symbiosis. The ISME Journal 2:404-416. 
Rodriguez, R., and R. Redman. 2008. More than 400 million years of evolution and some plants still can't make it on their own: plant stress tolerance via fungal symbiosis. Journal of Experimental Botany 59:1109-1114.

Rousk, J., E. B. A. A. th, P. C. Brookes, C. L. Lauber, C. Lozupone, J. G. Caporaso, R. Knight, and N. Fierer. 2010. Soil bacterial and fungal communities across a pH gradient in an arable soil. The ISME Journal 4:1340-1351.

Sathya, A., R. Vijayabharathi, and S. Gopalakrishnan. 2017. Plant growth-promoting Actinobacteria: a new strategy for enhancing sustainable production and protection of grain legumes. 3 Biotech 7:1-10.

Schlaeppi, K., N. Dombrowski, R. G. Oter, E. Ver Loren van Themaat, and P. Schulze-Lefert. 2014. Quantitative divergence of the bacterial root microbiota in Arabidopsis thaliana relatives. Proceedings of the National Academy of Sciences 111:585-592.

Schweitzer, J. A., J. K. Bailey, D. G. Fischer, C. J. LeRoy, E. V. Lonsdorf, T. G. Whitham, and S. C. Hart. 2008. Plant-soil microorganism interactions: heritable relationship between plant genotype and associated soil microorganisms. Ecology 89:773-781. 
Stackebrandt, E., and P. Schumann. 2006. Introduction to the taxonomy of Actinobacteria. Pages 297-321 in M. Dworkin, S. Falkow, E. Rosenberg, K.H. Schleifer, and E. Stackebrandt, editors. The Prokaryotes: an evolving electronic resource for the microbiological community. Third edition. Springer, New York, New York, USA.

Tian, H., H. Wang, X. Hui, Z. Wang, R. A. Drijber, and J. Liu. 2017. Changes in soil microbial communities after 10 years of winter wheat cultivation versus fallow in an organic-poor soil in the Loess Plateau of China. PLoS ONE 12:e0184223-15.

Treseder, K. K. 2004. A meta-analysis of mycorrhizal responses to nitrogen, phosphorus, and atmospheric CO2 in field studies. New Phytologist 164:347-355.

Vandenkoornhuyse, P., A. Quaiser, M. Duhamel, A. Le Van, and A. Dufresne. 2015. The importance of the microbiome of the plant holobiont. New Phytologist 206:1196-1206.

Wehner, J., J. R. Powell, L. A. H. Muller, T. Caruso, S. D. Veresoglou, S. Hempel, and M. C. Rillig. 2013. Determinants of root-associated fungal communities within Asteraceae in a semi-arid grassland. Journal of Ecology 102:425-436. 
Wintermans, P. C. A., P. A. H. M. Bakker, and C. M. J. Pieterse. 2016. Natural genetic variation in Arabidopsis for responsiveness to plant growth-promoting rhizobacteria. Plant Molecular Biology 90:623-634.

Zhang, J., K. Kobert, T. Flouri, and A. Stamatakis. 2014. PEAR: a fast and accurate Illumina Paired-End reAd mergeR. Bioinformatics 30:614-620. 


\section{CHAPTER 3}

\section{A TEST OF MICROBE-MEDIATED ADAPTATION IN PLANTS: MICROBE- MEDIATED ADAPTATION TO LIMESTONE BARRENS}

In preparation for Ecology Letters as Renee H. Petipas, Amy Wruck, and Monica A. Geber. Microbe-mediated local adaptation to limestone barrens in northern New York.

\section{Abstract}

Plant root-associated microbes are important in determining plant phenotype and tolerance to local environmental conditions, and thus they could affect patterns of local adaptation. Here we explore the role of microbes in plant local adaptation to limestone barrens (also called alvars) and neighboring old-fields in New York State. We conducted reciprocal transplant experiments in two years exploring microbe effects on plant germination, survival, and growth. We found that alvar seeds had higher probability of germination when transplanted into home soils with microbes, but only when transplanted into their home habitat. Similarly, alvar seedlings had a higher probability of survival when transplanted into their home live soils, but in this case transplant site was unimportant. We also found patterns of local adaptation were significantly affected by the presence of microbes. Microbes decreased germination rates for old-field seeds in their home habitat, which created a pattern of maladaptation where local old-field seeds had significantly lower germination than foreign alvar seeds. In contrast, microbes enhanced survival for alvar seedlings in their home habitat, which created a pattern of local adaptation where local alvar seeds had significantly higher survival than foreign old-field seeds. Our results indicate that microbial mutualists are 
important for plants growing in marginal alvar habitats, and that microbes changed patterns of local adaptation, enhancing alvar seedling survival but detracting from old-field seedling germination. Understanding the involvement of microbes in plant local adaptation is important for understanding basic questions in ecology, such as what determines patterns of plant distribution and abundance, but also for broader applied topics, such as predicting plant responses to human-mediated changes to the environment.

\section{Introduction}

Colonization by bacterial and fungal microbes is a ubiquitous and ancient feature of plant biology (Partida-Martinez and Heil 2011). The last decades have witnessed a revolution in our understanding of plant-microbe interactions. Previously, researchers believed that antagonistic interactions dominated, while plant pathogens are undoubtedly important, we now understand many plant-associated microbes have coevolved with plants in ways that fundamentally affect how plants interface with their environment. This new understanding demands that we re-evaluate our view of plant evolutionary ecology to consider how microbes affect fundamental processes, such as local adaptation.

Local adaptation occurs when natural selection operates on genetically based adaptive phenotypes in response to local conditions. The result is plant genotypes have higher fitness in their home habitat compared to plant genotypes from other ("foreign") habitats (Kawecki and Ebert 2004). Adaptive phenotypes are the result of plant genotype but also can be affected by plant-associated microbes. Microbes affect a 
wide array of plant functional traits (Friesen et al. 2011) and consequently alter plant response to local plant stressors. For example, microbes affect plant response to drought (Lau and Lennon 2012, Marasco et al. 2012, Gehring et al. 2017), herbivory (Lee et al. 2012), low nutrients (Johnson et al. 2010), heavy metals (Meharg and Cairney 2000) and pathogens (Berendsen et al. 2012).

Variation in intraspecific interactions between plants and microbes can lead to patterns of local adaptation. For example, ecotypes of Andropogon gerardii collected from areas with low phosphorus and low nitrogen were better able to access these resources when grown in combination with their home arbuscular mycorrhizal fungi (Johnson et al. 2010). Similarly, genotypes of Pinus edulis were $25 \%$ larger when grown with their drought tolerant ectomycorrhizal fungal communities under drought conditions (Gehring et al. 2017).

Despite growing interest in the ways in which microbes affect plant local adaptation (Johnson et al. 2010, Smith et al. 2011, Lau and Lennon 2012, Lankau 2013, Johnson et al. 2013, Wagner et al. 2014, Pickles et al. 2015, Revillini et al. 2016, Rúa et al. 2016, Van Nuland et al. 2016) most studies are done in the greenhouse, which removes plant microbe interactions from their complex environmental context. Understanding how the interaction is structured by the environmental context is critical because the outcomes of mutualisms are highly context dependent (Johnson 1993, Bronstein 1994) and environmental context is the fundamental property of local adaptation. We are the first group, to our knowledge, to use reciprocal transplants 
planted directly into two habitats to assess how biotic and abiotic aspects of the soil interact with plant source to influence germination, survival, and growth and hence patterns of local adaptation.

Here we used reciprocal transplant experiments in two years to understand how plant source, microbes, and the environment contribute to patterns of plant local adaptation. We moved microbes, seeds, and soils between two habitats, limestone barrens (also called alvars) and surrounding old-fields (Figure 3.1). With this design we can ask how habitat, seed source, soil source, and microbes interact to affect fitness. We can also explore the context dependency of positive microbe effects. And ultimately, with this design we can test how microbes affect patterns of local adaptation. We hypothesized that habitat, soil source, seed source, and microbes would all interact to determine fitness outcomes and that positive microbe effects would dominate on alvars. Finally, we hypothesized that these positive microbe effects would lead to patterns of adaptation being facilitated by microbes for plants growing on alvars. In contrast, we hypothesized that neutral to negative interactions dominate in the more benign, old-field habitat because there are fewer impediments to growth.

\section{Methods}

Study system

Alvars are floristically diverse, critically endangered habitats that occur throughout Northern Europe and around the Great Lakes in North America. They are characterized by distinct vegetation and thin soils that overlay dolostone or limestone bedrock (Reschke et al. 1999). Alvars are notable for their extreme temporal and spatial environmental heterogeneity. New York State recognizes three distinct alvar 


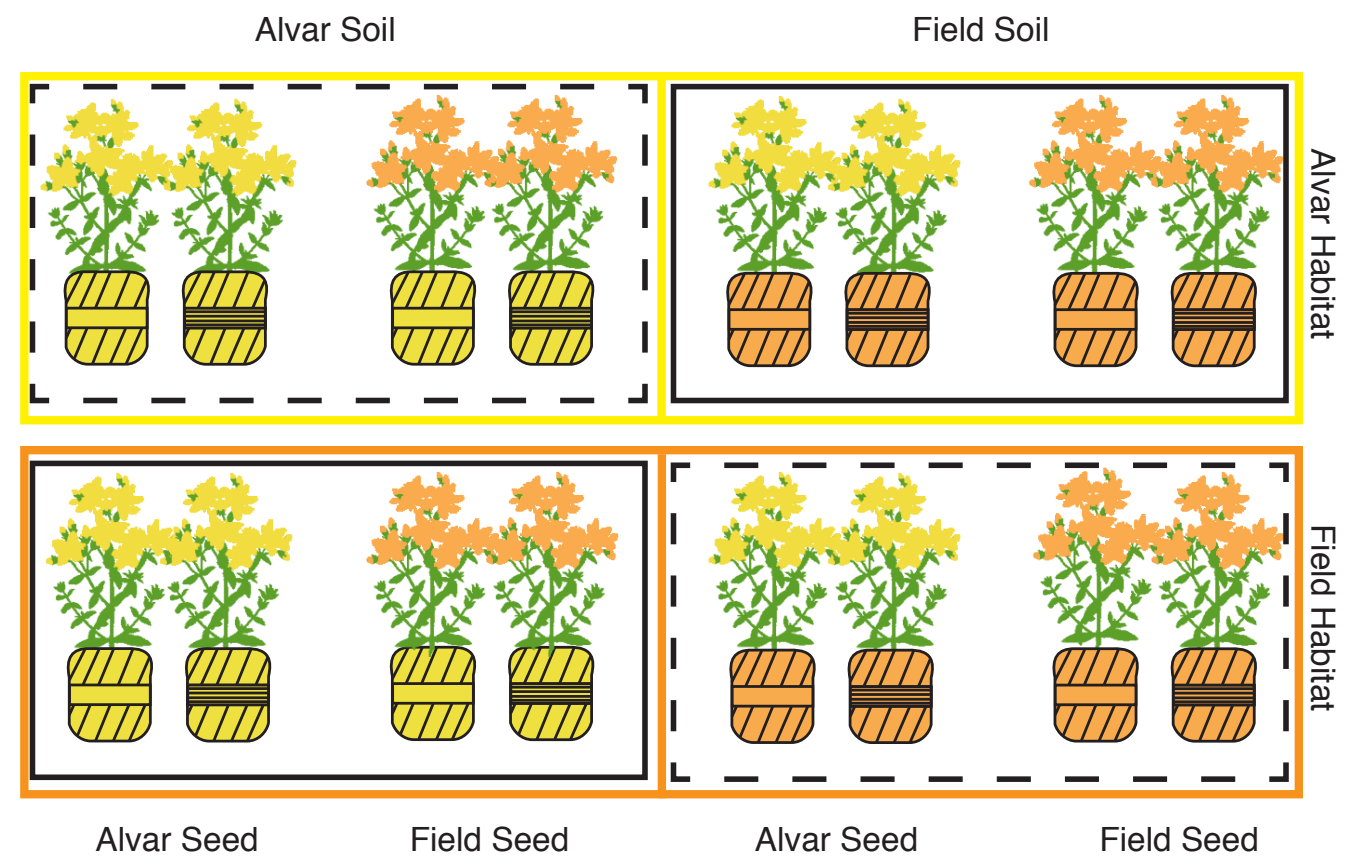

Figure 3.1: A fully factorial design was used to transplant seeds, soils (with and without microbes), into two habitats to investigate how microbes affect patterns of local adaptation. Yellow coloration indicates alvar seed source, soil source, and habitat; orange color indicates old-field seed source, soil source, and habitat. All treatments received autoclaved background soil from either old-field or alvar mixed with sand and calcined clay (indicated by crosshatching), and then some plants received a small amount of live soil inoculum ( $3 \%$ soil vol.) indicated by a rectangle filled with horizontal lines, or a small amount of autoclaved soil inoculum, indicated by the empty rectangle. The boxes outlined in dashed lines are those used to understand how microbes affect patterns of local adaptation. 
types: shrublands, grasslands, and pavement grasslands (Edinger et al. 2014). These physiognomic types are interspersed and have markedly different vegetation, soil depth, and hydrology. This is an interesting system to ask questions about local adaptation because over a relatively small spatial scale alvars are interspersed with more common habitats, such as old-fields, agricultural lands, and forests. We chose to explore plant local adaptation to alvar pavement grasslands compared to surrounding old-fields. Alvar pavements (henceforth referred to as alvars) have significantly higher $\mathrm{pH}$ (Figure S3.1A), shallower soils (Figure S3.1B), and higher nitrogen than old-fields (Figure S3.1C). However, phosphorus levels are similar (Figure S3.1D).

\section{Site Selection}

We identified three sites (Three-mile creek, Chaumont Barrens, Limerick Cedars) in Jefferson County, NY that had tracts of alvar land and adjacent old-fields (Figure 3.2). To find open areas on alvars, we used Google Earth (v. 7.1.8.3036). After identifying 10-15 open areas, we navigated to those areas using GPS (Garmin GPSMAP 76S), and from these we chose three suitable alvar habitats. We chose locations that had large openings ( $>2$ acres) and where our focal plant species, Hypericum perforatum was present. Hypericum perforatum was chosen for this experiment because it is widely found in alvars and adjacent old-fields and is known to be highly reliant on microbial symbionts (Seifert et al. 2009). We paired our alvar habitats with the closest possible old-field habitat (distances between alvars and fields at a site: Three-mile creek $(3-\mathrm{MI})=1.34 \mathrm{~km}$; Chaumont barrens $(\mathrm{CH})=1.95 \mathrm{~km}$; Limerick Cedars $(\operatorname{Lim})=1.7 \mathrm{~km}$; Coordinates for all the locations can be found in Supplemental data 


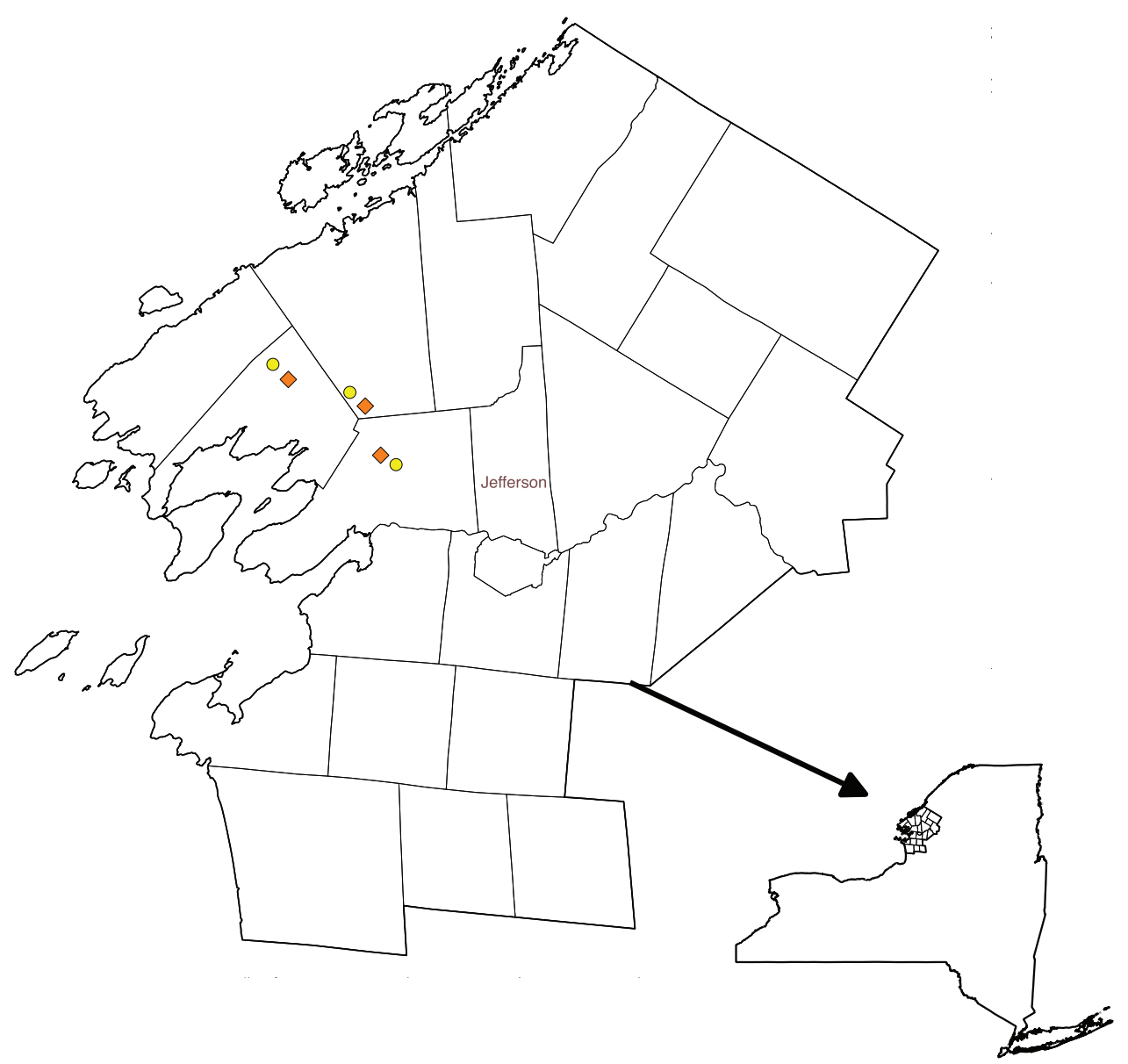

Figure 3.2: Reciprocal transplants were done at three different sites in Jefferson County, NY. For each site we identified one alvar (yellow circles) and one old-field (orange squares) habitat, and reciprocal transplants were done between habitats within a site (plants were never moved across sites). 
Table S3.1; Figure 3.2). At each of our habitat pairs, we delineated an area to be used for microbial inoculum and seed sampling and for transplanting our experimental plants. At two of the three sampling sites (3-MI and $\mathrm{CH}$ ), we measured 50m heading in the four cardinal directions to create a sampling/transplant area of approximately $8000 \mathrm{~m}^{2}$. At the Lim site the natural openings were smaller, so we were only able to designate a sampling/transplant location that was less than half the size $\left(3500 \mathrm{~m}^{2}\right)$ of the other two sites.

\section{Soil inoculum and seed sampling}

In 2014 and again in 2015, we collected experimental inoculum and seeds from the sites for our reciprocal transplant experiments planted out in 2015 and 2016. In both collection years we used the same collection protocol, but in 2014 we collected at all three sites and in 2015 we only collected soil inoculum and seeds at two sites (3-MI and $\mathrm{CH}$ ). In August of 2014 and 2015, at each site, we collected seeds and soil from $10 \mathrm{H}$. perforatum plants per habitat. One site was collected per day (both habitat types were collected on the same day at a site) and whether the old-field or alvar was collected first in the day was varied. For each sample, we identified a focal plant within our sampling area and because $H$. perforatum is capable of rhizomatous growth, we sampled plants spaced by a minimum of two meters. For each focal plant, we collected the seeds and soil immediately surrounding the plant including the roots. To collect a standardized amount of soil and roots we used a $1.5 \mathrm{~cm}$ chisel to a depth of $10 \mathrm{~cm}$, resulting in $\sim 700 \mathrm{ml}$ of soil per collection point. The entire plant, soil and roots, were placed in a Whirlpak bag and then on ice. Seeds were removed later in the day 
and all the soil and root samples were placed in the freezer at $-20^{\circ} \mathrm{C}$ until the transplant experiment. Seeds were placed in glassine bags, sealed in plastic containers with dessicant, and left at room temperature until use in experiments. The rhizosphere samples of each plant were used as inoculum "soil donors". One soil donor was used for one replicate in each treatment of a particular soil type (Figure 3.1) and then soil donor identity was treated as a random effect in statistical models. This allowed us to minimize the amount of soil collected on fragile alvars but also to pair live and autoclaved treatments so we could calculate the microbe effect (described in Data Analysis).

\section{Background soil, soil inoculum, and seed preparation}

We transplanted either seedlings or seeds of $H$. perforatum from alvars and from adjacent old-field habitats into the site where they were collected and into the paired habitat type, with either their home and away soils in a fully factorial design. To distinguish between the effects of habitat-specific differences in soil chemistry versus microbes on plant performance and adaptation, seeds were transplanted into both live soils and autoclaved soils (Figure 3.1). We filled experimental pots with 50\% autoclaved field-collected soil and 50\% mixture $(1: 1 \mathrm{v} / \mathrm{v})$ of autoclaved sand and calcined clay (Turface, Industrial Materials Corp., Deerfield, IL, USA). Background soil was collected in March 2014 and May 2015. To collect background soils, we returned to the same sampling area (described above) and identified between 20-30 Hypericum perforatum. At each plant, we sampled $480 \mathrm{ml}$ of soil to a depth of $20 \mathrm{~cm}$ until we had $12 \mathrm{~L}$ of soils per habitat, per site $(\mathrm{N}=6 ; 3$ alvar sites and 3 old-field sites). 
Background soils were stored at $4{ }^{\circ} \mathrm{C}$ until use in the experiment. We homogenized background soils and inoculums by hand. We chose this method to preserve some of the soil structure that would be important to support native microbial communities (Petersen and Klug 1994). Before use in the experiment, background field-collected soils and sand/calcined clay mix were autoclaved separately for 1 hour at $121^{\circ} \mathrm{C}$ and allowed to sit for 24 hours and then autoclaved again for 1 hour and allowed to sit for 24 hours. This autoclave protocol was designed to eradicate as much of the soil microbial communities as possible while minimizing changes to soil chemistry. Autoclaving resulted in minimal changes to soil nutrient composition (Figure S3.2). This mixture was added to pots made of nylon mesh (Sterlitech, Kent, WA, USA) with $0.45 \mu \mathrm{m}$ diameter pores that allowed the movement of nutrients and water in and out of pots but obstructed the movement of most microbes (McGuire 2007). We used these pots so we could transplant directly into the two habitats (Figure S3.3) and still preserve microbial treatments within the pots while preventing considerable contamination from the surrounding soil.

To introduce microbes to our experimental pots, we added a small amount ( $3 \%$ soil volume) of either live soil or autoclaved soil from our soil donor plants (described above). We chose to use whole soil inoculum because we didn't have a-priori hypotheses about which groups of microbes would be important, and we wanted to preserve the full range of taxa and their interactions (Hoeksema et al. 2010) that are important for determining microbe-mediated plant fitness outcomes. For example, plants can benefit simultaneously and non-additively from multiple microbial taxa 
(Afkhami and Stinchcombe 2016). After adding soil media and inoculum, pots were topped with $50 \mathrm{ml}$ of autoclaved sand; this created contrast between the pot surface and the surrounding soil so we could identify when there was significant contamination from the surrounding soil.

Seeds were sterilized for ten minutes using 10\% sodium hypochlorite (commercial bleach) and $1 \mathrm{ml}$ of commercially available dish detergent to act as a surfactant. After sterilization, seeds were rinsed three times with deionized reverse osmosis (DI/RO) water, moved to sterile filter paper in petri dishes, and placed for cold stratification. After seven days at $4^{\circ} \mathrm{C}$, seeds were transplanted directly into pots and moved to the field (Germination Transplant Experiment) or moved to the growth chamber until being transplanted into pots as seedlings (Seedling Transplant Experiment).

\section{Germination Transplant Experiment}

In 2016, we sterilized and stratified seeds, then we added 50 seeds directly to $10 \mathrm{~cm}$ nylon pots that were planted in both habitats in the field to assess germination. Plants were watered weekly until the conclusion of the experiment. Germination was monitored for seven weeks in the field.

\section{Seedling Transplant Experiment}

In 2015, we germinated seeds on sterile filter paper in petri dishes in a growth chamber before transplanting to pots. Seeds were germinated with 14 hours daylight and daytime temperatures at $25^{\circ} \mathrm{C}$ and nighttime temperatures at $13^{\circ} \mathrm{C}$. Humidity was 
at $30 \%$ during the day and $50 \%$ at night. To allow plants to establish, we then moved germinants to experimental pots in the greenhouse. In this experiment we used two different sizes of nylon pot. For the old-field transplant sites, we used pots that were $20 \mathrm{~cm}$ deep and on the alvar we transplanted out pots that were $10 \mathrm{~cm}$ deep. This was necessary to accommodate naturally occurring differences in soil depths (Figure S3.1B). Plants were fertilized once in the greenhouse to aid in establishment. Plants were watered in the field twice immediately after planting and then once per week until the end of the experiment. We recorded survival at four intervals after transplant. At $\sim 12$ weeks we removed plants from the transplant sites. Above ground biomass was cut away and weighed. Belowground material was washed clean of planting media. Roots were weighed (wet) and for each plant $~ 50-200 \mathrm{mg}$ of root material was collected haphazardly to assess mycorrhizal colonization. Root samples were stored at $-20^{\circ} \mathrm{C}$ until staining. Roots were rehydrated ( $\sim 5$ hours in $\mathrm{DI} / \mathrm{RO}$ water), then cleared with $10 \%$ potassium hydroxide $(\mathrm{KOH})$, acidified in $1 \%$ hydrochloric acid, and stained with $0.05 \%$ trypan blue in lactoglycerol (Phillips and Hayman 1970). Mycorrhizal colonization was estimated for a subset of plants $(\mathrm{N}=9$ per treatment) using the magnified intersection method (McGonigle et al. 1990). We examined 100 intersections at x200 magnification. At each intersection we assessed the presence of arbuscules, hyphae, vesicles, and septate fungi (non-mycorrhizal fungi).

\section{Data analysis}

In all analyses, we tested how main effects of habitat, plant source, soil source, and the presence of microbes interact to determine germination, survival, and biomass. In 
these models we included random effects of site (3-MI, CH, Lim), and because one soil donor was used across multiple treatments, we included a random effect of soil donor. When appropriate, we tested the assumptions of linear models using graphical approaches. We plotted residuals vs. fitted values to verify homogeneity of variances and histograms of residuals to confirm normal distributions (Zuur et al. 2009). When necessary we performed data transformation so data better fit the assumptions of linear regression. When we detected a significant main effect of microbes or an interaction between microbes and other fixed effects, we re-analyzed data using microbe-effect (ME) as the response variable. To calculate ME we paired plants within treatments by soil donor, and then we subtracted the response variable value of the plant that received autoclaved inoculum from the response variable value of the plant that received live inoculum. The resulting values were either positive (indicating a positive microbe effect), around zero (indicating no microbe effect), or negative (indicating a negative microbe effect). We then analyzed ME using mixed effect models with the same random effects described previously and habitat, plant source, and soil source as fixed effects. Planned contrasts were used to test specific hypotheses about the role of microbes in plant local adaptation. To do this we compared response variables of seed sources within live and sterile treatments using only the treatments outlined in dashed lines in Figure 3.1. This allowed us to compare survival, germination, and biomass of local vs. foreign seed sources in the two habitats, with and without their local microbes. Analyses were performed in R version 3.3.1 (R Development Core Team 2016). Estimated marginal means were used to explore treatment differences and specific hypotheses about local adaptation (lsmeans package, Lenth 2016). 


\section{Germination}

Summer of 2016 was unusually dry, consequently we had many zero values for germination, and thus our data did not fit the assumptions of linear regression.

Therefore, we analyzed our results using a hurdle model compartmentalized into a logistic regression and a generalized linear model. First, we summarized results from all census weeks into one value called maximum germination, which equaled the maximum number of germinants observed across all census dates. To perform the logistic regression, we re-coded our data as 0 if there was no germination in a pot and as a 1 if at least one seed germinated. We then used a model selection process to evaluate the effects of habitat, plant source, soil source, and microbes on the probability of germination (1) or not (0). In the second stage of the hurdle model, we excluded pots that did not have any germinants and only analyzed pots with germinated seedlings using a generalized linear model (glm) with a poisson distribution. We used a backward model selection process to identify the most parsimonious statistical model. We began by identifying the maximal model, which contained all factors and interactions. We then used a stepwise model simplification process by sequentially dropping terms and assessing if there was a significant increase in deviance with a term removed. If there was a significant increase in deviance, we restored the term to the model and continued testing lower order interactions until we arrived at the minimal adequate model (Crawley 2015). Models were compared using likelihood ratio tests (LRT) and a critical value of 0.05 . We then used estimated marginal means tests to understand how treatments differed. To analyze ME on the presence or absence of germination we used stepwise regression on 
ordinated logistic regression (or cumulative link models-clmm). In this analysis we treated microbe-effect as an ordinal categorical variable because the resulting values were either $-1,0$, or 1. Analyses were performed in R version 3.3.1 (R Development Core Team 2016) using packages lme4 (Bates et al. 2015) for the logistic regression and nlme (Pinheiro et al. 2017) for the glm and package ordinal (Christensen 2018) for cumulative link models (clmm).

\section{Seedling survival}

To test how habitat, plant source, soil source, and the presence of microbes interact to determine seedling survival we took two approaches. First, we performed survival analysis using Cox proportional hazards models containing fixed and random effects to analyze survival over the course of the experiment (four census dates). To perform this analysis, we calculated the number of days each individual survived from planting until death. In addition, we indicated if the individual was still alive at the conclusion of the experiment (i.e. right censored). We then used analysis of deviance to model effects. To visualize survival, we constructed Kaplan Meyer survival curves in R. We also analyzed the final survival census date ( Sept 26) alone using the stepwise model simplification process described in the germination section. Again, we used estimated marginal means tests to understand how treatments differed. We found congruent results between survival analysis over the course of the entire experiment and the final survival census date so to simplify the presentation of our results we are only discussing the final survival census date (survival analysis results table and survival curve figure can be found in supplemental, Table S3.2 and Figure S3.3). To analyze 
ME on survival, we used stepwise regression on ordinated logistic regression models (or cumulative link models-clmm). In this analysis, we treated microbe-effect as an ordinal categorical variable because the resulting values were either $-1,0$, or 1 . Analyses were performed in R version 3.3.1 (R Development Core Team, 2016). We used coxme function for the hazards model and ggsurvplot in the survival package (Therneau 2015) for the Kaplan Meyer curves. Package lme4 (Bates et al. 2015) was used for the logistic regression and package ordinal (Christensen 2018) was used for cumulative link models (clmm).

\section{Biomass}

To understand how biomass was influenced by habitat, plant source, soil source, and the presence of microbes we used stepwise regression on linear mixed effects models. We used a backward model selection process as described previously. To analyze ME on total biomass we used stepwise regression on linear mixed effect models.

\section{Mycorrhizal colonization}

We analyzed mycorrhizal colonization data in two-steps. First, we analyzed how the presence of live microbial inoculum (microbes) affected the total number of fungal structures found within roots. This analysis was used to evaluate how well our treatments held up over the experimental period. We used step-wise regression to compare a model that included a fixed effect of microbes to a model that only included random effects. Next, we analyzed data that only included plants that were initially exposed to live inoculum to understand how arbuscular and vesicular colonization was 
influenced by habitat, plant source, and soil source. We used the same model selection process described above and estimated marginal means to understand treatment differences. As a measure of how mutualistic mycorrhizal fungi were from the different habitats, we used linear regression within treatment groups of plants to explore how the number of arbuscules influenced plant biomass. Negative linear relationships indicate parasitic interactions, while positive linear relationships indicate mutualistic interactions (Johnson et al 2010).

\section{Results}

\section{Germination}

The probability of germination during the course of the experiment was affected by habitat, seed source, soil source, and the presence of microbes (Habitat*Seed Source*Soil Source*Microbes Interaction: $x^{2}=3.91, \mathrm{df}=1, P=0.05$; Figure 3.3; Table 3.1). Estimated marginal means tests indicate that the significant four-way interaction was largely driven by how microbes interacted with seed source and habitat. For example, probability of germination decreased by over $50 \%$ when alvar seeds were transplanted with alvar microbes into a foreign habitat compared with alvar seeds being transplanted with alvar microbes in their home habitat (Estimated marginal means test: $\mathrm{z}$. ratio $=2.15, P=0.03)$. However, when alvar seeds were paired with oldfield microbes, habitat was unimportant for germination (Estimated marginal means test: $z$. ratio $=-0.85, P=0.40)$. When we only analyzed non-zero values to determine factors that influence the number of seedlings produced, we found higher total 


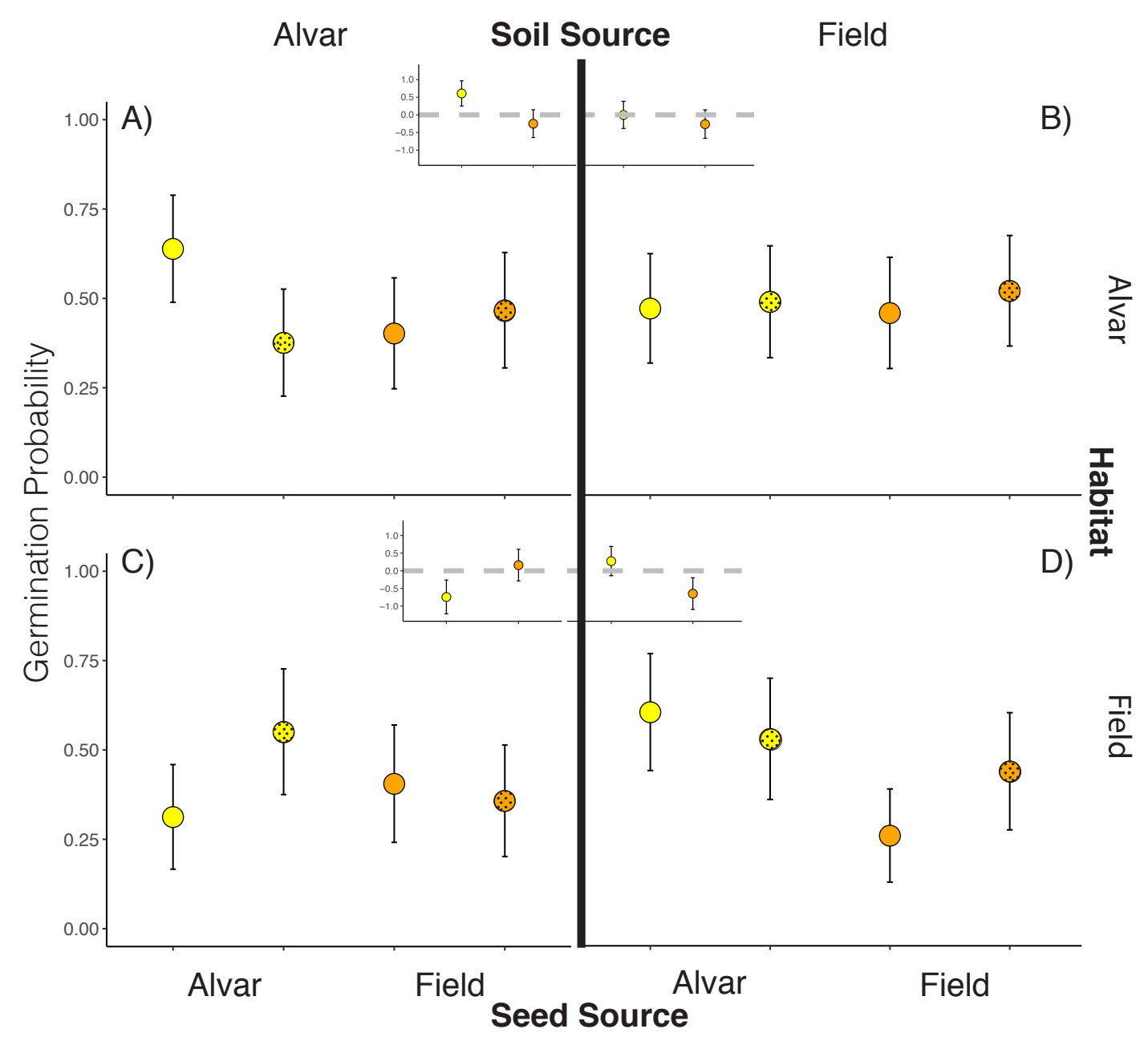

Figure 3.3 A-D: The probability of germination during the course of the experiment was affected by habitat, seed source, soil source, and the presence of microbes (habitat*seed source*soil source*microbes interaction). Alvar seeds (yellow circles) had highest germination when transplanted with alvar microbes in their home habitat. Old-field seeds (orange circles) had similar germination across treatments. Open circles indicate treatments that received live soil inoculum and stippled circles are treatments that received autoclaved soil inoculum. Points represent mean germination probability and bars represent standard error. Inset: Microbe effect on germination rate. Only alvar seeds, transplanted with alvar soils, into alvar habitat experienced positive microbe effects. Other treatment groups experienced either neutral or negative microbe-effects. 
Table 3.1: Percent germination of treatment groups. Microbe effect is the presented here as the difference in germination percentage between live and autoclaved treatments. $* \mathrm{~N}=$ total observations in each group. We had $\sim 30$ replicates for plants transplanted into alvar habitat and about $\sim 20$ replicates for plants transplanted into the old-field habitat because in 2016 one of our field sites was unavailable due to a change in ownership. Germination values are the percent of seeds in a treatment group that germinated over the course of the experiment.

\begin{tabular}{|lcccccc|}
\hline Habitat & Seed Source & Soil Source & Inoculum & N & Germination & Microbe Effect \\
\hline \hline Alvar & Alvar & Alvar & Live & 29 & 62.1 & \\
Alvar & Alvar & Alvar & Autoclaved & 30 & 40.0 & 22.1 \\
\hline Alvar & Alvar & Field & Live & 30 & 50.0 & \\
Alvar & Alvar & Field & Autoclaved & 27 & 51.9 & -1.9 \\
\hline Alvar & Field & Alvar & Live & 28 & 42.9 & \\
Alvar & Field & Alvar & Autoclaved & 27 & 48.1 & -5.2 \\
\hline Alvar & Field & Field & Live & 27 & 51.9 & \\
Alvar & Field & Field & Autoclaved & 28 & 53.6 & -1.7 \\
\hline Field & Alvar & Alvar & Live & 20 & 45.0 & \\
Field & Alvar & Alvar & Autoclaved & 19 & 68.4 & -23.4 \\
\hline Field & Alvar & Field & Live & 20 & 75.0 & \\
Field & Alvar & Field & Autoclaved & 19 & 68.4 & 6.6 \\
\hline Field & Field & Alvar & Live & 20 & 55.0 & \\
Field & Field & Alvar & Autoclaved & 20 & 50.0 & 5 \\
\hline Field & Field & Field & Live & 20 & 40.0 & \\
Field & Field & Field & Autoclaved & 20 & 60.0 & -20 \\
\hline \hline
\end{tabular}


Without Microbes

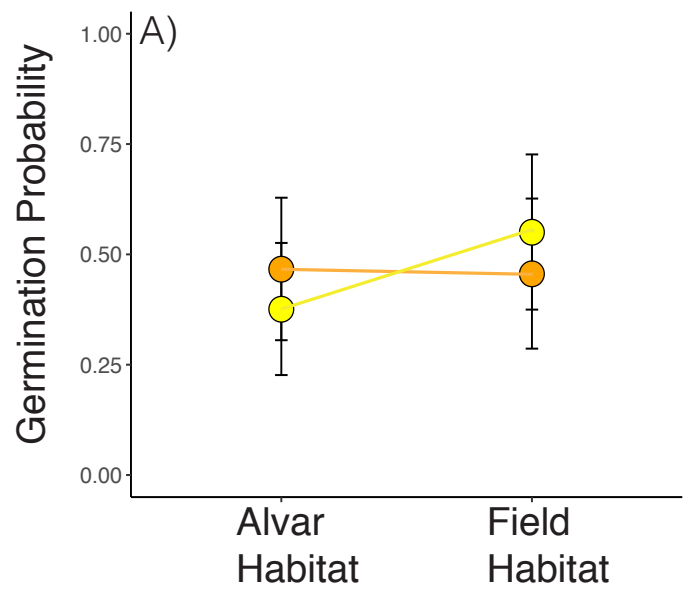

With Microbes

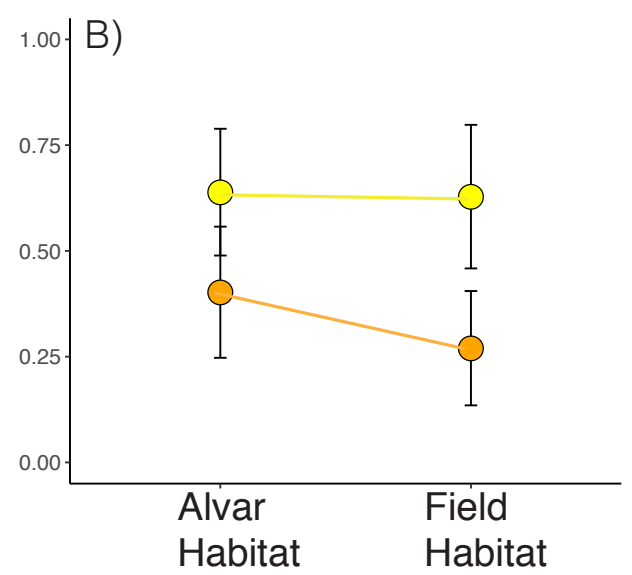

Figure 3.4 A-B: Germination probability reaction norms for treatments without microbes (A) and with microbes (B). Planned contrasts were used to test for the differences between local and foreign plant populations in each habitat with and without microbes. Without microbes no patterns of adaptation were evident. Treatments with microbes had decreased seed germination for old-field seeds (orange circles), and this led to a pattern of maladaptation for old-field seeds where they had significantly lower fitness than foreign alvar seeds (yellow cirlces) in their home habitat. Points represent mean germination probability and bars represent standard error. 
germination in the alvar habitat (Habitat: $\chi^{2}=5.87, \mathrm{df}=1, P=0.015$ ) and that more seeds germinated when alvar seeds were grown with microbes (regardless of source;

Seed.Source*Microbe interactions: $\left.\overline{x^{2}}=4.19, \mathrm{df}=1, P=0.04\right)$. Consistent with the full model analysis, microbes had the most positive effects on germination for the alvar seeds transplanted into their home site with home soil inoculum and significantly worse germination when transplanted with home soil inoculum in the old-field site (Habitat*Seed Source*Soil Source Interaction: $x^{2}=4.16, \mathrm{df}=1, P=0.04$; Figure 3.3 inset; Table 3.1). Patterns of local adaptation for germination were significantly affected by the presence of microbes. In the treatment without microbes there was no evidence of local adaptation (Figure 3.4A). Adding microbes changed patterns of adaptation by decreasing old-field seedling germination, thereby creating a pattern of maladaptation where old-field seeds had lower fitness than alvar seeds in their home habitat (Estimated marginal means test: z.ratio $=2.19, P=0.03$; Figure 3.4B)

\section{Seedling survival}

The probability of seedling survival was jointly affected by habitat and soil source (Habitat*Soil Source: $\left.x^{2}=10.30, \mathrm{df}=1, P=0.001\right)$. Plants (regardless of seed source) survived better when transplanted into soils that were natal to a particular habitat. This was especially pronounced for the sympatric combination of old-field soil in the oldfield habitat, where survival for seedlings transplanted into old-field soil in the oldfield habitat was $\sim 30 \%$ greater than seedlings transplanted into alvar soils in the oldfield habitat (Estimated marginal means test: $\mathrm{z} . \mathrm{ratio}=-3.61, P=0.0003$ ). We also detected a significant plant source, soil source, and microbial interaction 


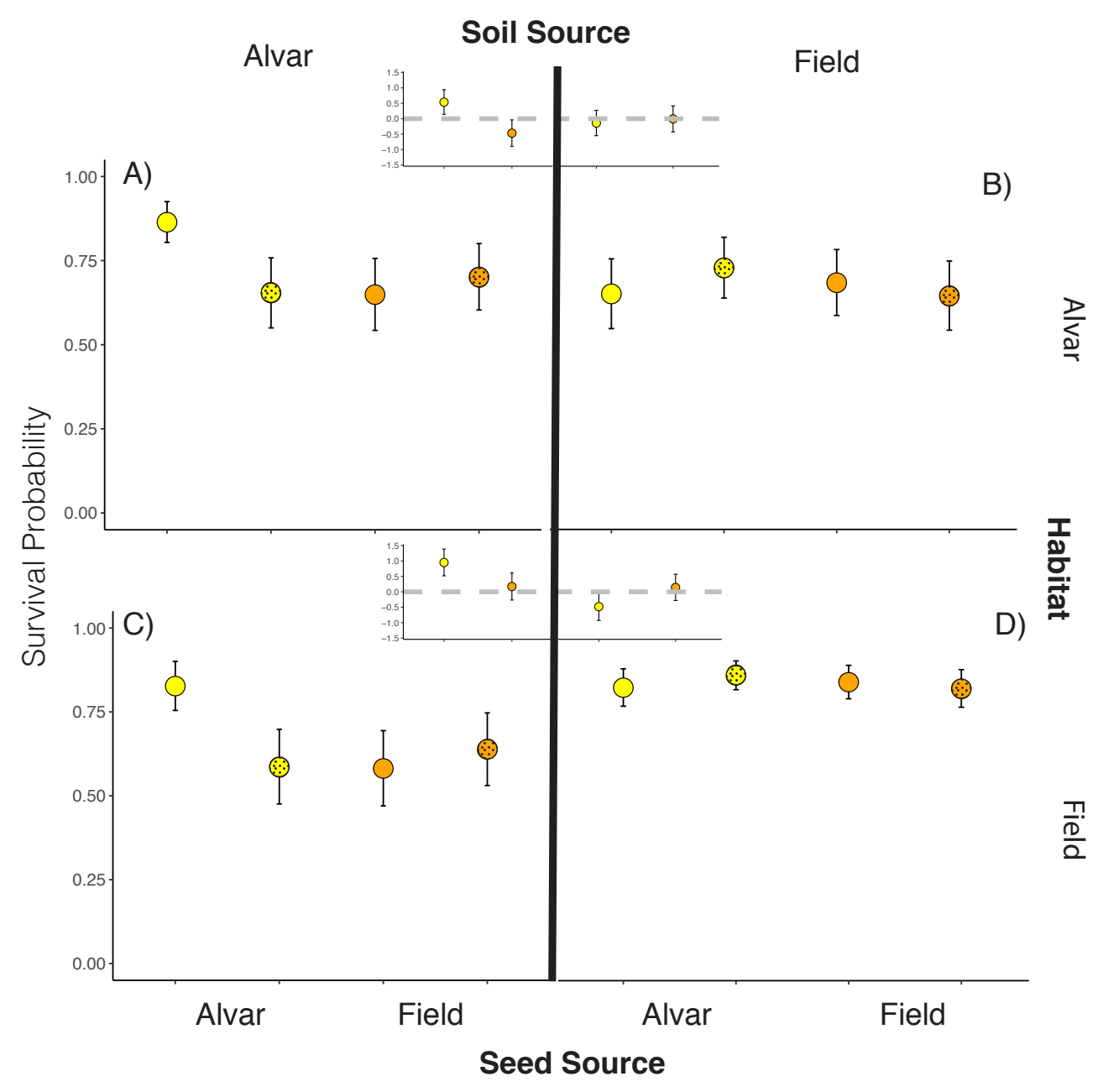

Figure 3.5 A-D: Probability of seedling survival was significantly increased for alvar seedlings (yellow circles) when they were transplanted with live, alvar soils. Microbemediated enhancement to survival occurred regardless of transplant habitat. Old-field seedling (orange circles) survival was highest in old-field soils in the old-field habitat. Points represent mean survival probability and bars represent standard error. Open circles indicate treatments that received live soil inoculum and stippled circles are treatments that received autoclaved soil inoculum. Inset: Microbe effect on survival. Alvar seeds, transplanted with alvar soils, experienced positive microbe effects in oldfield and alvar habitats. Other treatment groups experienced either neutral or negative microbe-effects. 
Table 3.2: Percent survival of treatment groups. Microbe effect (ME) is the difference in survival percentage at the last census between live and autoclaved treatments. The colors indicates fully home treatments (yellow $=$ alvar, orange $=$ old-field) or treatments where only seeds are moved (light yellow=alvar, orange=light orange).

\begin{tabular}{|c|c|c|c|c|c|c|c|c|c|c|c|c|}
\hline \multirow[b]{2}{*}{ Habitat } & \multirow[b]{2}{*}{ Seed Source } & \multirow[b]{2}{*}{ Soil Source } & \multirow[b]{2}{*}{ Inoculum } & \multicolumn{2}{|c|}{ Census 1} & \multicolumn{2}{|c|}{ Census 2} & \multicolumn{2}{|c|}{ Census 3} & \multicolumn{2}{|c|}{ Census 4} & \multirow[b]{2}{*}{ ME } \\
\hline & & & & $\mathbf{N}$ & Surv. & $\mathbf{N}$ & Surv. & $\mathbf{N}$ & Surv. & $\mathbf{N}$ & Surv. & \\
\hline Alvar & Alvar & Alvar & Live & 30 & 90.0 & 30 & 90.0 & 30 & 86.7 & 30 & 83.3 & \\
\hline Alvar & Alvar & Alvar & Autocl. & 30 & 76.7 & 30 & 73.3 & 30 & 70.0 & 30 & 70.0 & 13.3 \\
\hline Alvar & Alvar & Field & Live & 30 & 93.3 & 30 & 86.7 & 30 & 83.3 & 28 & 71.4 & \\
\hline Alvar & Alvar & Field & Autocl. & 30 & 93.3 & 30 & 86.7 & 30 & 86.7 & 29 & 72.4 & -1.0 \\
\hline Alvar & Field & Alvar & Live & 30 & 80.0 & 30 & 76.7 & 30 & 73.3 & 26 & 57.7 & \\
\hline Alvar & Field & Alvar & Autocl. & 30 & 80.0 & 30 & 73.3 & 30 & 73.3 & 28 & 67.9 & -10.2 \\
\hline Alvar & Field & Field & Live & 30 & 86.7 & 30 & 90.0 & 30 & 86.7 & 29 & 65.5 & \\
\hline Alvar & Field & Field & Autocl. & 30 & 73.3 & 30 & 70.0 & 30 & 70.0 & 30 & 63.3 & 2.2 \\
\hline Field & Alvar & Alvar & Live & 30 & 80.0 & 28 & 78.6 & 27 & 81.5 & 27 & 81.5 & \\
\hline Field & Alvar & Alvar & Autocl. & 30 & 56.7 & 29 & 65.5 & 29 & 62.1 & 29 & 51.7 & 29.8 \\
\hline Field & Alvar & Field & Live & 30 & 86.7 & 28 & 78.6 & 28 & 78.6 & 28 & 78.6 & \\
\hline Field & Alvar & Field & Autocl. & 30 & 96.7 & 29 & 93.1 & 29 & 93.1 & 29 & 89.7 & -11.1 \\
\hline Field & Field & Alvar & Live & 30 & 73.3 & 30 & 63.3 & 30 & 63.3 & 29 & 62.1 & \\
\hline Field & Field & Alvar & Autocl. & 30 & 73.3 & 28 & 64.3 & 28 & 60.7 & 27 & 63.0 & -0.9 \\
\hline Field & Field & Field & Live & 30 & 93.3 & 30 & 90.0 & 30 & 90.0 & 30 & 90.0 & \\
\hline Field & Field & Field & Autocl. & 30 & 93.3 & 30 & 90.0 & 30 & 90.0 & 30 & 86.7 & 3.3 \\
\hline
\end{tabular}


Without Microbes

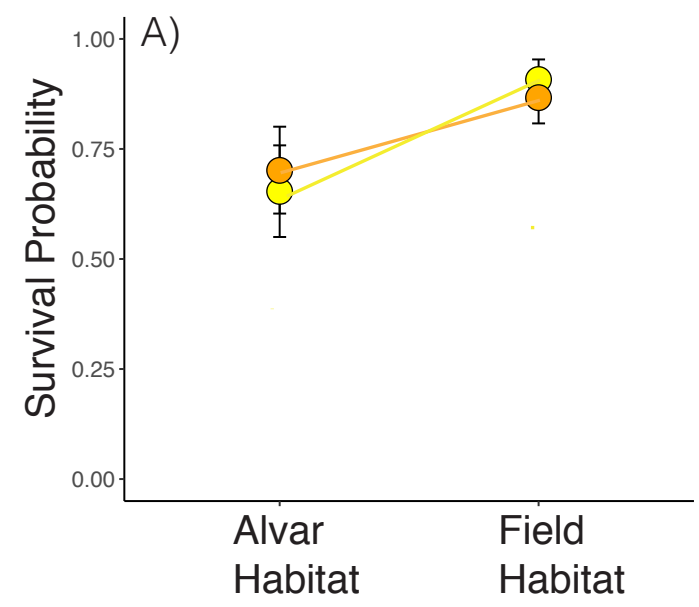

With Microbes

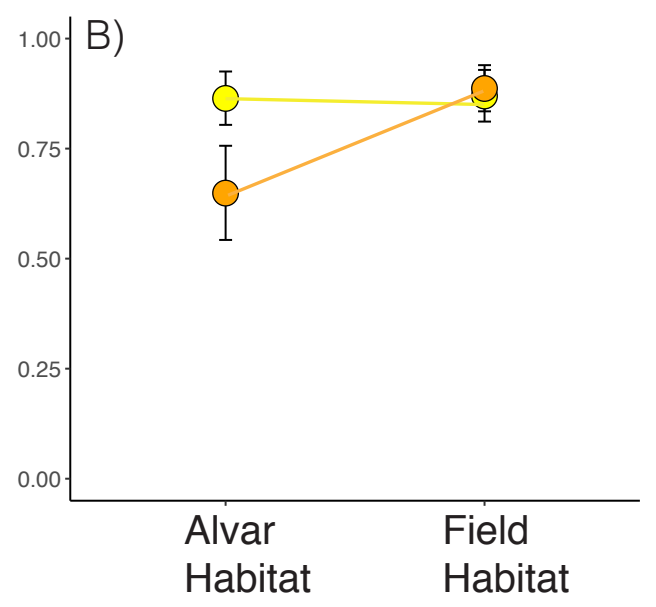

Figure 3.6 A-B: Survival probability reaction norms for treatments without microbes (left) and with microbes (right). Planned contrasts were used to test for the differences between local and foreign plant populations in each habitat with and without microbes. Without microbes no patterns of adaptation were evident. Treatments with microbes had increased seedling survival for alvar seedlings (yellow circles), and this led to a pattern of local adaptation where alvar seedlings had significantly higher fitness than foreign old-field seedlings (orange circles) in their home habitat. Points represent mean survival probability and bars represent standard error. 
(Seed Source*Soil Source*Microbes Interaction: $\chi^{2}=4.99, \mathrm{df}=1, P=0.03$ ). Alvar seedlings were $37 \%$ more likely to survive when transplanted into alvar soils with microbes compared with old-field seedlings (Estimated marginal means test: $\mathrm{z}$ ratio=2.67, $P=0.008$; Figure 3.5 A-D; Table 3.2). Survival was not significantly different between alvar and old-field seedlings in old-field soils with (z.ratio $=-0.34, P=0.73$ ) or without microbes (z.ratio $=0.88, P=0.38$ ) or in sterilized alvar soils (z.ratio $=-0.54$, $P=0.59)$ Consistent with the full model analysis, microbes had the most positive effects on survival for the alvar seedlings transplanted with their home soil inoculum (regardless of transplant habitat; Seed Source*Soil Source Interaction: $x^{2}=4.45, \mathrm{df}=1$, $P=0.03$; Figure 3.5 A-D inset; Table 3.2). Patterns of local adaptation were significantly affected by microbes. No pattern of local adaptation was evident when plants were transplanted without microbes (Figure 3.6A). In contrast, alvar microbes significantly affected alvar seedling survival, thereby leading to patterns of local adaptation where local alvar seedlings had higher fitness than foreign old-field seedlings in the alvar habitat (z.ratio $=2.67, P=0.008$; Fig 3.6B)

\section{Biomass}

The minimal model for total biomass included a significant effect of soil source (Soil Source: $\left.\overline{x^{2}}=12.81, \mathrm{df}=1, P=0.0003\right)$ and an interaction between habitat and microbes (Habitat*Microbes: $x^{2}=10.26, \mathrm{df}=1, P=0.0013$; Figure 3.7 A-D; Table 3.3). Plants grown in old-field soils had significantly more total biomass. Plants grown in the alvar habitat had equivalent biomass regardless of microbial treatment (Estimated marginal means test: t.ratio $=0.117, \mathrm{df}=290.36, \mathrm{P}=0.9$ ), but plants transplanted into the old- 


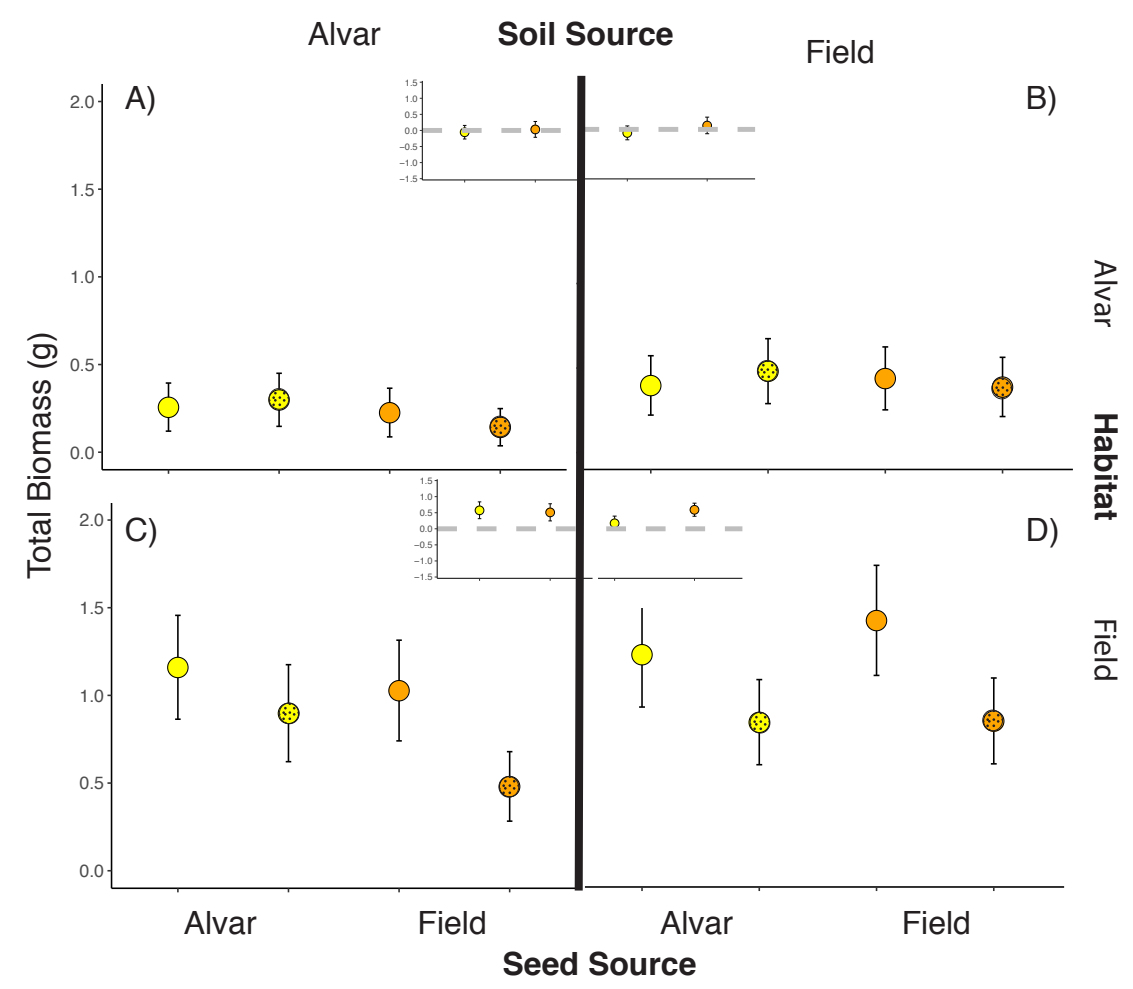

Figure 3.7 A-D: Plants transplanted into the old-field sites had more total biomass when transplanted with live soil inoculum. We did not find evidence that microbes disproportionately affected plants from one source or that microbes from one soil source were particularly beneficial to plants, but rather plants generally benefitted from microbes in the old-field habitat. Open circles indicate treatments that received live soil inoculum and stippled circles are treatments that received autoclaved soil inoculum. Inset: Microbe effect on biomass. Alvar (yellow circles) and old-field (orange circles) plants both experience positive microbe effects when transplanted into alvar soils in the old-field habitat. Old-field seeds experience positive microbe effects when transplanted into old-field soils in the old-field habitat and alvar seeds experience very slight positive microbe effects when transplanted into old-field soils in the old-field habitat. 
Table 3.3: Plant total biomass measurements. Microbe effect is the presented here as the difference in total biomass between live and autoclaved treatments. The colors indicates fully home treatments (yellow $=$ alvar, orange $=$ old-field) or treatments where only seeds are moved (light yellow=alvar, orange=light orange.

\begin{tabular}{|c|c|c|c|c|c|c|c|}
\hline \multirow[b]{2}{*}{ Habitat } & \multirow[b]{2}{*}{ Seed Source } & \multirow[b]{2}{*}{ Soil Source } & \multirow[b]{2}{*}{ Inoculum } & \multicolumn{4}{|c|}{ Biomass } \\
\hline & & & & $\mathbf{N}$ & Mean & $\overline{\text { SE }}$ & ME \\
\hline Alvar & Alvar & Alvar & Live & 25 & 0.29 & 0.03 & \\
\hline Alvar & Alvar & Alvar & Autoclaved & 21 & 0.35 & 0.05 & -0.05 \\
\hline Alvar & Alvar & Field & Live & 20 & 0.47 & 0.07 & \\
\hline Alvar & Alvar & Field & Autoclaved & 21 & 0.59 & 0.08 & -0.13 \\
\hline Alvar & Field & Alvar & Live & 15 & 0.31 & 0.07 & \\
\hline Alvar & Field & Alvar & Autoclaved & 19 & 0.22 & 0.04 & 0.08 \\
\hline Alvar & Field & Field & Live & 19 & 0.58 & 0.07 & \\
\hline Alvar & Field & Field & Autoclaved & 19 & 0.49 & 0.07 & 0.09 \\
\hline Field & Alvar & Alvar & Live & 22 & 1.23 & 0.21 & \\
\hline Field & Alvar & Alvar & Autoclaved & 15 & 1.10 & 0.28 & 0.14 \\
\hline Field & Alvar & Field & Live & 22 & 1.45 & 0.18 & \\
\hline Field & Alvar & Field & Autoclaved & 26 & 1.11 & 0.19 & 0.34 \\
\hline Field & Field & Alvar & Live & 18 & 1.23 & 0.24 & \\
\hline Field & Field & Alvar & Autoclaved & 17 & 0.65 & 0.18 & 0.59 \\
\hline Field & Field & Field & Live & 27 & 1.82 & 0.30 & \\
\hline Field & Field & Field & Autoclaved & 25 & 1.13 & 0.22 & 0.68 \\
\hline
\end{tabular}



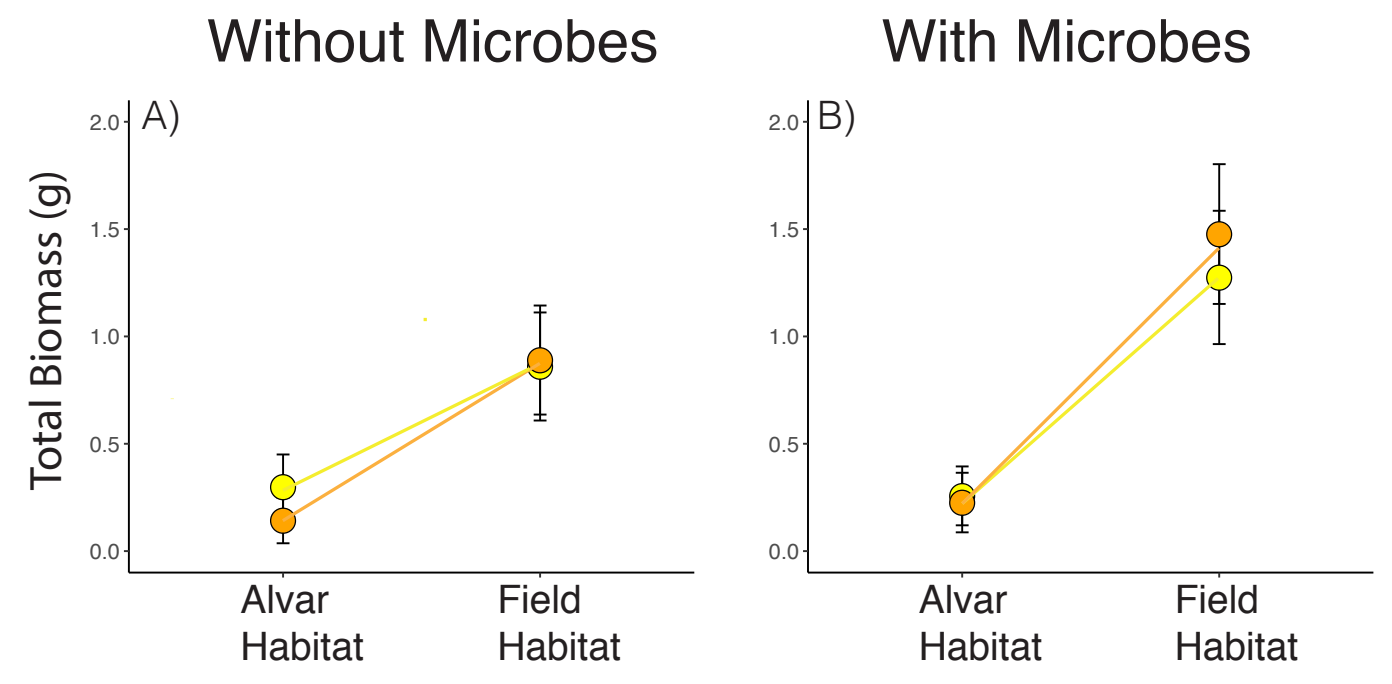

Figure 3.8 A-B: Total biomass (g) reaction norms for treatments without microbes (left) and with microbes (right). Planned contrasts were used to test for the differences between local and foreign plant populations in each habitat with and without microbes. Without microbes no patterns of adaptation were evident and this was unchanged with the addition of microbes. Points represent mean total biomass and bars represent standard error. 
field habitat benefited from microbes (Estimated marginal means test: t.ratio $=4.75, \mathrm{df}$ $=288.71, \mathrm{P}<0.0001)$. Consistent with the full model analysis, microbes had the most positive effects on biomass in the old-field habitat (Habitat: $x^{2}=8.88, \mathrm{df}=1, P=0.003$; Figure 3.7 A-D inset; Table 3.3). There was no evidence of local adaptation in treatments without (Figure 3.8 A) or treatments with microbes (Figure 3.8 B) for the response variable of biomass.

\section{Mycorrhizal colonization}

On average autoclaved plants had $12 \%$ less total colonization than plants that were planted with live inoculum (Microbes: $x^{2}=9.50, \mathrm{df}=1, P=0.002$ ). For plants inoculated with live soil, soil source (Soil Source: $x^{2}=4.67, \mathrm{df}=1, P=0.03$ ) and seed source (Seed Source: $\left.x^{2}=8.46, \mathrm{df}=1, P=0.004\right)$ independently affected the proportion of arbuscules occurring in roots. Plants transplanted into live alvar soils had more arbuscules (Figure 3.9 A-D; Table 3.4), and alvar plants had more arbuscules (Figure 3.9 A-D; Table 3.4), regardless of soil source. The minimal model for vesicular colonization included main effect of habitat (Habitat: $x^{2}=18.85, \mathrm{df}=1, \mathrm{P}<0.0001$ ). This was driven by the fact that plants transplanted into alvar habitat produced $\sim 76 \%$ more vesicles than plants transplanted into the old-field habitat. We found a significant positive relationship between arbuscules and total biomass when alvar seeds were paired with their home soil but only in the old-field habitat $\left(\mathrm{R}^{2}=0.62, \mathrm{~F}=14.09, \mathrm{P}=0.01\right.$; Figure 3.10 B; Table S3.3), whereas we didn't find a significant relationship between arbuscules and biomass in the other treatments (Figure 3.10 A, C-H; Table S3.3). 


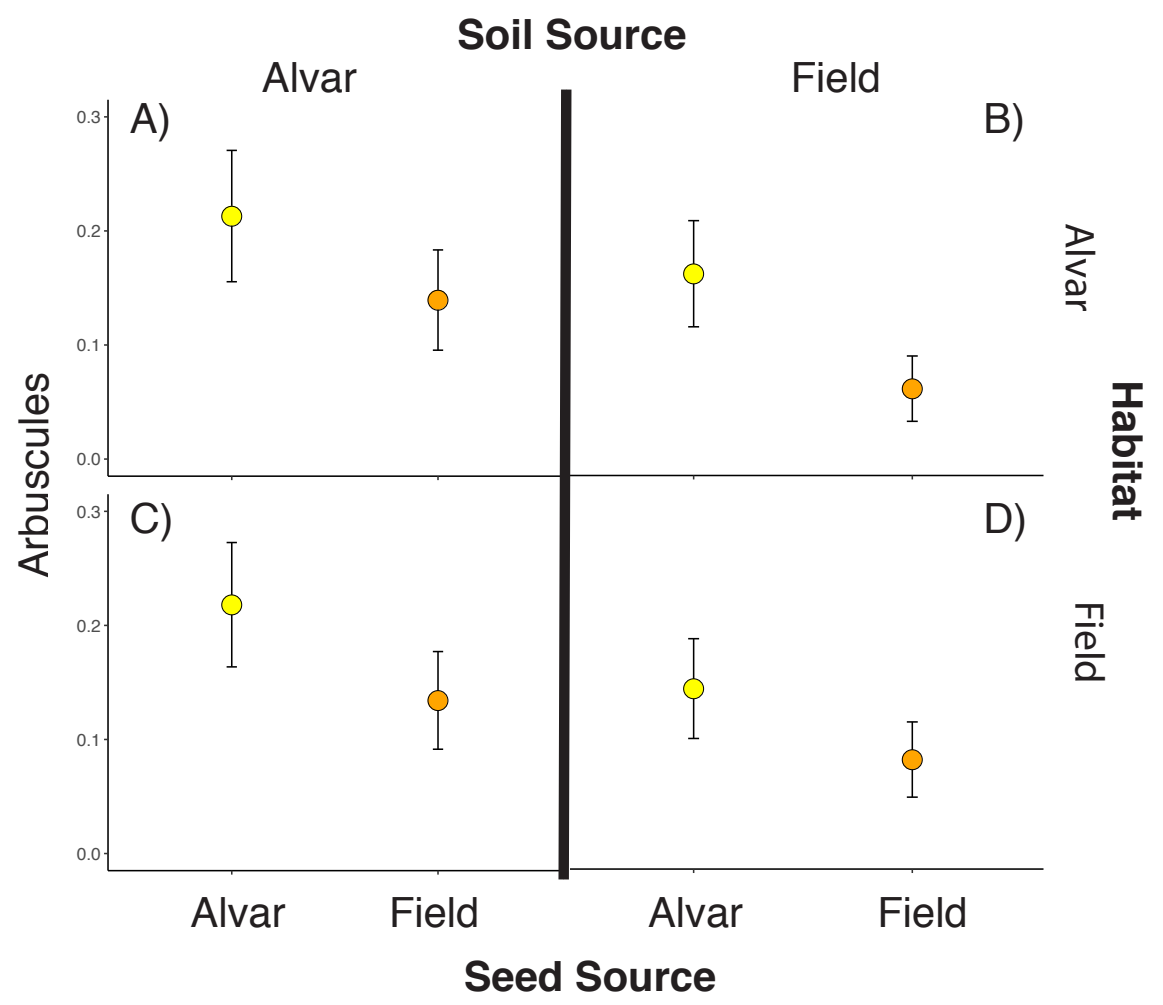

Figure 3.9 A-D: Alvar plants produced more arbuscules per unit root length regardless of soil source or habitat, and plants transplanted into the alvar soils produced more arbuscules regardless of habitat or seed source. Points represent mean proportion of arbuscular colonization and bars represent standard error. 
Table 3.4: Average proportion of mycorrhizal colonization. ${ }^{*} \mathrm{~N}=$ total observations in each group, Total=proportion of intersections where arbuscules, vesicles, or fungal hyphae were observed, Arbuscular=proportion of intersections where arbuscules were observed, Vesicular=proportion of intersections where vesicles were observed, and Non-AMF=proportion of intersections where septate fungi (usually considered non-AMF) were observed.

\begin{tabular}{|c|c|c|c|c|c|c|c|c|c|c|c|c|}
\hline \multirow[b]{2}{*}{ Habitat } & \multirow[b]{2}{*}{ Seed Source } & \multirow[b]{2}{*}{ Soil Source } & \multirow[b]{2}{*}{ Inoculum } & \multirow[b]{2}{*}{$\mathbf{N}$} & \multicolumn{2}{|c|}{ Total } & \multicolumn{2}{|c|}{ Arbuscular } & \multicolumn{2}{|c|}{ Vesicular } & \multicolumn{2}{|c|}{ Non-AMF } \\
\hline & & & & & Mean & SE & Mean & SE & Mean & SE & Mean & SE \\
\hline Alvar & Alvar & Alvar & Live & 8 & 0.95 & 0.03 & 0.25 & 0.07 & 0.37 & 0.04 & 0.26 & 0.07 \\
\hline Alvar & Alvar & Alvar & Autocl. & 8 & 0.84 & 0.07 & 0.13 & 0.05 & 0.31 & 0.08 & 0.50 & 0.08 \\
\hline Alvar & Alvar & Field & Live & 9 & 0.91 & 0.03 & 0.17 & 0.02 & 0.26 & 0.03 & 0.32 & 0.06 \\
\hline Alvar & Alvar & Field & Autocl. & 9 & 0.92 & 0.03 & 0.21 & 0.04 & 0.28 & 0.03 & 0.54 & 0.07 \\
\hline Alvar & Field & Alvar & Live & 9 & 0.90 & 0.03 & 0.16 & 0.04 & 0.30 & 0.06 & 0.33 & 0.05 \\
\hline Alvar & Field & Alvar & Autocl. & 9 & 0.93 & 0.03 & 0.08 & 0.02 & 0.24 & 0.05 & 0.39 & 0.05 \\
\hline Alvar & Field & Field & Live & 9 & 0.95 & 0.01 & 0.07 & 0.01 & 0.30 & 0.05 & 0.31 & 0.05 \\
\hline Alvar & Field & Field & Autocl. & 8 & 0.79 & 0.06 & 0.08 & 0.04 & 0.19 & 0.04 & 0.56 & 0.06 \\
\hline Field & Alvar & Alvar & Live & 9 & 0.90 & 0.03 & 0.23 & 0.04 & 0.21 & 0.04 & 0.24 & 0.04 \\
\hline Field & Alvar & Alvar & Autocl. & 8 & 0.76 & 0.07 & 0.14 & 0.03 & 0.14 & 0.04 & 0.15 & 0.04 \\
\hline Field & Alvar & Field & Live & 9 & 0.83 & 0.07 & 0.21 & 0.07 & 0.16 & 0.04 & 0.30 & 0.03 \\
\hline Field & Alvar & Field & Autocl. & 9 & 0.60 & 0.10 & 0.07 & 0.02 & 0.10 & 0.03 & 0.28 & 0.05 \\
\hline Field & Field & Alvar & Live & 9 & 0.85 & 0.05 & 0.18 & 0.06 & 0.18 & 0.03 & 0.17 & 0.04 \\
\hline Field & Field & Alvar & Autocl. & 9 & 0.81 & 0.06 & 0.06 & 0.03 & 0.18 & 0.05 & 0.21 & 0.04 \\
\hline Field & Field & Field & Live & 9 & 0.76 & 0.07 & 0.11 & 0.03 & 0.13 & 0.03 & 0.18 & 0.02 \\
\hline Field & Field & Field & Autocl. & 9 & 0.65 & 0.05 & 0.09 & 0.01 & 0.08 & 0.01 & 0.20 & 0.03 \\
\hline
\end{tabular}


A)

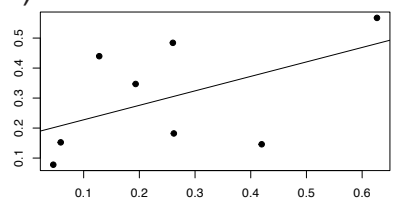

C)

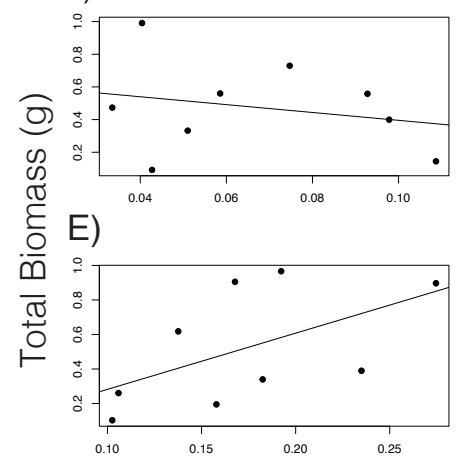

G)

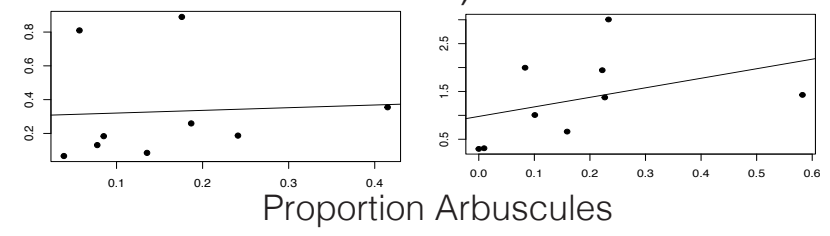

B)

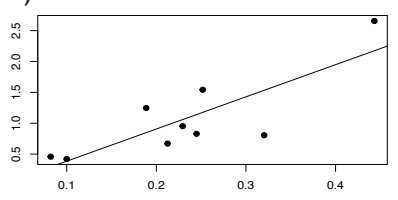

D)

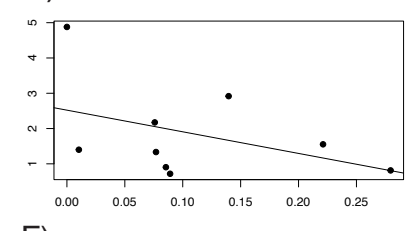

F)

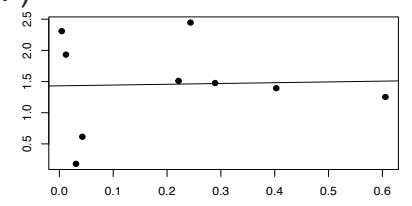

$\mathrm{H})$

Figure 3.10 A-H : Alvar seeds planted with alvar soils in the old-field habitat (B) were the only plants that had a positive relationship between the proportion of arbuscules in the roots and the total biomass of the plant, indicating coevolved interactions that maximize benefit to both partners. The following treatments showed no relationship between proportion of arbuscules and total plant biomass: A) Alvar habitat, alvar seed, and alvar soil, C) alvar habitat, old-field seed, and old-field soil, D) old-field habitat, old-field seed, and old-field soil, E) alvar habitat, alvar seed, and oldfield soil, F) old-field habitat, alvar seed, and old-field soil, G) alvar habitat, old-field seed, and alvar soil, and H) old-field habitat, old-field seed, and alvar soil. 


\section{Discussion}

There is growing interest in the topic of microbes and plant adaptation (Johnson et al. 2010, Smith et al. 2011, Lau and Lennon 2012, Lankau 2013, Johnson et al. 2013, Wagner et al. 2014, Pickles et al. 2015, Revillini et al. 2016, Rúa et al. 2016, Van Nuland et al. 2016, Petipas et al. 2017, González et al. 2018). Our experiment provides one of the strongest tests to date of microbe-mediated adaptation. Through the use of reciprocal transplant experiments, planted directly into the soil environment, we were able to ask how patterns of plant fitness and the direction of microbe effects were shaped by interactions between plant source, microbial source, and the local environment. We also compared local vs. foreign populations of plants with and without local microbes to test specific hypotheses about the role of microbes in plant local adaptation. We found that alvar plants experienced more positive microbe effects for germination and seedling survival when planted in combination with their home microbes, and these effects were potentially driven by coevolution between alvar plants and local mycorrhizal fungi. In contrast, we found that old-field plants tended to experience neutral to negative interactions with microbes in early life history and no evidence of mutualistic coevolution. Microbes had variable effects on patterns of plant local adaptation. Microbes decreased germination rates for old-field seedlings leading to a pattern of maladaptation, whereas they increased alvar seedling survival leading to patterns of local adaptation, where alvar seedlings had higher survival in their home habitat compared with foreign old-field seedlings. Interestingly, no patterns of local adaptation were evident in treatments that received sterilized inoculum. In the 
following discussion, we will first tackle where microbe effects were the strongest and then how microbes affected patterns of local adaptation.

In this study, we found asymmetrical benefits between habitats of interacting with microbes. Plants do not universally benefit from interactions with microbes, even those generally referred to as mutualists, but rather these interactions are highly context dependent (Johnson 1993, Bronstein 1994). The stress gradient hypothesis posits that as stress increases mutually beneficial interactions dominate and antagonistic interactions are reduced (Bertness and Callaway 1994). There is wide support for this idea in the plant facilitation literature (He et al. 2013), but it is also a promising framework to understand the context dependency of beneficial plantmicrobe interactions (O'Brien et al. 2015, David et al. 2018). Early support for this idea comes from findings that resource mutualisms provide optimal benefit to hosts when nutrients are limiting (Johnson 1993). However, tests in a variety of plantmicrobe systems are increasingly common (Defossez et al. 2011, Aghili et al. 2014, O’Brien 2015, David et al. 2018).

Our findings support the idea that mutualistic interactions dominate in stressful environments but only for early life stages. In many habitat types, early seedling mortality is high due to seedling vulnerability to biotic and abiotic stress (Harper 1977). Therefore, natural selection should operate on phenotypes that allow for the proper timing of germination and enhance seedling survival (Postma and Ågren 2016). Selection is likely even more pronounced in harsh habitats (Bradshaw 1971), such as 
alvars that have shallow soils, experience low water availability, and extremely high soil temperatures. Perhaps, in response to strong selection on early life-history stages alvar plants have evolved cooperative relationships with microbes. For example, seedling survival increased $37 \%$ when alvar seedlings are planted with alvar microbes and probability of germination increased $88 \%$ in the presence of alvar microbes in their home habitat.

However, we didn't find evidence that mutualistic interactions were more common on alvars for later growth stages. Total biomass was higher when seedlings were planted with microbes in old-field habitats (with no effects of soil source or seed source). The reason that microbes are not as important to alvar plants for biomass production could be the result of three (non-mutually exclusive) factors. First, microbes may not be as important for alvar plant growth in later growth stages. We expected that large plant size would be advantageous in both alvar and old-field habitats. However, selection might not favor large biomass on alvars, since it is not a competitive environment and large plants could be unsustainable in dry years. Second, disproportionate contamination in plants transplanted into the alvar habitat diminished our ability to detect habitat by seed source interactions. Transplanting pots directly into the ground was advantageous in allowing us to achieve a high level of biological realism but the downside was contamination. This was evident when we stained roots at the conclusion of the experiment, and high levels of contamination were detected in all treatment groups but especially in those transplanted into the alvar habitat. Contamination was more acute in alvar habitats because we used small (10 cm deep) 
transplant pots and some roots penetrated the pots by the conclusion of the experiment. Finally, we could have had reduced statistical power because of low seedling survival in some treatment groups. For example, we only had $\sim 50 \%$ survival for alvar plants that were transplanted into sterilized alvar soil in the old-field habitat. This reduction in sample size could have made it difficult to detect treatment effects on biomass.

Consistent with our findings that alvar plants experienced more positive microbe effects that can facilitate patterns of local adaptation, we also found that alvar plants had a higher proportion of arbuscules within their roots. Furthermore, these arbuscules were positively correlated with plant biomass when transplanted into their home soils. This relationship indicates mutualistic coevolution with local mycorrhizal fungi (Johnson et al. 2010). However, we found a significant positive linear relationship in the old-field habitat only and a trend in the alvar habitat. This could be caused by very high levels of stress in the alvar habitat by the end of the experiment, which could have been exacerbated by small pot size that prevented lateral root growth. Very high levels of stress (as opposed to ambient levels) could change the balance of cost to benefits of hosting mutualistic symbionts. To corroborate this assertion, we found that plants transplanted into the alvar habitat had a higher proportion of vesicles. Vesicular colonization is often seen as indicative of fungal hoarding (Johnson 1993), and the number of vesicles increases under various plant stressors, such has high soil temperatures (Entry et al. 2002) 
We chose to stain for mycorrhizal fungi at the conclusion of our experiment because mycorrhizal fungi are ubiquitous plant symbionts (occurring in $80 \%$ of vascular plant families; Schüßler et al. 2001) that have documented effects on plant germination, survival (Horton and van der Heijden 2008), and reproductive fitness (Smith and Read 1998). Arbuscular mycorrhizal fungi also affect patterns of local adaptation (Rúa et al. 2016, Johnson et al. 2010). In addition, Hypericum perforatum benefits from mycorrhizal colonization across its native and introduced range (Seifert et al. 2009). Although we looked at mycorrhizal fungi in the plant roots, we inoculated plants with whole soil inoculum. Therefore, many other important plant-associated microbial taxa could be responsible for the observed effects. Two important taxonomic groups that are likely associated with Hypericum are plant growth promoting rhizobacteria (PGPR) and dark septate endophytes (DSE). Interest has been growing in the role of PGPR in enhancing plant growth and evidence exists that they can affect both survival and germination (Lucy et al. 2004). Less is known about dark septate endophytes, but it seems that under certain conditions they can be mutualistic with their plant hosts (Jumpponen and Trappe 1998). Dark septate endophytes are particularly common in arid environments and have been hypothesized to be important for plant drought tolerance (Mandyam and Jumpponen 2014). In other work, we described how bacterial and non-mycorrhizal fungal diversity differed between habitats within roots of Hypericum perforatum. We found that indeed fungal and bacterial communities are significantly different between habitats, but additional work needs to be done to link taxa described in this descriptive research to taxa that are mediating plant fitness effects on alvars. 
The role of microbes in plant local adaptation is an active area of research. Microbes can change patterns of local adaptation by affecting plant functional traits (Friesen et al. 2011) and subsequently interactions with the local environment (Johnson et al. 2010, Gehring et al. 2017). However, when and where we might expect to see these effects is still unclear. Some studies find broad support for the potential role of microbes in plant local adaptation. Common garden experiments with Bradyrhizobia and the annual legume, Amphicarpaea bracteate, suggested that plant reproductive fitness was maximized when plants were combined with local genotypes of microbes. Average seed biomass increased by $39 \%$ when plants were transplanted with a native bacterial genotype (Parker 1995). Similarly, survival of poplar trees was enhanced 2.5fold when trees were planted into native soils (Smith et al. 2011). However, other works find little evidence of population level structuring of plant-microbe interactions. Populations of Acacia and their associated rhizobia were collected throughout southeastern Australia and grown in a fully factorial design. Although the authors found generally positive effects of microbial inoculation, they found little evidence of adaptation in sympatric pairs of microbes and plants (Barrett et al. 2011).

Similar to previous work, we found that interactions between local plants and local microbes affect plant fitness, and thus change patterns of plant phenotype and fitness (Parker 1995, Smith et al. 2011, Johnson et al. 2010). Additionally, our work indicates that: 1) microbial effects on local adaptation are more pronounced in early life-history stages (germination and seedling survival), but more general microbial benefits 
dominate later in life. And 2) microbes can either affect patterns of local adaptation through increasing fitness or decreasing fitness. For example, alvar microbes enhanced alvar seedling germination but old-field microbes decreased old-field seedling germinations. An important caveat is that previous studies used a common garden approach and therefore fail to capture interactions between plants and microbes that are habitat-specific. We took a different approach and planted experimental units directly into the soil environment in two habitats. This allowed us to construct reaction norms and evaluate patterns of local adaptation rather than speculating about patterns of local adaptation based on microbial-mediated changes in fitness.

Our results support the idea that positive microbe interactions dominate in more stressful habitats. Unraveling factors that affect the functioning of mutualisms should be one of the highest priorities of plant-microbe research because it has direct bearing on our ability to incorporate microbes in meaningful ways into conservation, restoration, and agriculture. We also add support to the idea that microbes can affect patterns of local adaptation. Our study is the first to perform rigorous reciprocal transplant experiments in the field to understand the role microbes play in local adaptation. Microbe-mediated local adaptation is a previously over-looked mechanism by which plants come to have higher fitness under local conditions than foreign genotypes. This research is important to inform our understanding of the evolutionary ecology of plants, but also in applied use of microbes in field such as restoration, conservation, and agriculture. 


\section{REFERENCES}

Afkhami, M. E., and J. R. Stinchcombe. 2016. Multiple mutualist effects on genomewide expression in the tripartite association between Medicago truncatula, nitrogen-fixing bacteria and mycorrhizal fungi. Molecular Ecology 25:4946-4962.

Aghili, F., J. Jansa, A. H. Khoshgoftarmanesh, M. Afyuni, R. Schulin, E. Frossard, and H. A. Gamper. 2014. Wheat plants invest more in mycorrhizae and receive more benefits from them under adverse than favorable soil conditions. Applied Soil Ecology 84:93-111.

Barrett, L. G., L. M. Broadhurst, and P. H. Thrall. 2011. Geographic adaptation in plant-soil mutualisms: tests using Acacia spp. and rhizobial bacteria. Functional Ecology 26:457-468.

Bates, D., M. Mächler, B. Bolker, and S. Walker. 2015. Fitting linear mixed-effects models using lme4. Journal of Statistical Software 67:1-48.

Berendsen, R. L., C. M. J. Pieterse, and P. A. H. M. Bakker. 2012. The rhizosphere microbiome and plant health. Trends in Plant Science 17:478-486.

Bertness, M. D., and R. Callaway. 1994. Positive interactions in communities. Trends in Ecology \& Evolution 9:191-193. 
Bradshaw, A. D. 1971. Plant evolution in extreme environments. Pages 20-50 in R. Creed, editor. Ecological genetics and evolution: essays in honour of E. B. Ford. Blackwell Scientific Publications, Oxford, UK.

Bronstein, J. L. 1994. Conditional outcomes in mutualistic interactions. Trends in Ecology and Evolution 9: 214-217.

Christensen, R. H. B. 2018. ordinal - regression models for ordinal data. R package version 2018.4-19. https://cran.r-project.org/web/packages/ordinal/index.html.

Crawley, M. J. 2015. Statistics: an introduction using R. Second edition. Wiley, Chichester, West Sussex, UK.

David, A. S., K. B. Thapa-Magar, and M. E. Afkhami. 2018. Microbial mitigationexacerbation continuum: a novel framework for microbiome effects on hosts in the face of stress. Ecology 99:517-523.

Defossez, E., B. Courbaud, B. Marcais, W. Thuiller, E. Granda, and G. Kunstler. 2011. Do interactions between plant and soil biota change with elevation? A study on Fagus sylvatica. Biology Letters 7:699-701. 
Edinger, G. J., D. J. Evans, S. Gebauer, T. G. Howard, D. M. Hunt, and A. M. Olivero, editors. 2014. Ecological communities of New York state: a revised and expanded edition of Carol Reschke's ecological communities of New York state. Second edition. New York Natural Heritage Program, New York State Department of Environmental Conservation, Albany, New York, USA.

Entry, J. A., P. T. Rygiewicz, L. S. Watrud, and P. K. Donnelly. 2002. Influence of adverse soil conditions on the formation and function of Arbuscular mycorrhizas. Advances in Environmental Research 7:123-138.

Friesen, M. L., S. S. Porter, S. C. Stark, E. J. von Wettberg, J. L. Sachs, and E. Martinez-Romero. 2011. Microbially mediated plant functional traits. Annual Review of Ecology, Evolution, and Systematics 42:23-46.

Gehring, C. A., C. M. Sthultz, L. Flores-Rentería, A. V. Whipple, and T. G. Whitham. 2017. Tree genetics defines fungal partner communities that may confer drought tolerance. Proceedings of the National Academy of Sciences 114:11169-11174.

González, J. B., R. H. Petipas, O. Franken, E. T. Kiers, K. E. Veblen, and A. K. Brody. 2018. Herbivore removal reduces influence of arbuscular mycorrhizal fungi on plant growth and tolerance in an East African savanna. Oecologia 187:123-133. 
Harper, J. L. 1977. Population biology of plants. Academic Press, London, UK.

He, Q., M. D. Bertness, and A. H. Altieri. 2013. Global shifts towards positive species interactions with increasing environmental stress. Ecology Letters 16:695-706.

Hoeksema, J. D., V. B. Chaudhary, C. A. Gehring, N. C. Johnson, J. Karst, R. T. Koide, A. Pringle, C. Zabinski, J. D. Bever, J. C. Moore, G. W. T. Wilson, J. N. Klironomos, and J. Umbanhowar. 2010. A meta-analysis of context-dependency in plant response to inoculation with mycorrhizal fungi. Ecology Letters 13:394407.

Horton T. R., and van der Heijden M. G. A. 2008. The role of symbioses in seedling establishment and survival. Pages 189-214 in M. A. Leck, V. T. Parker, R. L. Simpson, editors. Seedling Ecology and Evolution. Cambridge University Press, Cambridge, UK.

Johnson, N. C. 1993. Can fertilization of soil select less mutualistic mycorrhizae? Ecological Applications 3:749-757.

Johnson, N. C., C. Angelard, I. R. Sanders, and E. T. Kiers. 2013. Predicting community and ecosystem outcomes of mycorrhizal responses to global change. Ecology Letters 16:140-153. 
Johnson, N. C., G. W. T. Wilson, M. A. Bowker, J. A. Wilson, and R. M. Miller. 2010. Resource limitation is a driver of local adaptation in mycorrhizal symbioses. Proceedings of the National Academy of Sciences 107:2093-2098.

Jumpponen, A., and J. M. Trappe. 1998. Dark septate endophytes: a review of facultative biotrophic root-colonizing fungi. New Phytologist 140:295-310.

Kawecki, T. J., and D. Ebert. 2004. Conceptual issues in local adaptation. Ecology Letters 7:1225-1241.

Lankau, R. A., and R. N. Nodurft. 2013. An exotic invader drives the evolution of plant traits that determine mycorrhizal fungal diversity in a native competitor. Molecular Ecology 22:5472-5485.

Lau, J. A., and J. T. Lennon. 2012. Rapid responses of soil microorganisms improve plant fitness in novel environments. Proceedings of the National Academy of Sciences 109: 14058-14062.

Lee, B., S. Lee, and C. M. Ryu. 2012. Foliar aphid feeding recruits rhizosphere bacteria and primes plant immunity against pathogenic and non-pathogenic bacteria in pepper. Annals of Botany 110:281-290. 
Lenth, R. V. 2016. Least-square means: The R package 1smeans. Journal of Statistical Software 69:1-33.

Lucy, M., E. Reed, and B. R. Glick. 2004. Applications of free living plant growthpromoting rhizobacteria. Antonie van Leeuwenhoek 86:1-25.

Mandyam, K., and A. Jumpponen. 2014. Seeking the elusive function of the rootcolonising dark septate endophytic fungi. Studies in Mycology 53:173-189.

Marasco, R., E. Rolli, B. Ettoumi, G. Vigani, F. Mapelli, S. Borin, A. F. Abou-Hadid, U. A. El-Behairy, C. Sorlini, A. Cherif, G. Zocchi, and D. Daffonchio. 2012. A drought resistance-promoting microbiome is selected by root system under desert farming. PLoS ONE 7:e48479.

McGonigle, T., M. Miller, D. Evans, G. Fairchild, and J. Swan. 1990. A new method which gives an objective measure of colonization of roots by vesiculararbuscular mycorrhizal fungi. New Phytologist 115:495-501.

McGuire, K. L. 2007. Common ectomycorrhizal networks may maintain monodominance in a tropical rain forest. Ecology 88:567-574.

Meharg, A. A., and J. Cairney. 2000. Ectomycorrhizas - extending the capabilities of rhizosphere remediation? Soil Biology and Biochemistry 32:1475-1484. 
O'Brien, A. M., R. J. H. Sawers, J. Ross-Ibarra, and S. Y. Strauss. 2015. Extending the Stress-Gradient hypothesis: greater adaptation between teosinte and soil biota at higher stress sites. BioRxiv: [doi: 10.1101/031195]

Parker, M. P. 1995. Plant fitness variation caused by different mutualist genotypes. Ecology $76: 1525-1535$.

Partida-Martinez, L. P., and M. Heil. 2011. The microbe-free plant: fact or artifact? Frontiers in Plant Science 2:1-16.

Petersen, S. O., and M. J. Klug. 1994. Effects of sieving, storage, and incubation temperature on the phospholipid fatty acid profile of a soil microbial community. Applied and Environmental Microbiology 60:2421-2430.

Petipas, R. H., J. B. González, T. M. Palmer, and A. K. Brody. 2017. Habitat-specific AMF symbioses enhance drought tolerance of a native Kenyan grass. Acta Oecologica 78:71-78.

Phillips, J. M., and D. S. Hayman. 1970. Improved procedures for clearing roots and staining parasitic and vesicular-arbuscular mycorrhizal fungi for rapid assessment of infection. Transactions of the British Mycological Society 55:158-161. 
Pickles, B. J., B. D. Twieg, G. A. O'Neill, W. W. Mohn, and S. W. Simard. 2015. Local adaptation in migrated interior Douglas-fir seedlings is mediated by ectomycorrhizas and other soil factors. New Phytologist 207:858-871.

Pinheiro, J., D. Bates, S. DebRoy, D. Sarkar, and R Core Team. 2017. nlme: linear and nonlinear mixed effects models. R package version 3.1-131. https://CRAN.Rproject.org/package $=$ nlme/.

Postma, F. M., and J. Ågren. 2016. Early life stages contribute strongly to local adaptation in Arabidopsis thaliana. Proceedings of the National Academy of Sciences of the United States of America 113:7590-7595.

R Development Core Team. 2017. R: a language and environment for statistical computing. R Foundation for Statistical Computing, Vienna, Austria. https://www.r-project.org.

Reschke, C., R. Reid, J. Jones, T. Feeney, and H. Potter. 1999. Conserving great lakes alvars: final technical report of the International Alvar Conservation Initiative. The Nature Conservancy, Chicago, Illinois, USA.

Revillini, D., C. A. Gehring, and N. C. Johnson. 2016. The role of locally adapted mycorrhizas and rhizobacteria in plant-soil feedback systems. Functional Ecology 30:1086-1098. 
Rúa, M. A., A. Antoninka, P. M. Antunes, V. B. Chaudhary, C. Gehring, L. J. Lamit, B. J. Piculell, J. D. Bever, C. Zabinski, J. F. Meadow, M. J. Lajeunesse, B. G. Milligan, J. Karst, and J. D. Hoeksema. 2016. Home-field advantage? evidence of local adaptation among plants, soil, and arbuscular mycorrhizal fungi through meta-analysis. BMC Evolutionary Biology 16:1-15.

Schüßler, A., D. Schwarzott, and C. Walker. 2001. A new fungal phylum, the Glomeromycota: phylogeny and evolution. Mycological research 105:1413-1421.

Seifert, E. K., J. D. Bever, and J. L. Maron. 2009. Evidence for the evolution of reduced mycorrhizal dependence during plant invasion. Ecology 90:1055-1062.

Smith, D. S., J. A. Schweitzer, P. Turk, J. K. Bailey, S. C. Hart, S. M. Shuster, and T. G. Whitham. 2011. Soil-mediated local adaptation alters seedling survival and performance. Plant and Soil 352:243-251.

Smith, S. E., and D. J. Read. 2008. Mycorrhizal symbiosis. Third edition. Academic Press, Boston, Massachusetts, USA.

Therneau, T. 2015. A package for survival analysis in S. R package version 2.38. https://cran.r-project.org/web/packages/survival/index.html 
Van Nuland, M. E., R. C. Wooliver, A. A. Pfennigwerth, Q. D. Read, I. M. Ware, L. Mueller, J. A. Fordyce, J. A. Schweitzer, and J. K. Bailey. 2016. Plant-soil feedbacks: connecting ecosystem ecology and evolution. Functional Ecology 30:1032-1042.

Wagner, M. R., D. S. Lundberg, D. Coleman-Derr, S. G. Tringe, J. L. Dangl, and T. Mitchell-Olds. 2014. Natural soil microbes alter flowering phenology and the intensity of selection on flowering time in a wild Arabidopsis relative. Ecology Letters 17:717-726

Zuur, A. F., E. N. Ieno, G. M. Smith, A. A. Saveliev, and N. Walker. 2009. Mixed effects models and extensions in ecology with R. Springer, New York, New York, USA. 


\section{APPENDIX}

Table S2.1: Bacterial operational taxonomic units (OTUs) identified as differentially abundant in either alvars or old-fields at a cutoff value of $P=0.001$. Thirty-nine OTUs were over-represented in the alvar and nineteen were more commonly found in the oldfields. Significance values are not adjusted for multiple comparisons.

\begin{tabular}{ccccccc} 
OTU & Habitat & Stat & Phylum & Class & Order & Family \\
\hline \hline OTU_189 & alvar & 0.89 & Chloroflexi & Thermomicrobia & JG30-KF-CM45 & NA \\
OTU_412 & alvar & 0.89 & Actinobacteria & Thermoleophilia & Solirubrobacterales & NA \\
OTU_139 & alvar & 0.87 & Actinobacteria & Acidimicrobiia & Acidimicrobiales & C111 \\
OTU_19 & alvar & 0.86 & Actinobacteria & Actinobacteria & Actinomycetales & Pseudonocardiaceae \\
OTU_326 & alvar & 0.86 & Proteobacteria & Alphaproteobacteria & Rhizobiales & NA \\
OTU_78 & alvar & 0.86 & Proteobacteria & Alphaproteobacteria & Rhizobiales & Bradyrhizobiaceae \\
OTU_90 & alvar & 0.86 & Actinobacteria & Acidimicrobiia & Acidimicrobiales & C111 \\
OTU_523 & alvar & 0.85 & Proteobacteria & Alphaproteobacteria & Sphingomonadales & Sphingomonadaceae \\
OTU_89 & alvar & 0.83 & Proteobacteria & Alphaproteobacteria & Rhodospirillales & Rhodospirillaceae \\
OTU_155 & alvar & 0.82 & Planctomycetes & Planctomycetia & Pirellulales & Pirellulaceae \\
OTU_332 & alvar & 0.81 & Acidobacteria & Chloracidobacteria & RB41 & NA \\
OTU_107 & alvar & 0.81 & Proteobacteria & Alphaproteobacteria & Rhizobiales & Hyphomicrobiaceae \\
OTU_795 & alvar & 0.79 & Acidobacteria & Chloracidobacteria & RB41 & NA \\
OTU_627 & alvar & 0.78 & Proteobacteria & Alphaproteobacteria & Rhodospirillales & Rhodospirillaceae \\
OTU_142 & alvar & 0.78 & Chloroflexi & Thermomicrobia & JG30-KF-CM45 & NA \\
OTU_185 & alvar & 0.78 & Proteobacteria & Alphaproteobacteria & Rhizobiales & Hyphomicrobiaceae
\end{tabular}




\begin{tabular}{|c|c|c|c|c|c|c|}
\hline OTU_116 & alvar & 0.77 & Chloroflexi & Anaerolineae & S0208 & NA \\
\hline OTU_207 & alvar & 0.73 & Actinobacteria & Thermoleophilia & Gaiellales & Gaiellaceae \\
\hline OTU_951 & alvar & 0.72 & Chloroflexi & Anaerolineae & A31 & S47 \\
\hline OTU_251 & alvar & 0.72 & Proteobacteria & Alphaproteobacteria & Rhizobiales & NA \\
\hline OTU_2889 & alvar & 0.70 & Bacteroidetes & Saprospirae & Saprospirales & Chitinophagaceae \\
\hline OTU_643 & alvar & 0.69 & Actinobacteria & Thermoleophilia & Gaiellales & Gaiellaceae \\
\hline OTU_2512 & alvar & 0.69 & Proteobacteria & Alphaproteobacteria & Rhizobiales & Rhizobiaceae \\
\hline OTU_3211 & alvar & 0.69 & Bacteroidetes & Cytophagia & Cytophagales & Cytophagaceae \\
\hline OTU_434 & alvar & 0.67 & Proteobacteria & Betaproteobacteria & Rhodocyclales & Rhodocyclaceae \\
\hline OTU_546 & alvar & 0.67 & Proteobacteria & Alphaproteobacteria & NA & NA \\
\hline OTU_390 & alvar & 0.67 & Chloroflexi & Anaerolineae & S0208 & NA \\
\hline OTU_115 & alvar & 0.65 & Chloroflexi & Anaerolineae & SBR1031 & $\mathrm{A} 4 \mathrm{~b}$ \\
\hline OTU_461 & alvar & 0.64 & Actinobacteria & MB-A2-108 & 0319-7L14 & NA \\
\hline OTU_397 & alvar & 0.64 & Firmicutes & Clostridia & Clostridiales & Clostridiaceae \\
\hline OTU_949 & alvar & 0.63 & Chloroflexi & Anaerolineae & $\mathrm{A} 31$ & S47 \\
\hline OTU_154 & alvar & 0.63 & Proteobacteria & Deltaproteobacteria & Desulfuromonadales & Geobacteraceae \\
\hline OTU_574 & alvar & 0.62 & Proteobacteria & Alphaproteobacteria & Rhodospirillales & Rhodospirillaceae \\
\hline OTU_1840 & alvar & 0.62 & Actinobacteria & Actinobacteria & Actinomycetales & Micromonosporaceae \\
\hline OTU_2337 & alvar & 0.62 & Planctomycetes & Planctomycetia & Gemmatales & Isosphaeraceae \\
\hline OTU_580 & alvar & 0.61 & Acidobacteria & S035 & NA & NA \\
\hline OTU_450 & alvar & 0.60 & Nitrospirae & Nitrospira & Nitrospirales & 0319-6A21 \\
\hline OTU_741 & alvar & 0.59 & Proteobacteria & Alphaproteobacteria & Rhodospirillales & Rhodospirillaceae \\
\hline OTU_628 & alvar & 0.58 & Actinobacteria & Thermoleophilia & Gaiellales & Gaiellaceae \\
\hline OTU_68 & field & 0.86 & Proteobacteria & Alphaproteobacteria & Rhizobiales & Hyphomicrobiaceae \\
\hline OTU_22 & field & 0.86 & Proteobacteria & Alphaproteobacteria & Rhizobiales & Hyphomicrobiaceae \\
\hline OTU_59 & field & 0.81 & Proteobacteria & Alphaproteobacteria & Sphingomonadales & Sphingomonadaceae \\
\hline OTU_49 & field & 0.80 & Actinobacteria & Thermoleophilia & Gaiellales & Gaiellaceae \\
\hline
\end{tabular}




\begin{tabular}{|ccccccc|} 
OTU_72 & field & 0.80 & Actinobacteria & MB-A2-108 & 0319-7L14 & NA \\
OTU_162 & field & 0.79 & Proteobacteria & Betaproteobacteria & Methylophilales & Methylophilaceae \\
OTU_225 & field & 0.79 & Actinobacteria & Thermoleophilia & Gaiellales & Gaiellaceae \\
OTU_110 & field & 0.76 & Actinobacteria & MB-A2-108 & 0319-7L14 & NA \\
OTU_69 & field & 0.76 & Proteobacteria & Gammaproteobacteria & Xanthomonadales & Sinobacteraceae \\
OTU_2804 & field & 0.75 & Actinobacteria & Thermoleophilia & Gaiellales & Gaiellaceae \\
OTU_5485 & field & 0.75 & Verrucomicrobia & Spartobacteria & Chthoniobacterales & Chthoniobacteraceae \\
OTU_2622 & field & 0.74 & Actinobacteria & Thermoleophilia & Gaiellales & Gaiellaceae \\
OTU_34 & field & 0.72 & Proteobacteria & Gammaproteobacteria & Enterobacteriales & Enterobacteriaceae \\
OTU_95 & field & 0.68 & Proteobacteria & Alphaproteobacteria & Rhodospirillales & Rhodospirillaceae \\
OTU_464 & field & 0.66 & Acidobacteria & Acidobacteriia & Acidobacteriales & Acidobacteriaceae \\
OTU_829 & field & 0.65 & Proteobacteria & Betaproteobacteria & Methylophilales & Methylophilaceae \\
OTU_553 & field & 0.64 & Chloroflexi & Anaerolineae & A31 & S47 \\
OTU_812 & field & 0.62 & Actinobacteria & Actinobacteria & Actinomycetales & Nocardioidaceae \\
OTU_1430 & field & 0.52 & Bacteroidetes & Saprospirae & Saprospirales & Chitinophagaceae \\
\hline
\end{tabular}



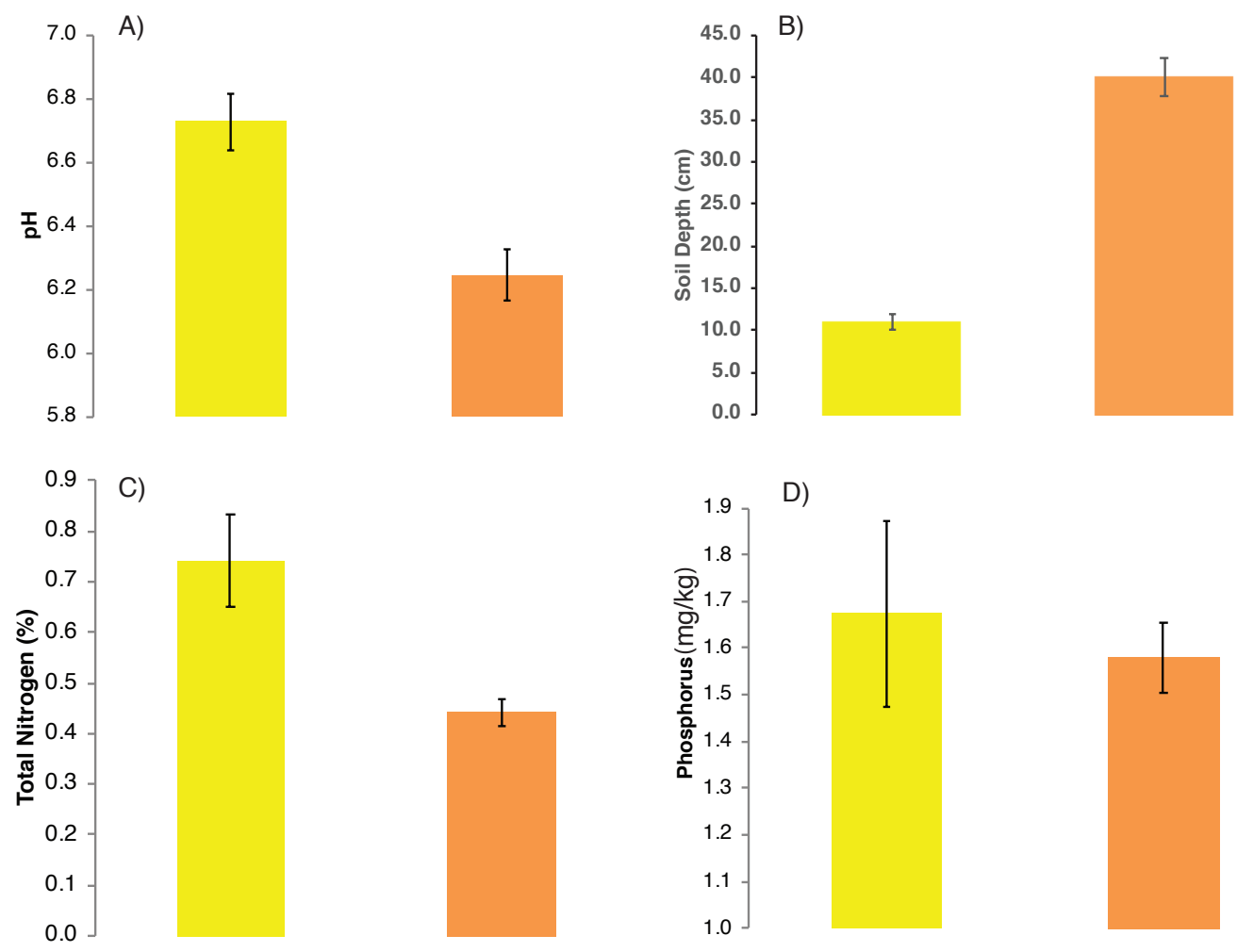

Figure S3.1: Alvar soils have higher $\mathrm{pH}$ (A), shallower soils (B), and more total nitrogen (C) than old-field soils. However, phosphorus does not differ between the two habitats (D). 
Table S3.1: Coordinates for each habitat pair used in the transplant experiment.

\begin{tabular}{lllc} 
Site & Habitat & \multicolumn{2}{c}{ Coordinates } \\
\hline \hline Three Mile Creek & Alvar & N44 7'45.88" & W76 10'6.44" \\
& Field & N44 7'3.67" & W76 9'47.54" \\
& & & \\
Chaumont Barrens & Alvar & N44 6'27.40" & W76 5'33.20" \\
& Field & N44 5'49.10" & W76 4'24.10" \\
& & & \\
Limerick Cedars & Alvar & N44 3'5.00" & W76 2'29.60" \\
& Field & N44 03'31.39”' & W76 03'35.48
\end{tabular}




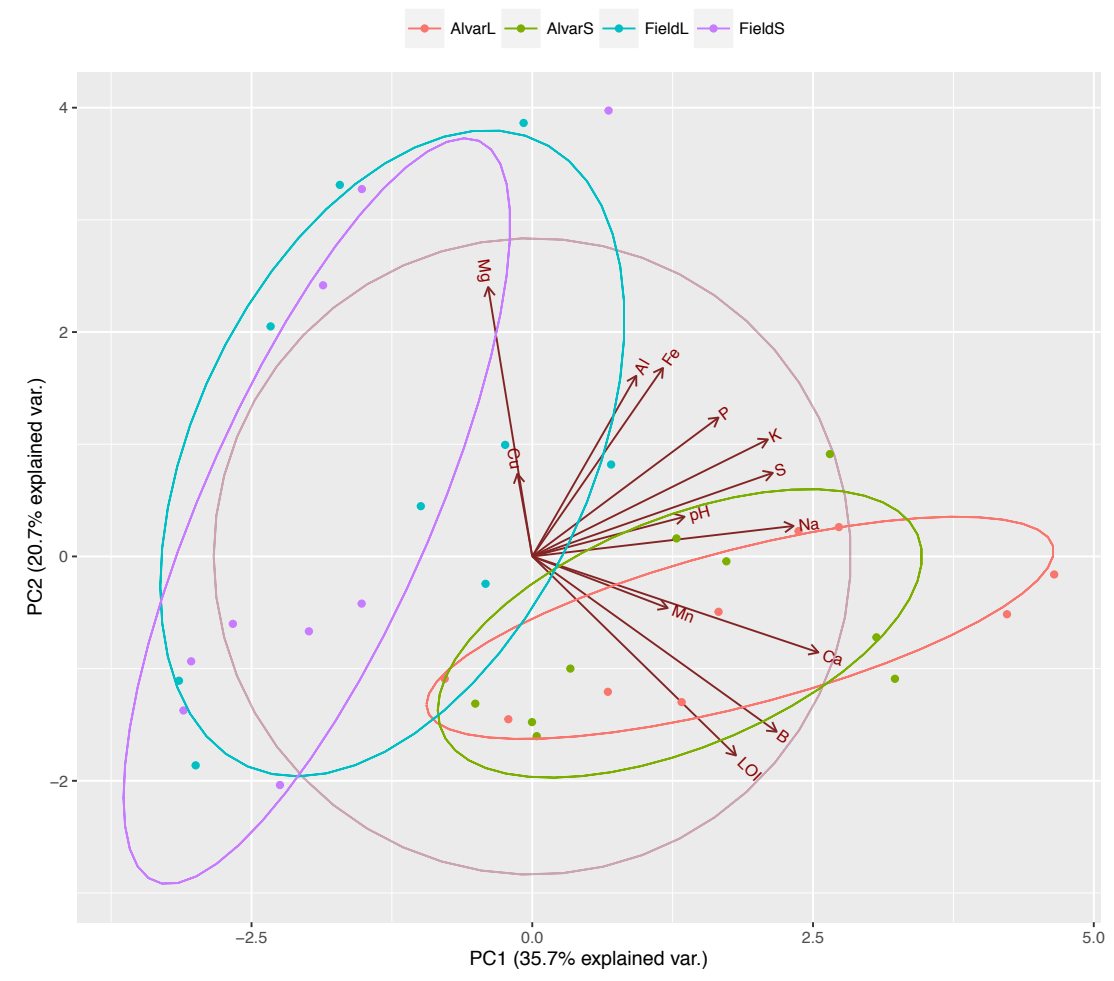

Figure S3.2: Principle component ordination of soil nutrient samples demonstrating that soil autoclaving did not drastically change nutrient composition of the soils used in the transplant experiment. The blue circle is the live soils collected from the oldfield, and the purple circle is the old-field soil that was autoclaved. The red circle is the live soils collected from the alvar, and the green circle is the alvar soil that was autoclaved. Despite autoclaving circles from one habitat still occupy the same area. 


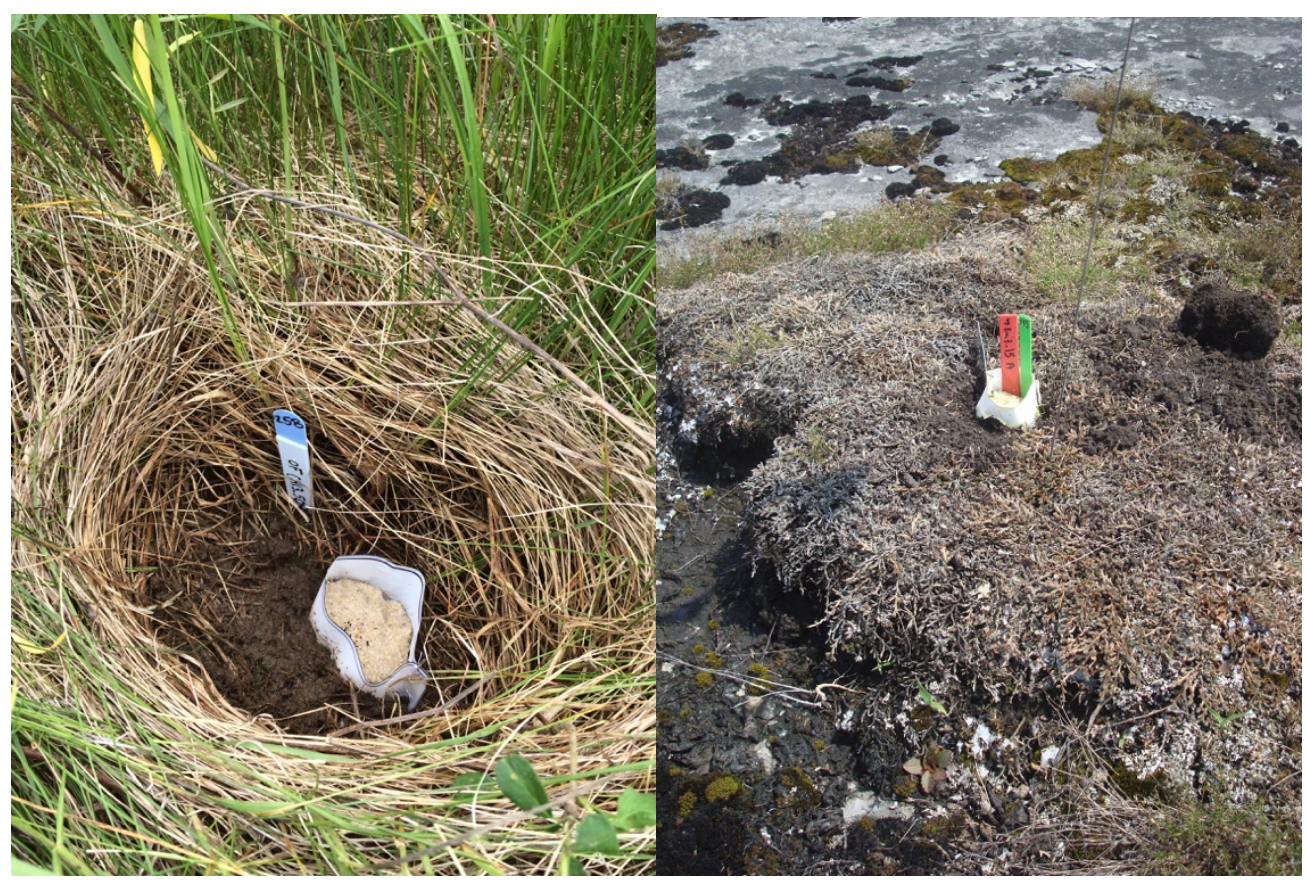

Figure S3.3: Images of nylon pots transplanted directly into the ground. The image on the left is a pot used in the germination experiment that was transplanted into the field habitat and the image on the right is a pot used in the germination experiment that was transplanted into the alvar habitat. 
Table S3.2: Analysis of Deviance Table on Survival Analysis. Terms added sequentially first to last. Significance codes: 0 ‘***', 0.001 '**', 0.01 '*', 0.05 '.'

\begin{tabular}{|c|c|c|c|c|c|}
\hline Fixed Effect & Log Likelihood & Chi-square & df & P-Value & \\
\hline NULL & -782.33 & & & & \\
\hline Habitat & -767.20 & 30.25 & 1 & 4E-08 & $* * *$ \\
\hline Soil Source & -764.48 & 5.44 & 1 & 0.020 & $*$ \\
\hline Inoculum & -764.02 & 0.93 & 1 & 0.335 & \\
\hline Seed Source & -763.45 & 1.14 & 1 & 0.285 & \\
\hline Habitat*Soil Source & -757.85 & 11.20 & 1 & 0.001 & $* * *$ \\
\hline Habitat*Inoculum & -757.80 & 0.09 & 1 & 0.766 & \\
\hline Soil Source*Inoculum & -757.18 & 1.22 & 1 & 0.265 & \\
\hline Habitat*Seed Source & -756.45 & 1.47 & 1 & 0.226 & \\
\hline Soil Source*Seed Source & -756.22 & 0.45 & 1 & 0.504 & \\
\hline Inoculum*Seed Source & -754.89 & 2.66 & 1 & 0.103 & \\
\hline Habitat*Soil Source*Inoculum & -754.29 & 1.20 & 1 & 0.273 & \\
\hline Habitat*Soil Source*Seed Source & -754.18 & 0.23 & 1 & 0.630 & \\
\hline Habitat*Inoculum*Seed Source & -754.04 & 0.27 & 1 & 0.601 & \\
\hline Soil Source*Inoculum*Seed Source & -751.34 & 5.41 & 1 & 0.020 & * \\
\hline Habitat*Inoculum*Seed Source*Soil Source & -750.78 & 1.12 & 1 & 0.21 & \\
\hline
\end{tabular}




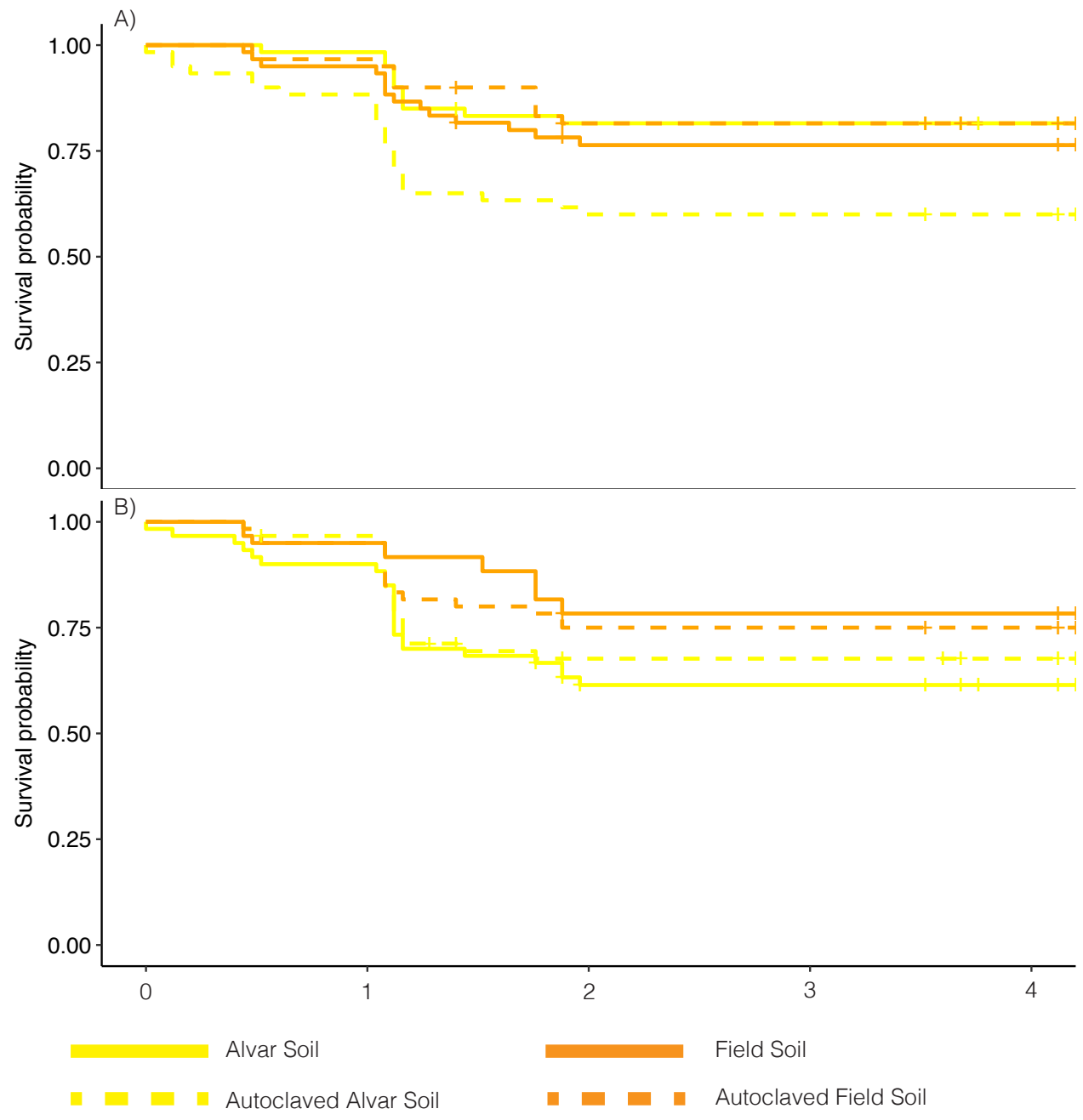

Figure S3.3: Kaplan Meyer survival curve for alvar seeds (A) and old-field seeds (B). The X-axis indicates time at transplant (0) through four survival census dates (1-4) and the $\mathrm{Y}$-axis is probability of survival. To simplify the visualization, we subset the data by seed source and averaged over habitat because habitat was not a significant term in our analysis. Alvar seeds had the lowest survival over the course of four survival census dates in alvar soil that was autoclaved. Old-field seedlings survived best in their home soil regardless of microbes. 
Table S3.3: Regressions of total plant biomass on arbuscule number for treatments. Regressions were performed on plants that received live soil inoculum only.

\begin{tabular}{|c|c|c|c|c|c|c|c|} 
Habitat & \multicolumn{2}{c}{ Seed Source Soil Source } & $\mathrm{N}$ & \multicolumn{2}{c}{$\mathrm{R}^{2}$} & $\mathrm{~F}$ & $\mathrm{P}$ \\
\hline \hline Alvar & Alvar & Alvar & 8 & 0.14 & 2.15 & 0.19 & \\
\hline Alvar & Alvar & Field & 9 & 0.20 & 3.04 & 0.12 & \\
\hline Alvar & Field & Alvar & 9 & -0.14 & 0.03 & 0.88 & \\
\hline Alvar & Field & Field & 9 & -0.08 & 0.42 & 0.54 & \\
\hline Field & Alvar & Alvar & 9 & 0.62 & 14.09 & $\mathbf{0 . 0 1}$ & $*$ \\
\hline Field & Alvar & Field & 9 & -0.14 & 0.01 & 0.93 & \\
\hline Field & Field & Alvar & 9 & 0.04 & 1.29 & 0.29 & \\
\hline Field & Field & Field & 9 & 0.06 & 1.51 & 0.26 & \\
\hline
\end{tabular}

